\title{
CHROMOSOME BANDING AND
}

HETEROCHROMATIN IN VICIA FABA

Submitted for the degree of Doctor of Philosophy at the Botany Department, Victoria University of Wellington, New Zealand.

Roland Elliston Rowland

Jan. 1977. 


\section{CONTENTS}

LIST OF ILLUSTRATIONS

Page No.

ABSTRACT

1. Rationale for Studying Vicia faba

2. An Historical Survey of Heterochromatin

(a) Early Studies by Other Investigators 3

(b) Classification of Heterochromatin 6

(c) Multifaceted Behaviour of Heterochromatin 6
(d) Chromosome Banding

(e) Chromosome Location of Repetitive DNA by In Situ Hybridization

METHODS

1. Root-tip sections. Procedure for staining Chromatin with Heidenhain's Haematoxylin

2. Root-tip Squashes : Preparation of Chromosomes for Karyotyping

3. Cold Treatment

4. Acid Treatment

5. Quinacrine Mustard Fluorescence

6. SSC-Giemsa Banding

7. NaOH-SSC-Giemsa Banding

8. Trypsin-Giemsa Banding

9. Urea-Giemsa Banding

10. Gll Banding

11. Reverse Banding

12. Lacto-Aceto-Orcein (LAO) Banding

13. Fixed LAO Banding

14. Late-labelling Autoradiography

(a) In Vivo Labelling of DNA 19

(b) Staining of Roots 20

(c) Autoradiography 20

15. In Situ Molecular Hybridization 20

(a) Isolation of DNA 20

(b) DNA Transcription 20

(c) Preparation of Root-tip Chromosomes $\quad 21$

(d) Hybrid Formation 22

(e) Autoradiography and Staining of Chromosomes 23

(f) Analysis of Grain Location 23

16. DNA Reassociation Kinetics 24

17. Summary of Modification and Development of Methods 
$\begin{array}{ll}\text { RESULTS } & 26\end{array}$

I. The Vicia faba "Coles Early Dwarf" Karyotype 26

II. Interphase Heterochromatin 29

III. Banding on C-Metaphase Chromosomes 30

1. Cold Treatment Bands 30

2. Acid Treatment Bands 31

3. Quinacrine Mustard Fluorescence 32

4. Giemsa Banding 32

(a) SSC-Giemsa Banding 32

(b) Sequential Analysis of SSC-Giemsa Banding 34

(c) Trypsin-Giemsa Banding 35

(d) Urea-Giemsa Banding 35

(e) Additional Methods Employed in Giemsa Banding 36

5. Lacto-Aceto-Orcein Banding 36

(i) LAO technique applied to fixed root-tips 37

IV. Temporal Replication of Heterochromatin DNA 38

v. In Situ Hybridization 39

DISCUSSION

I. Cold Treatment 41

II. Temporal Replication of DNA 43

1. Base Content of Early and Late Replicating DNA 44

III. Fluorescent Banding with Quinacrine Mustard (QM) 45

1. Role of Base Content in QM Banding 46

2. Role of Proteins in QM Banding 49

3. Single or Double-Stranded DNA and QM Banding 50

4. Repetitive DNA and QM Banding 50

A Short Résumé of QM Banding 51

IV. Giemsa Banding 52

An Assessment of Giemsa Banding $\quad 55$

1. Inherent Longitudinal Differences in Concentration of Chromosome Material 56

2. Giemsa Banding and Differences in DNA Composition
Along the Chromosome Arms

3. Preferential Renaturation of Repetitive DNA 59

4. Selective Disruption of Band or Non-band
Chromosomal Material

5. DNA-Protein or Protein-Protein Modifications 65

V. Lacto-Aceto-Orcein Banding 70

A Short Résumé of Lacto-Aceto-Orcein Banding 74 
VI. In Situ Hybridization

VII. Chromosome Bands and Heterochromatin 80

VIII. Summary of Findings with Comparison to Other Studies 85

SUMMARY 87

ACKNOWLEDGEMENTS 89

REFERENCES 90

ADDENDUM 101

FIGURES $102-166$

\section{APPENDICES}

I. Transcription of RNA complementary to total V. faba DNA 167

II. Ultracentrifugation of total V. faba DNA 169

III. DNA reassociation curve 170 


\section{LIST OF ILLUSTRATIONS}

Page No.

Tables

1. Common karyotype symbols used for Vicia faba chromosomes

2. Regional grain count of $40 \mathrm{M}$ chromosomes after in situ hybridization with total ${ }^{3} \mathrm{H}-\mathrm{CRNA}$

\section{$\underline{\text { Figures }}$}

1 - 4 Standard karyotype of Vicia faba 102-107

$5 \& 6$ Interphase nuclei of root-tip sections 108-111

7 Range in no. of chromocenters/interphase nucleus 112

8 -14 Cold treated, Feulgen-stained squashes

$15 a-d$ cold treatment bands in $V$. faba chromosomes shown by other investigators

$122-124$

16-18 Acid-treated, Feulgen-stained squashes

19-21 Quinacrine mustard fluorescent bands

22-29 SSC-Giemsa banded squashes 129-135

30-36 Trypsin-Giemsa banded squashes

37-39 Urea-Giemsa banded squashes

40 Reverse banded squash

41 Gll banded squash

42a-f Giemsa bands in $V$. faba chromosomes shown by other investigators

43-49 Lacto-aceto-orcein banded squashes

$50 \mathrm{~N}$-band in V. faba M chromosome (Funaki, et al., 1975)

5la-i Representation of band patterns shown on the M chromosome in this study

52-55 Autoradiographs of root-tip cells pulsed with ${ }^{3} \mathrm{H}$-thymidine (late and early-labelled squashes)

56-58 Autoradiographs of in situ hybridization preparations

59 Histogram of $M$ chromosome regional grain count after in situ hybridization with total ${ }^{3} \mathrm{H}-\mathrm{cRNA}$ 
This study documents the distribution of bands in Vicia faba root-tip chromosomes as shown by acid treatment, quinacrine mustard fluorescence, various forms of Giemsa banding and orcein banding methods, and demonstrates the coincidence of these bands with the position of heterochromatin as shown by cold treatment and late replication.

Heterochromatin in the large metacentric M chromosome is located in two areas: (a) around the centromere and (b) adjacent to the secondary constriction. The latter is not late-replicating but is judged to represent classical nucleolusassociated heterochromatin.

Heterochromatin in the smaller sub-telocentric S chromosomes is located in the intercalary and proximal areas of their long arms and in the short arm of two chromosomes. The variable expression of particular chromosome segments with different banding techniques testifies to certain differences between heterochromatic regions and emphasizes the existence of several classes of heterochromatin.

In situ molecular hybridization of labelled complementary RNA to chromosomal DNA indicates the presence of repetitive DNA in both euchromatin and heterochromatin of the $V$. faba genome. 


\section{INTRODUCTION}

With the advent of recent chromosome banding techniques differentially stained chromosome regions have been revealed in many animal and plant cells, some of which were hitherto unknown (Caspersson et al., 1968; Drets and Shaw, 1971). This discovery has necessitated a careful appraisal of that portion of the genome termed heterochromatin, a word often freely used to designate those regions of the chromosome which stain differentially and are considered to possess certain distinctive properties as, for example, late replication, relative genetic inertness and allocycly (Lima-de-Faria, 1969).

The present study was undertaken to:

(1) Verify the position of heterochromatin on the chromosomes of Vicia faba "Coles Early Dwarf", as defined by established techniques, namely cold induction of negative $\mathrm{H}$-segments and late DNA-replication.

(2) Characterise the similarities and differences of chromosome band distribution in this species using recently developed cytological techniques such as fluorescent banding, various forms of Giemsa banding and orcein banding.

(3) Localize repetitive DNA sequences by in situ molecular hybridization. The recent development of in situ hybridization, a technique whereby labelled complementary RNA molecules are bound to DNA of the chromosomes (reviewed by Hennig, 1973; Rae, 1972), has demonstrated that certain heterochromatic sites are rich in repetitive DNA sequences.

Results from these three areas of study are compared in an attempt to further our understanding of heterochromatin in $V$. $f a b a$. 


\section{Rationale for Studying Vicia faba}

Vicia faba was selected for study because it significantly contributed towards our early understanding of heterochromatin. The distribution of $\mathrm{H}-$ segments (heterochromatic segments) revealed by cold treatment on c-metaphase chromosomes had been established by McLeish (1953) and others, although as will be seen later, the distribution patterns published differed in detail. The temporal pattern of DNA replication was well defined (Evans, 1964, and others), with H-segment distribution coinciding broadly with late replicating regions. $\quad V$. faba thus provided a basis for confirmation and comparison between established heterochromatin sites and bands revealed by new cytological techniques.

A few years prior to the commencement of this study Caspersson et al., (1968, 1969a, b) published results on fluorescent banding in V. faba; and Giemsa banding in animal tissues was a new phenomenon. These advances provided the impetus for pursuing a comparative study of heterochromatin in $V$. faba chromosomes.

\section{An Historical Survey of Heterochromatin}

\section{(a) Early Studies by Other Investigators}

Heterochromatin has intrigued cytogeneticists for the past forty years. On the one hand it forces itself on our attention on account of the interesting and striking properties which it exhibits, whilst on the other hand the large and relatively inconclusive literature which has grown around the subject has had a deterring effect on many investigators. It has even been suggested that the term "heterochromatin" should be removed from the scientific language (Baker and Callan, 1950). Judging from the current literature, it does not appear that this is likely to happen, and it is gratifying that recent work has shed much new light on this hitherto intractable problem. 
The term "heterochromatin" was coined by Heitz in 1928 to denote those chromosomes or parts of chromosomes, in the liverwort Pellia, which retained their deeply stained appearance during interphase when the remaining chromosome regions became poorly visible. Originally the term was purely descriptive as was the much older term "heteropycnosis" (Gutherz, 1907). "Heterochromatin", however, soon acquired genetic implications which were largely derived from work with Drosophiza. It was found that the whole of the heterochromatic $Y$ chromosome carries very few genes and the same applies to over one third of the $\mathrm{X}$ chromosome (Muller and Painter, 1932; Hannah, 1951). It was concluded that heterochromatin is largely devoid of genes, whilst the remaining portion of the genome (euchromatin, a term also used by Heitz, 1928) was the most genetically active. More recent fractionation studies by Frenster, Allfrey and Mirsky (1963) did indeed show that RNA synthesis is active in diffuse chromatin and suppressed in condensed chromatin; and this result was substantiated by electron microscope autoradiography of intact uridine-2-C 4 labelled thymus nuclei (Littau et al., 1964). These observations on RNA synthesis in nuclear subfractions and in intact nuclei strengthen the long-held idea that condensed, pycnotic chromatin is relatively inactive.

Cytological aspects of heterochromatin were studied by Darlington and La Cour $(1938,1940)$ in Paris and Trizlium. They found that in Feulgen stained preparations heterochromatin has a tendency to stain less deeply in metaphase than euchromatin, but that the reverse is true in interphase. They also found that by growing the seedlings at cold temperatures they could induce weakly stained (referred to as negatively-stained) areas on the chromosomes which they called H-segments. It was postulated that heterochromatin fails to maintain its maximum nucleic acid charge, 
a phenomenon they termed nucleic acid starvation. This view has become less acceptable since the demonstration by Wilson and Boothroyd (1944) and Boothroyd (1953) that cold reactivity was most likely due to the undercontraction of the heterochromatic segments. Cooper (1959) further summarized the data from chromosome studies on Drosophiza and suggested that heterochromatin and euchromatin differed in their physical conformation and in the expression of their genes, but not in their overall DNA content. This proposal was substantially verified by autoradiographic and microspectrophotometric studies which showed that differential replication of DNA played no role in the reactivity of chromosomes to cold treatment (Boothroyd and Lima-de-Faria, 1964; Woodard et al., 1964, 1966). The hypothesis of allocycly, however, put forward by Darlington and La Cour (1940), which implies a lack of synchronisation between heterochromatin and euchromatin with regard to nucleic acid synthesis and other characteristics of chromosome behaviour, has been strikingly confirmed by the results of autoradiography. These have shown that in most organisms most heterochromatin DNA replicates out of phase with the remainder of the DNA (Lima-de-Faria, 1969). Evans (1964) and others have clearly shown this to be so in Vicia faba where heterochromatin replicates late in $\mathrm{S}$ phase whereas euchromatin replicates early in the $\mathrm{S}$ phase. Most organisms studied show this pattern to varying degrees.

Within a few decades, therefore, our knowledge of the nature of heterochromatin had been considerably clarified. There can be no longer any doubt that it represents a portion of the genome that differs from the rest, in most cases by its timing of DNA synthesis, its genetic inactivity, and its cycle of condensation. 
(b) Classification of Heterochromatin

One of the most useful classifications of heterochromatin is its sub-division into constitutive and facultative heterochromatin (Brown, 1966). Constitutive heterochromatin occurs at corresponding positions in homologous chromosomes and is regarded as a permanent structural feature of a given chromosome pair. Examples include the heterochromatic blocks in many plant chromosomes, the centromeric regions of many organisms, and the $\alpha$ and $\beta$ heterochromatin in Drosophila salivary gland chromosomes.

Facultative heterochromatin is expressed on only one of a pair of homologous chromosomes. The best known example is the genetically inactivated $\mathrm{x}$ chromosome of human $\mathrm{xx}$ females. This heteropycnotic chromosome forms the sex chromatin body or Barr body of female interphase cells (Barr and Bertram, 1949; Lyon, 1962). Some investigators have used the term semi-facultative in reference to the single $\mathrm{x}$ chromosome of the male short-horned grasshopper and crickets (Comings, 1972a). During spermatogonial divisions of these species the $\mathrm{x}$ chromosome passes through a phase of incomplete condensation to complete condensation. White (1940) termed this negative and positive heteropycnosis respectively. In the female the $\mathrm{x}$ is euchromatic. This then provides the interesting situation of a chromosome which is not permanently heterochromatic, but is also not strictly facultative since being hemizygous it does not inactivate either of two homologues in the original sense of the term.

(c) Multifaceted Behaviour of Heterochromatin

It is well known that heterochromatin displays a very broad spectrum of cytological and genetical effects, e.g. position effects (Lewis, 1950 for review), ectopic pairing (Cohen, 1976), effects on recombination frequency (Strickberger, 1968), changes 
in time of replication in relation to differentiation (Lima-deFaria, 1969), euchromatinization of heterochromatin (Wolf, 1968; Miller, Berlowitz and Regelson, 1971) and chromosomal aberrations at heterochromatic sites (Kihlman, 1957, 1959, 1960; Evans and Scott, 1964; Cohn, 1961). These diverse effects may well imply that even apart from the two broad categories of heterochromatin mentioned above (constitutive and facultative), heterochromatin does not represent a homogeneous population of chromatin but may well consist of a variety of subtypes.

(d) Chromosome Banding

In 1968 Caspersson et al.published photographs of the somatic complement of Vicia faba showing the preferential binding of the fluorescent alkylating agent quinacrine mustard dihydrochloride $(\mathrm{QM})$, to areas of the chromosome arms. These areas appeared to correspond to cold-induced negative bands. The use of fluorochromes flourished : quinacrine (Q), ethidium bromide, and acriflavine being widely used in an attempt to understand further the basis of the banding process. In some cases the treatments produced quite unusual results. For instance, using quinacrine, Vosa (1970) showed enhanced fluorescence at heterochromatic sites in $V$. faba whereas in Tulbaghia pulchella there is a reversal effect $i . e$ a reduction of fluorescence at heterochromatic sites. Quinacrine has no alkylating group (as opposed to quinacrine mustard which does) but shows an identical but reduced banding pattern to QM in V. faba (Caspersson et al., 1969a).

Perhaps more surprising to cytologists was the discovery in some animal tissues of new fluorescent bands undetected by previous techniques. In many cases individual chromosomes could now be more accurately identified. This was greeted with enthusiastic acclaim especially amongst human cytogeneticists 
where fluorescent banding initially proved to be of much value in karyotyping individuals. Most notable was the discovery of the highly fluorescent human Y chromosome. Following the leads provided by Caspersson's group at Stockholm, the variation and reproducibility of fluorescent patterns of individual chromosomes was described in a large number of organisms and confirmed independently in many laboratories.

Further research into fluorescent banding has contributed much towards our understanding of the chromosome in these specialized areas. Most evidence to date suggests that the DNA of many highly fluorescent heterochromatic regions is rich in adenine and thymine (see p. 46). Some reports are anomalous as in mouse AT-rich centromeric regions which show weaker fluorescence than the chromosome arms and much research is now being conducted into clarifying this issue. The weight of evidence so far, however, strongly suggests some correlation between fluorescent banding and base content.

Shortly after the discovery of fluorescent banding came the development of a plethora of alternative banding techniques. The forerunner of these techniques was provided by Pardue and Gall (1970) at Yale in connection with studies of in situ molecular hybridization. They were modifying a method by which RNA molecules can be made to adhere to denatured DNA in cytological preparations; a piece of RNA with a base sequence complementary to a stretch of DNA will bind to form a molecular hybrid. Working with mouse material they noticed that the region adjacent to the centromere of each chromosome stained deeply with Giemsa stain. It seemed that the more deeply stained centromeric regions were also those areas which were first to bind the complementary RNA. The technique was therefore thought to provide a method for demonstrating those chromosome regions which were composed of 
highly repetitive DNA sequences and also an explanation for the observations made over the previous thirty years that centromeric regions sometimes stained differently from the rest of the chromosome.

Arrighi and Hsu (1971a, b) modified the molecular hybridization technique to include only the denaturation, renaturation and Giemsa staining stages, in order to investigate the distribution of differentially-stained cross-bands in a wide range of mammals, including man. They showed that the centromere region of most autosomes and parts of some sex chromosomes stained deeply and coincided with the distribution of constitutive heterochromatin. These centromeric bands were named C-bands.

In addition, Arrighi and Hsu demonstrated that banding on the human $Y$ chromosome was strikingly similar to that seen with quinacrine fluorochrome staining (Casperssonet al., 1970; Pearson, 1970).

The results achieved by the denaturation-reassociation technique not only provided a simple differential staining technique but also gave some insight into the probable organisation of DNA within particular chromosome regions. This was a further breakthrough in describing heterochromatin. Not only did this portion of the genome have the ability to bind with certain fluorochromes but also its DNA was understood to be different in comprising highly repetitive sequences (as was the original interpretation of the denaturation-reassociation technique).

Within a short time discrepancies in banding patterns arose according to the banding method applied. Normally, when a slide is prepared to show Giemsa bands there is a wide variation between chromosomes in the clarity of the bands. Indeed some chromosomes show no bands and others vague bands somewhat reminiscent of the 
bands shown by quinacrine mustard fluorescence. This latter observation must have occurred more or less simultaneously in many laboratories as a flood of reports was published in 1971, 1972 describing "new" techniques for producing Giemsa bands along the chromosomes. All of these techniques varied the denaturation/ renaturation regimes in one way or another in attempts to produce the bands more reliably. It soon became apparent that Giemsa bands existed along the chromosome arms (G-bands) as well as around the centromere (C-bands) (Drets and Shaw, 1971), whilst some specialized techniques such as the Gll method showed banding in exclusive areas of the chromosomes (Gagne and Laberge, 1972).

One of the more significant techniques was that of Sumner, Evans and Buckland (1971) in Edinburgh who found that denaturation could be eliminated from the procedure and time of SSC (sodiumsaline-citrate) treatment reduced in some tissues down to one hour. Then seabright (1971) modified the technique radically by submitting fixed chromosomes to a brief trypsin digestion prior to Giemsa staining which elicited clear G-bands.

A wide debate ensued in the literature on what causes Giemsa banding, ranging from differential renaturation of repetitive DNA, differences in base composition, differences in DNA concentration, selective disruption of chromosomal material to DNA-protein interactions. The issue is somewhat clearer today but is still the subject of much current research. An examination of this topic with reference to present findings and other advances is reserved for later discussion.

This then represented the current state of affairs in the art of band production around the time of commencement of this thesis. Within a few years the status of heterochromatin had changed: on the one hand an overwhelming burst of cytological 
and biochemical research was shedding new light (albeit controversial) on the nature of chromosome bands which were increasingly referred to as heterochromatin, whilst on the other hand the emergence of different banding patterns using different techniques necessitated the clarification of band location in any one organism. Furthermore, as any banded region was being regarded as heterochromatin, confusion arose as to the overall structure of this portion of the genome; the implications of each method for chromosome structure increasingly applied only to specific banded regions.

Compounding this situation was the common claim that heterochromatin possessed certain characteristics based on a newly developed technique with no clear reference to coincidence with the historical use of the term. Did these new banding techniques reflect heterochromatin as shown by established techniques in any one particular species? If some banded areas were "new heterochromatic segments", what characteristics did they possess in terms of previous definitions?

Thus the present investigation arose: to characterise the similarities and differences of chromosome band distribution in Vicia faba after cold treatment, acid treatment, fluorescent banding, various forms of Giemsa banding, and orcein banding (a new technique), and to clarify these new chromosome banding techniques with respect to previous definitions of heterochromatin.

(e) Chromosome Location of Repetitive DNA by In Situ Hybridization

It was previously mentioned that Pardue and Gall revealed differential staining of chromosomes in the process of performing in situ molecular hybridization. This introduced a new aspect in the study of heterochromatin. 
The discovery of repetitive DNA sequences in the genome of higher organisms has been ascribed to Britten and his co-workers (1965, 1966) and stems from the detection of satellite DNA by density gradient ultracentrifugation in the early 1960's. Initial experiments with mouse DNA showed that when total DNA was centrifuged in neutral CsCl a fraction of it differed in buoyant density from the main band DNA (Kit, 1961, 1962). This minor component, which in the mouse is lower in buoyant density, was termed satellite DNA. A few years later it was shown that the complementary strands of mouse satellite DNA reassociated rapidly after denaturation by heat, strongly suggesting that satellite DNA was composed of relatively short repeating polynucleotide sequences (Britten and Waring, 1965; Britten and Kohne, 1966).

Subsequent work by Britten and Kohne $(1967,1968)$ on rate of strand reassociation and repetitiveness (reassociation kinetics) soon established that repetitive DNA was widespread in the animal and plant kingdoms and not necessarily confined to satellite DNA. For example, mouse satellite DNA comprises 10\% of the total genome, yet reassociation kinetics have established that a considerable percentage of mouse DNA is repetitive possibly $30 \%$ or more (Britten and Kohne, 1968).

The capacity of denatured DNA to reassociate into duplex molecules led directly to the technique of in situ molecular hybridization in cytological preparations. Pardue and Gall (1969), John, Birnstiel and Jones (1969) and Buongiorno-Nardelli and Amaldi (1970) developed this technique independently to indicate that ribosomal RNA hybridizes specifically and exclusively to the DNA which codes for it (rDNA). 
The technique consists of denaturing by heat or alkali the DNA of the cells while they still adhere to the slide. After neutralizing, highly radioactive RNA extracted from cultured tissues is added in solution at high concentration to the slide when some of the labelled molecules are taken up by certain parts of the chromosomes and nucleus. (For technical details on in situ hybridization see reviews by Rae (1972), Steffensen and Wimber (1972), and Hennig (1973)). Standard autoradiographic procedures follow to determine grain location.

Pardue and Gall (Zoc. cit.) and John et al. (Zoc. cit.) chose Xenopus oocytes for their experiments because during oogenesis these cells undergo a special replication for amplification of rDNA. In the late pachytene nucleus, the amplified rDNA constitutes about $10 \%$ of the total DNA and forms a cytologically distinct cap partially covering the chromosomes. Pardue and Gall (1969) further stated that "under the annealing conditions used, only that DNA which is present in the genome in highly multiple copies should exhibit hybridization".

Buongiorno-Nardelli and Amaldi (1970) also successfully hybridized rRNA to nucleoli in Chinese hamster cells.

Further development of the method led to the use of highly radioactive RNA transcribed in vitro from extracted DNA. This step increased the specific activity of the RNA by a factor of 10 to 100. Labelled transcription products were then hybridized to chromosomal DNA in situ. By this method Jones (1970) and Pardue and Gall (1970) showed that a large fraction of mouse satellite DNA is located near the centromeres of the metaphase chromosomes, comparable to the distribution of C-bands.

In situ hybridization experiments with RNA enzymically prepared from total DNA, however, revealed a labelling pattern not confined only to the centromeric region. For example Hennig, 
14.

Hennig and Stein (1970) and Jones and Robertson (1970) showed grains in the banded regions along the arms of Drosophiza chromosomes. Many studies thereafter showed that the distribution of repetitive DNA sequences in the chromosomes of many organisms (mainly dipteran, amphibian and mammalian tissues) coincided closely with heterochromatin location (see review by Rae, 1972).

Two questions arose in relation to repetitive DNA and heterochromatin: Is all heterochromatin composed of repeated DNA sequences and are all repetitive DNA fractions expressed as heterochromatin? The answer to the first question is "yes with a few exceptions" and to the second question "no". Studies in Drosophiza spp. (Gall et al., 1971), Rhynchosciara (Eckhardt and Gall, 1971) and Microtus agrestis (Arrighi et al., 1970a), transcribing from total repetitive DNA, main band DNA, or whole DNA have all shown chromocenters and heterochromatic regions especially enriched with repetitive DNA. In addition, however, light labelling can sometimes be observed along the chromosome arms suggesting the presence of repetitive DNA sequences in euchromatic regions. On the other hand an example of heterochromatin seen not to contain repetitive DNA is the facultative segment on the Microtus $\mathrm{X}$ chromosome.

As a result of the above findings it was thus pertinent to the present investigation to establish the relationship between heterochromatin distribution and repetitive DNA location in Vicia faba chromosomes.

In situ hybridization has since been widely used in heterochromatin studies and DNA sub-fraction work, particularly in the chromosomal localization of different satellite DNA components and ribosomal DNA subunits. The technique has also been employed to show the site of synthesis of tRNA and histone mRNA, mainly in 
Drosophiza, Xenopus and Chinese hamster cells, and of giant nuclear RNA molecules isolated from Chironomus polytene chromosomes (Hennig, 1973). In plants, however, the method has not been exploited until very recently. Wimber et al. (1974), for example, have localized 5S RNA gene sites in Zea mays and Timmis, Deumling and Ingle (1975) have shown the chromosome location of satellite DNA components in Scizla sibirica and Vicia faba.

Further improvements to the in situ hybridization technique are continually being made with the intention of localizing DNA sequences with low orders of base repetition. Indeed, the method of iodinating isolated RNA (to increase specific activity) has led Prensky et al. (1973) to proclaim "we should be well on our way towards localizing individual genes in diploid chromosomes". This aim is probably approaching realization with the more recent technique combining scanning electron microscopy with the use of a non-radioactive label. Manning et al. (1975) labelled rRNA molecules with biotin, hybridized the RNA to chromosomal DNA, then bound polymethycrylate spheres selectively to the biotin. These spheres can be seen with the S.E.M., showing the detailed location of rDNA cistrons.

The RNA-DNA in situ hybridization technique, therefore, is continually being refined. The development of the technique was a significant advance in cytogenetical research which has equipped experimenters with a powerful new tool to probe further the relationship between molecular structure and function and chromosome structure. 


\section{METHODS}

The following terms are defined for reference.

The methods were applied routinely unless otherwise stated.

(a) colchicine pretreatment: the pretreatment of root-tips, excised from 10-day old bean seedlings, in $0.05 \%$ colchicine for $3 \frac{1}{2}$ hours.

(b) fixation: the killing and fixing of root-tips in a mixture of 1:3 glacial acetic acid/methanol overnight.

(c) pectinase treatment: the treatment of root-tips with $10 \%$ aqueous pectinase for 5 hours at $37^{\circ} \mathrm{C}$. Vicia faba roots have a tough root cap, thus pectinase treatment was essential to achieve satisfactory chromosome spreads. The treatment was used routinely after fixation to soften the tissue for maceration and squashing when $\mathrm{HCl}$ treatment at $60^{\circ} \mathrm{C}$ was not included in the technique.

(d) liquid nitrogen technique: the technique of removing a coverslip from a slide by freezing the slide in liquid nitrogen, prising the coverslip off with a razor blade and dipping the slide in $100 \%$ ethanol before leaving it to air dry .

(e) squash preparation: includes steps (a), (b), (c) and (d).

(f) slides were routinely mounted in Depex.

1. Root-tip Sections.

Procedure for Staining Chromatin with Heidenhain's

Haematoxylin

Lateral root-tips were fixed in Navashin's fixative for 24 hours, dehydrated, then embedded in wax, sectioned (10 $\mu \mathrm{m}$ thickness), stained in Heidenhain's haematoxylin and mounted as outlined by Johansen (1940) . 
2. Root-tip Squashes: Preparation of Chromosomes for

Karyotyping

Lateral root-tips were pretreated with colchicine, fixed, then stained and prepared by the conventional Feulgen squash technique. Coverslips were removed by the liquid nitrogen method, the slides air dried and mounted.

\section{Cold Treatment}

Boxes containing 8-day old seedlings were transferred to a $4^{\circ} \mathrm{C}$ chamber for 3-4 days, then excised root-tips were treated as in (2) above.

\section{Acid Treatment}

Either (a) Pretreatment and fixation as in (2) above, followed by $1 \mathrm{~N} \mathrm{HCl}$ - 45\% acetic acid (1:9) treatment for $15 \mathrm{~min}$ at $60^{\circ} \mathrm{C}$ then Feulgen staining.

Or (b) Feulgen staining as in (2) above but with prolonged maceration ( $30 \mathrm{~min}$ ) in $45 \%$ acetic acid.

\section{Quinacrine Mustard Fluorescence}

The method of Caspersson et al. (1968) was applied with the following modification : fixed lateral root-tips were treated with pectinase prior to maceration.

\section{SSC - Giemsa Banding}

Squash preparations were treated with $2 \times$ SSC* $\left.^{*} \mathrm{pH} 7.0\right)$ at $65^{\circ} \mathrm{C}$ for 20 hours, rinsed in three changes of deionized water, air dried, then stained with Giemsa ( $2 \mathrm{mls}$ of Gurr's improved R66 diluted $50 \mathrm{x}$ with 0.1M Sorensen's buffer, $\mathrm{pH}$ 6.9). Slides were monitored at regular intervals after $2 \mathrm{~h}$ in Giemsa stain. ${ }^{*} \mathrm{SSC}=0.15 \mathrm{M}$ sodium chloride, $0.015 \mathrm{M}$ trisodium citrate. 
7. $\mathrm{NaOH}$ - SSC - Giemsa Banding

The method of Arrighi and Hsu (197lb) was followed

(omitting RNase treatment). Squash preparations were treated with $0.07 \mathrm{~N} \mathrm{NaOH}$ for 30 sec-2 min prior to SSC-Giemsa treatment.

\section{Trypsin - Giemsa Banding}

Squash preparations were treated as follows:

2 washes in $100 \%$ ethanol, brief $1 \mathrm{~N}$ saline wash, then treatment with a buffered trypsin solution in an ice bath for 4-7 min. The buffer composition was $1.6 \mathrm{~g} \mathrm{NaCl}, 0.04 \mathrm{~g} \mathrm{KCl}$, $0.4 \mathrm{~g} \mathrm{KH}_{2} \mathrm{PO}_{4}, 0.23 \mathrm{~g} \mathrm{Na}_{2} \mathrm{HPO}_{4}, 0.02 \mathrm{~g} \mathrm{CaCl}_{2}, 0.02 \mathrm{~g} \mathrm{MgCl}_{2} .6 \mathrm{H}_{2} \mathrm{O}$, $0.5 \mathrm{~g}$ trypsin (from beef pancreas-BDH), dissolved in deionized water and made up to $200 \mathrm{ml}$ (Deaven and Petersen, 1973).

The slides were then washed in $70 \%, 95 \%$ and $100 \%$ ethanol, air dried, then placed into Giemsa stain (M/10 Sorensen's buffer, pH 6.9) and monitored at regular intervals after 5 min.

\section{Urea - Giemsa Banding}

The method used by Dobel, Rieger and Michaelis (1973) in V. faba root-tip preparations was applied.

Lateral root-tips were treated with colchicine, fixed, hydrolysed for $5 \mathrm{~min}$ in $0.2 \mathrm{~N} \mathrm{HCl}$ at $60^{\circ} \mathrm{C}$, squashed and the coverslips removed. The slides were then incubated in $6 \mathrm{M}$ urea for $30 \mathrm{~min}$ at room temperature, immersed in M/15 Sorensen's phosphate buffer (pH 7.2) for $5 \mathrm{~min}$ then stained in a $2 \%$ Giemsa solution at $\mathrm{pH} 6.8$ for $8-12 \mathrm{~min}$.

10. Gll Banding

Squash preparations were treated with a 2\% Giemsa solution in $0.1 \% \mathrm{Na}_{2} \mathrm{HPO}_{4} \cdot 12 \mathrm{H}_{2} \mathrm{O}$ buffer adjusted to $\mathrm{pH} 11$ with $\mathrm{NaOH}$, and monitored at regular intervals after $5 \mathrm{~min}$ (Gagne and Laberge, 1972) . 
11. Reverse Banding

Squash preparations were treated with $20 \mathrm{mM}$ phosphate buffer, pH 6.5 at $87^{\circ} \mathrm{C}$ for $10 \mathrm{~min}$, then stained with Giemsa (M/10 Sorensen's buffer, pH 6.9) (Dutrillaux and Lejeune, 1971).

12. Lacto - Aceto - Orcein (LAO) Banding

The method Kurita (1958) applied to AlZium spp. chromosomes was followed.

After colchicine treatment, (Kurita used 8-oxyquinoline as an antimitotic agent) root-tips were washed briefly in deionized water, treated with $1 \mathrm{~N} \mathrm{HCl} \mathrm{-} \mathrm{45 \%} \mathrm{acetic} \mathrm{acid} \mathrm{(1:9)} \mathrm{for} 15 \mathrm{~min}$ at $60^{\circ} \mathrm{C}$, macerated in $2 \%$ orcein in glacial acetic acid - 85\% lactic acid (1:1) for $15 \mathrm{~min}$ then squashed.

\section{Fixed LAO Banding}

Root-tips were fixed after colchicine treatment then treated as in (12) above.

\section{Late-labelling Autoradiography}

The procedure followed is a modification of several techniques described by Evans (1964), Webster and Davidson (1968) and MacLeod (1968).

Beans were germinated in sawdust and the young seedlings suspended by perspex plates in an aerated water bath at $22^{\circ} \mathrm{C}$.

(a) In Vivo Labelling of DNA

The roots of seedlings were immersed in a $100 \mathrm{ml}$ beaker of ${ }^{3} \mathrm{H}$-thymidine solution $(3.3 \mu \mathrm{C} / \mathrm{ml})$ for $30 \mathrm{~min}$. During this "pulse", ${ }^{3} \mathrm{H}$-thymidine is incorporated into replicating DNA.

The seedlings were then rinsed thoroughly in deionized water and transferred back to the water bath for a "chase" period. 
Some lateral roots were excised immediately, pretreated with colchicine for 2 hours and fixed. This process was repeated at 20 min intervals.

(b) Staining of Roots

Root-tips were stained and prepared by the Feulgen squash technique. Coverslips were removed and the slides air dried.

(c) Autoradiography

The slides were dipped in Ilford L4 nuclear emulsion (diluted with deionized water $1: 1$ ) by standard procedures and exposed for 3-5 weeks. The autoradiographs were developed with Microphen for $5 \mathrm{~min}$, fixed, washed in several changes of deionized water, air dried and mounted.

\section{In Situ Molecular Hybridization}

(a) Isolation of DNA

Whole DNA was extracted from bean seedlings according to the method of Marmur (1961). For final purification the DNA was pelleted by preparative centrifugation for $4 \mathrm{~h}$ at 200,000 $\mathrm{x}$ g. The pellet was dissolved in $0.1 \mathrm{x}$ SSC. Several samples were tested for purity by electrophoresis on polyacrylamide gels.

(b) DNA Transcription

The method of transcribing highly radioactive RNA complementary to DNA was essentially that described by Pardue, Gerbi, Eckhardt and Gall (1970).

The reaction was carried out in $1 \mathrm{ml}$ of buffer containing 8 units of $E$. coli RNA polymerase enzyme, $10 \mu \mathrm{g}$ of whole DNA, and $100 \mu \mathrm{C}$ each of $\mathrm{ATP}-{ }^{3} \mathrm{H}\left(\left[2-{ }^{3} \mathrm{H}\right]\right.$ adenosine triphosphate, 16.4 $\mathrm{C} / \mathrm{mM}), \operatorname{CTP}-{ }^{3} \mathrm{H}\left(\left[5-{ }^{3} \mathrm{H}\right]\right.$ cytidine triphosphate, $\left.23 \mathrm{C} / \mathrm{mM}\right), \mathrm{GTP}-{ }^{3} \mathrm{H}$ ( $\left[8-{ }^{3} \mathrm{H}\right]$ guanosine triphosphate, $\left.10.5 \mathrm{C} / \mathrm{mM}\right)$ and UTP $-{ }^{3} \mathrm{H}\left(\left[5-{ }^{3} \mathrm{H}\right]\right.$ uridine triphosphate, $23 \mathrm{c} / \mathrm{mM})$. The buffer composition was 
$0.04 \mathrm{M}$ Tris pH $7.9,0.15 \mathrm{M} \mathrm{KCl}, 0.0046 \mathrm{M} \mathrm{MgCl}_{2}, 0.002 \mathrm{M} \mathrm{MnCl}_{2}$, $7 \times 10^{-5} \mathrm{M}$ EDTA, and $0.0058 \mathrm{M}$ mercaptoethanol. The reaction mixture was incubated for $1 \frac{1}{2} \mathrm{~h}$ at $37^{\circ} \mathrm{C}$. $10 \mu 1$ samples were taken for analysis after $0 \mathrm{~min}, 15 \mathrm{~min}, 30 \mathrm{~min}, 60 \mathrm{~min}, 90 \mathrm{~min}$ (see App. Ia).

After $1 \frac{1}{2} \mathrm{~h}$ incubation, $3 \mathrm{ml}$ of $0.04 \mathrm{M}$ Tris $\mathrm{pH} 7.8$, containing $80 \mu \mathrm{g}$ of DNase-1 (Sigma, RNase-free) and $1.0 \mathrm{mg}$ of $E$. coli rRNA was added and the mixture held at room temperature for $20 \mathrm{~min}$. $0.4 \mathrm{ml}$ of $10 \%(\mathrm{w} / \mathrm{v}) \mathrm{SLS}^{*}$ and $4 \mathrm{ml}$ of Kirby's phenol:cresol mixture were then added, shaken for $10 \mathrm{~min}$ and centrifuged at 3,000 rpm for $5 \mathrm{~min}$. The reaction mixture was then loaded onto a sephadex G-50 column. The column was eluted with $10 \mathrm{mM}$ Tris pH 7.4 buffer solution and $50 \mu \mathrm{l}$ samples from each $6 \mathrm{ml}$ fraction were measured spectrophotometrically and by liquid scintillation (App. Ib). Those fractions containing high M.W. ethanol/ether precipitable counts were pooled (i.e. fractions 8,9 and 10).

After adjusting the $\mathrm{NaCl}$ concentration to $0.5 \mathrm{M}$ the pooled product was precipitated with 2 volumes of $95 \%$ ethanol at $-20^{\circ} \mathrm{C}$ overnight. The precipitate was centrifuged (8,000 rpm for $15 \mathrm{~min})$ rinsed with $80 \%$ ethanol and the pellet dissolved in $1.5 \mathrm{ml} 0.1 \mathrm{x}$ SSC. Several 10 HI samples were taken for analysis (see App. Ic). Approximately $1 \mu \mathrm{g}$ of complementary polynucleotide (cRNA) was produced; specific activity about $2 \times 10^{6} \mathrm{cpm} / \mu \mathrm{g}$. For hybridization the CRNA was precipitated, centrifuged, dissolved in $0.4 \mathrm{ml} 0.1 \mathrm{x} \mathrm{SSC}$ then adjusted to a $0.5 \mathrm{ml}$ solution of $0.6 \mathrm{M}$ sodium chloride, $0.06 \mathrm{M}$ sodium citrate to which $0.5 \mathrm{ml}$ of formamide was added.

(c) Preparation of Root-tip Chromosomes

Lateral root-tips were pretreated with colchicine and fixed for $1 \mathrm{~h}$. They were then treated with pectinase, macerated in a drop of $45 \%$ acetic acid and squashed on microscope slides which 
previously had been sonicated and acid-washed. Coverslips were removed by the liquid nitrogen method and the slides air dried. $100 \mu \mathrm{I}$ of RNase solution $(100 \mu \mathrm{g} / \mathrm{ml} \mathrm{pH} 5.0$, preheated at $80^{\circ} \mathrm{C}$ for $10 \mathrm{~min}$ during preparation) was placed on the tissue of each slide and covered with a coverslip. The slides were placed into moist chambers (as described by Gall and Pardue, 1971) and held at $40^{\circ} \mathrm{C}$ for $1 \mathrm{~h}$. They were then rinsed twice with $2 \mathrm{x}$ SSC, passed through $70 \%$ ethanol and $95 \%$ ethanol and air dried.

(d) Hybrid Formation

The method of hybridizing RNA to DNA in situ was essentially that described in detail by Gall and Pardue (1971).

Modifications were made to the method of denaturation as $\mathrm{NaOH}$ treatment results in gross distortion of the $V$. faba chromosomes, and to incubation time and temperature according to the findings of Moar, Purdom and Jones (1975).

Chromosomal DNA was denatured by immersing the prepared slides in $0.1 \mathrm{x} \mathrm{SSC}$ at $100^{\circ} \mathrm{C}$ for $3 \mathrm{~min}$. The slides were then plunged into cold $0.1 \times$ SSC, rinsed in $70 \%$ ethanol, $100 \%$ ethanol and air dried. Test slides were stained with methyl green/pyronin to indicate satisfactory denaturation.

$10 \mathrm{ml}$ of salt solution used to dissolve the cRNA was placed into each of several plastic petri dishes. These dishes, which served as moist chambers during the incubation period, were placed in an oven at $60^{\circ} \mathrm{C}$ for $1 \mathrm{~h}$ preceding hybridization.

$50 \mu 1$ of cRNA solution was placed on the tissue of each slide and covered with an acid-washed coverslip. Each slide was placed into an equilibrated petri dish, incubated at $60^{\circ} \mathrm{C}$ for $1 \mathrm{~h}$, then transferred to a $40^{\circ} \mathrm{C}$ oven for another three hours. After incubation each slide was washed three times in $2 \mathrm{x}$ SSC and air dried. $200 \mu \mathrm{l}$ of RNase solution $(20 \mu \mathrm{g} / \mathrm{ml} \mathrm{pH} 5.0$, preheated as before at $80^{\circ} \mathrm{C}$ for $10 \mathrm{~min}$ ) was placed on the tissue 
and covered with a coverslip. The slides were held in moist chambers as above at room temperature for $1 \mathrm{~h}$, rinsed three times with $2 \times$ SSC then with deionized water.

Parallel competition experiments included a 50-fold excess of unlabelled denatured $V$. faba DNA over radioactive cRNA during the hybridization step.

(e) Autoradiography and Staining of Chromosomes

Autoradiographs were prepared by standard procedures with an exposure time of 3-5 weeks.

The slides were immersed in Snow's (1963) alcoholic carmine for $20 \mathrm{~min}$, rinsed in deionized water, air dried and mounted.

(f) Analysis of Grain Location

(1) $40 \mathrm{M}$ chromosomes were randomly selected for grain counting with one proviso: that the chromosome arms were nonoverlapping.

(2) The analysis was conducted on the assumption that the emission of $\beta$-particles from all regions of the $\mathrm{M}$ chromosome had an equal chance of reaching the emulsion.

(3) Each M chromosome was divided into 10 regions in the following manner:

(i) Each arm, and not total chromosome length, was subdivided to minimise difficulties associated with differential contraction.

(ii) The arms were sub-divided in a "morphologically meaningful" way, $i . e$. with consideration for possible grain localization around the centromere, secondary constriction or certain intercalary regions.

(iii) To satisfy (ii) and obtain as near to equal-sized sections for statistical purposes, the satellite was divided into two, the M2 arm from centromere to secondary constriction into three, and the M1 arm into five (Table 2, p. 40). 
(iv) Counts were from photographs taken at high magnification (100 x oil immersion lens) and divisions made with vernier calipers.

(4) Sub-division of the M chromosome in a biologically meaningful manner, however, imposed limitations on the validity of statistical tests:

(i) An analysis of variance was not recommended by reason of the small numbers in each category (Armstrong, pers. comm.).

(ii) Differential contraction of the chromosome arms would result in small size differences between the chromosome regions. The pooled data, therefore, are a close but not a strict representation of ten equalsized regions along the $M$ chromosome. For this reason the statistical analysis $\left(x^{2}\right.$ test for random grain location) and histogram were used only as useful guides. The significant probability was taken as 5\%.

\section{DNA Reassociation Kinetics}

Sonicated DNA (length 500 nucleotides) was denatured by boiling for $10 \mathrm{~min}$, and incubated at $60^{\circ} \mathrm{C}$ in $0.12 \mathrm{M}$ phosphate buffer (PB). At various intervals $50 \mu \mathrm{g}$ samples were passed over a hydroxyapatite column at $60^{\circ} \mathrm{C}$. After the loading of each sample the column was eluted once with $2.5 \mathrm{ml}$ of $0.15 \mathrm{M} \mathrm{PB}$ and twice with $2.5 \mathrm{ml}$ of $0.3 \mathrm{M} \mathrm{PB}$ then re-equilibrated with $0.12 \mathrm{M}$ PB. The DNA concentration during the reassociation reaction was $1 \mathrm{mg} / \mathrm{ml}$. The absorbancy of each fraction was measured at $260 \mathrm{~nm}$ and $320 \mathrm{~nm}$.

A reassociation $\left(c_{0} t\right)$ curve was constructed from these data. 
17. Summary of Modification and Development of Methods

Although the above banding techniques were pioneered by other workers, in nearly every case the method was modified by the present author to suit Vicia faba material. In some cases considerable experimentation was involved before satisfactory banding was achieved and several recipes were abandoned. This was especially so for Giemsa banding.

Those techniques which required modification and development in the present study were: cold treatment (to a minor degree; more $\mathrm{H}$-segments were seen upon reducing colchicine pretreatment time); acid treatment, which the author developed (independently from Takehisa, 1973) upon observing achromatic bands in squash preparations subjected to prolonged maceration ; SSC-Giemsa banding (this technique entailed much experimentation with varying solution concentrations, $\mathrm{pH}$, and times of treatment. The present procedure was developed prior to published reports of Giemsa banding in $V . f a b a$ ); trypsin banding (Deaven and Petersen's (1973) recipe required changes in treatment times); the preparation of chromosomes for in situ hybridization, especially in achieving denaturation of DNA without degrading the chromosomes. In this respect heat denaturation was preferable to $\mathrm{NaOH}$ denaturation.

An incidental but important discovery in the present study was the sensitivity of $V$. faba chromosomes to alkaline $\mathrm{pH}$. Treatment with any solution with a $\mathrm{pH}>7.2$ resulted in rapid degradation of the chromosomes. Indeed in the handling of $V$. faba chromosomes, whether it be for chromosome banding or the lengthy preparation for in situ hybridization, $\mathrm{pH}$ values were not permitted to exceed 7.2 (except where specifically stated as in the Gll method). 


\section{RESULTS}

I. The Vicia faba "Coles Early Dwarf" Karyotype

Table $1 /$ shows the common classifications used for $V$. faba chromosomes. The present study adopts the nomenclature of Evans (1961).

The diploid complement consists of twelve chromosomes (Fig.1): one pair of easily distinguishable metacentric (M) chromosomes is approximately twice the length of each of five pairs of subtelocentric (S) chromosomes. Evans classified the S chromosomes as $\underline{\text { a to }}$ e based on centromere position and differing total lengths (Fig. 2).

Fig. 3 is a karyogram of Fig. 1. The arms of each $\mathrm{M}$ chromosome differ both in length and in morphology. The M2 arm has a secondary constriction at the nucleolar organizer region and bears a prominent satellite. Of the $\mathrm{S}$ chromosomes only the Sd pair is readily distinguishable from the others because of its very small short arm (Figs. 1 and 3 ). The other $S$ pairs cannot be reliably distinguished because of their similar total lengths and arm ratios.

Chromosome recognition has been reviewed by sybenga (1959), Patau (1960), Sasaki (1961) and Bentzer et al. (1971). These investigations have emphasized the need for caution when identifying chromosomes of similar size and morphology. Differential chromosome contraction and differing cytological techniques result in variations in arm ratios and overall chromosome lengths (as is well illustrated by the M chromosomes in Fig. 3) leading to possible misidentifications. 
To overcome ambiguity in identifying $V$. faba chromosomes, Michaelis and Rieger (1971) have used new, more easily classifiable karyotypes, brought about by induced mutations. They show a secondary constriction in the short arm of chromosome II (= Sa). In the present study, an achromatic region at this position was detected only after prolonged maceration, special acid treatment, or after cold treatment (Figs. 18, 48 and 13).

In standard Feulgen preparations sometimes an achromatic band is found in the Ml arm close to the centromere (Fig. 18). Fig. 1 in Michaelis and Rieger (1971) shows this same band clearly. Less frequent is the appearance of two adjacent achromatic bands close to the centromere on the M2 arm. The appearance of these $\mathrm{M}$ bands along with the band in the small arm of an $\mathrm{S}$ chromosome pair (possibly Sa) was later found to be associated with the length of time the root-tips are macerated in $45 \%$ acetic acid (see p. 32). This may account for some of the differences between various published $V$. faba karyotypes.

Fixed, squashed but unstained chromosomes seen under phase contrast microscopy usually appear uniformly dense (Fig. 4a). Highly contracted chromosomes, however, often have phase dense areas at the chromosome ends and flanking the centromeres (Fig.4b). These areas, which probably reflect differential contraction, are not apparent after Feulgen staining.

In summary, only one chromosome pair of the diploid set of twelve can be recognised unequivocally and consistently (the $\mathrm{M}$ chromosomes). The distinctness of the large metacentrics assumes greater importance when some preparations are subjected to harsh treatment, as in the present study, after which these two chromosomes are generally the only identifiable pair. Consequently this thesis is weighted towards studying the M chromosome, although any clear information manifested by the $\mathrm{S}$ chromosomes is documented. 
28.

Table 1. Common karyotype symbols used for Vicia faba (n=6)

\section{chromosomes}

Author

Metacentric chromosome

Evans (1961)

M

Sjodin (1971)

1

Michaelis and Rieger (1971) 1
Sub-telocentric chromosomes

$\mathrm{Sa} \mathrm{Sb} \mathrm{Sc} \mathrm{Sd} \mathrm{Se}$

$\begin{array}{lllll}2 & 3 & 5 & 6 & 4\end{array}$

II III IV VI V 
II. Interphase Heterochromatin

In interphase nuclei of both meristematic and differentiated cells of root-tips, heterochromatin is seen as darkly staining, roughly circular chromocenters (Figs. 5a-e and $6 \mathrm{a}, \mathrm{b})$, ranging from 4-14 with an average of 8-9 in number; and 0.5-3 $\mu \mathrm{m}$ in diameter (data from 50 cells; Fig. 7).

Measurements of chromocenters did not offer evidence in support of an inverse correlation between number and size that might suggest heterochromatic fusions.

The chromocenters are often polarized suggesting they are localized at the centromeres (or ends) of chromosomes, the polarization being a consequence of chromosome movement in the preceding anaphase.

One or two compact chromocenters can usually be seen closely associated with the nucleolus. This is judged to be heterochromatin associated with the nucleolus organizing regions (see again p. 83) . 


\section{Banding on c-Metaphase Chromosomes}

1. Cold Treatment Bands

Cold treatment induces negative bands although these vary in clarity. The $\mathrm{M}$ chromosome shows a distinct band on each arm close to the centromere (Figs. 8 and 5la), as has been documented by others (Fig. 15a-d). These two bands are designated $\mathrm{Ml} / \mathrm{l}$ and $\mathrm{M} 2 / 1$.

Unequivocal identification of the centromere was sometimes difficult as it often resembles a negative band. Positive identification was possible, however, in non-colchicine coldtreated anaphase complements in which the centromeres are pulled polewards whilst the true negative bands are seen on the stretched chromosome arms (Fig. 9).

Cold bands on s chromosomes are less conspicuous and their distribution more variable (Fig. 10).

The degree of chromosome contraction is crucial to manifestation of cold bands, especially on the S chromosomes. Difficulty was encountered initially in revealing bands by cold treatment (as testified by Caspersson et al., 1968, 1969a), but a reduction of colchicine treatment from $3 \frac{1}{2}$ hours to only 2 hours, greatly enhanced the appearance of cold bands. The shorter colchicine treatment resulted in a higher frequency of less contracted complements which showed more negative bands. In maximally contracted chromosomes only the single mid-bands on some $\mathrm{S}$ chromosomes (Fig. 12; probably La Cour's (1951) X segments) and the $\mathrm{M}$ chromosome centromeric bands are prominent. In less contracted complements many alternating light and dark crossbands occur along the length of most chromosomes (Figs. 10 and 11), reminiscent of the complex Giemsa-banded pattern seen in chromosomes of some animal species. It is questionable whether some of these bands are induced by cold or are the result of 
natural coiling patterns. Similar "bands" are seen at midprophase in standard Feulgen preparations.

The present studies agree with previously published reports on the position of the centromeric negative bands on the $\mathrm{M}$ chromosome, although the small intercalary band on the Ml arm identified by Evans and Bigger (1961) (Fig. 15b) and perhaps visible in Grant and Heslot's (1966) photograph (Fig. 15a) was not seen.

Cold treatment often revealed a band in the short arm of two S chromosomes (Fig. 13) which was not found after standard Feulgen treatment without prolonged maceration. Michaelis and Rieger (1971) regard this band as part of the normal karyotype. Frequently, after cold treatment, distinct positivelystained swellings are seen midway along many S chromosomes (Fig.12). Similar structures produced in response to cold have been reported recently in V. faba chromosomes by Takehisa (1976).

Preparations were examined under phase contrast microscopy for bands after each step in the cold and standard techniques:

(i) In unfixed squashes, chromosomes are greatly distorted and unsuitable for study.

(ii) Fixed root-tips grown at room temperature show chromosomes usually with uniform density (exceptions as in Fig. 4b).

(iii) Fixed cold-treated root-tips consistently show the M1 and M2 bands (Fig. 14a, b).

\section{Acid Treatment Bands}

Acid treatment reveals three clear negative bands on the M chromosome, two corresponding in position to those revealed by cold treatment, the third (M2/2) arising on the M2 arm close to the centromere (Figs. 16, 17 and 51b). 
After standard Feulgen staining, prolonged maceration (>30 $\mathrm{min}$ ) of root-tips in $45 \%$ acetic acid will also induce the appearance of band Ml/I (Fig. 18) and occasionally M2/1 and M2/2.

These bands (M1/1, M2/I and $\mathrm{M} 2 / 2$ ) are equivalent to bands 1, 2 and 3 respectively, as classified by Takehisa (1973).

The $\mathrm{S}$ chromosomes do not show negative banding after acid treatment but for an achromatic band in the short arm of two chromosomes (Sa?) (Fig. 18).

\section{Quinacrine Mustard Fluorescence}

This technique consistently reveals one band on the Ml arm, (M1/1) much brighter than the rest, and two (M2/1, M2/2) close together on the M2 arm (Fig. 19). Occasionally an indistinct band (M2/3) is produced just distal to M2/1 (Figs. 20, 21 and 51c).

Differential fluorescence appears to be absent from intercalary regions, although a slight increase in fluorescence is often found close to the centromere on the long arms of some $\mathrm{S}$ chromosomes (Figs. 19 and 20).

\section{Giemsa Banding}

Al1 techniques used to induce Giemsa banding (pp. 17, 18, 19) cause the chromosomes to swell and their outlines become indistinct. Simultaneously, specific regions of the chromosome arms become differentially stained. Published reports on Giemsa banding in $V$. faba show varying patterns for both $\mathrm{M}$ and $\mathrm{S}$ chromosomes (Fig. 42a-f).

(a) SSC-Giemsa Banding

This technique was the most reliable method for showing Giemsa bands. Darkly stained regions are seen around the $\mathrm{M}$ chromosome centromeres (Figs. 22, 23 and 51d); one band is prominent on the Ml side of the centromere (Ml/l), whilst on the 
M2 arm three neighbouring segments (M2/1, M2/2 and $M 2 / 3$ ) can be resolved although in most cases bands $M 2 / 1$ and $M 2 / 3$ merge to form one larger band (wider bar in Fig. 22).

Fig. 24 shows the M centromeres differentially stained (see again p. 34).

The S chromosomes show a complex banding pattern. Fig. 23 is an attempt to group the five pairs of $\mathrm{S}$ chromosomes according to their band distributions. This karyogram was constructed from Fig. 22 but the author emphasizes that the recognition of five different types within the $\mathrm{S}$ chromosomes comes from the observation of several banded complements.

The most easily recognised $\mathrm{S}$ chromosome displays a single narrow band midway along the length of its long arm (Figs. 22 and 23).

Since the remaining $\mathrm{S}$ chromosomes possess bands in similar positions (in the proximal half of the long arm), the pairs cannot be easily distinguished from each other. Thus classification of these chromosomes relies on number and size of crossbands rather than on their position. In favourable preparations a second pair of $\mathrm{S}$ chromosomes can be distinguished showing one broad mid-band with an adjacent narrower proximal band (Figs. 22, 23, more clear in Fig. 24).

Two further chromosome pairs have almost identical patterns with two equal-sized cross-bands close together midway along the long arms (Figs. 22 and 23).

The remaining chromosome pair may show an intricate series of three or four adjacent bands which are partially distinguishable (see Fig. 31 from a trypsin-treated preparation, not clearly visible in Fig. 23). 
34 .

In addition to intercalary bands all s chromosomes display, to varying degrees, differential staining adjacent to and on the long arm side of their centromeres (Figs. 22 and 23).

After SSC-Giemsa treatment, the chromocenters of interphase nuclei appear to be more numerous (Fig. 25; cf. Figs. 5 and 6).

(b) Sequential Analysis of SSC-Giemsa Banding

Chromosomes were examined by phase contrast and bright field microscopy after (i) the fixation, and (ii) the SSC steps of the overall Giemsa banding procedure (p. 17).

Preparations examined after SSC treatment were subsequently observed again after Giemsa staining.

(i) Fixation

Directly after fixation, squashed c-metaphase chromosomes show no differentiation of light or dense regions along the chromosome arms.

(ii) Fixation/SSC

After treatment most chromosomes show two positive dots at the centromere, one on each sister chromatid (Figs. 26a, 27a and 5ld). Different techniques applied to other organisms reveal similar dots termed C-dots (Eiberg, 1974).

Phase-lucent cross-bands appear in certain positions along many chromosome arms. For example, the M chromosome in Fig. 28a shows one phase-lucent band on the Ml arm close to the centromere and two similar bands on the M2 arm.

(iii) Fixation/sSC/Giemsa

The phase-lucent bands evident after SSC treatment stain positively by Giemsa (Figs. 28a, b and 29a, b). The centromere regions, presumably the centromeric dots, can be seen after SSC-Giemsa staining (Fig. 24) but these are revealed more consistently by the Gll 
method (p. 18) (Figs. 41 and 5lf).

(c) Trypsin-Giemsa Banding

Chromosomes stained after 1-2 min trypsin treatment appear swollen and slightly understained with suggestions of bands (Fig. 30).

After 4-7 min trypsin treatment there is a considerable decrease in chromosome stainability with a corresponding differentiation of bands (Figs. 31, 32 and 5le). There is very little increase in stain intensity of the latter. Concomitant with decrease in chromosome stainability is the appearance of an amorphous "ghost" around the boundary of each chromosome (Figs.31, 32 and 33), which is not seen around chromosomes which retain their stain (Fig. 34).

Ghosting is mostly absent in banded regions; this is particularly seen in one of the S chromosomes (Figs. 35 and 36). Coalescence of ghosting around bands tends to mask this feature as in Figs. 31 and 32 .

In advanced stages of trypsin digestion ( $>7$ min) individual chromosomes, along with their bands, are so faint they are barely discernible.

(d) Urea-Giemsa Banding

Duplication of the urea method ( $p .18$ ) of Dobel, Rieger and Michaelis (1973) confirmed their results in part. In the present study two M2 bands (M2/1, M2/2) are shown (Fig. 37) although these are less distinct than those in Fig. 42 d.

More distinctly and consistently, two bands are seen, one on either side and directly adjacent to the centromere (Figs. 38 and 5lg). These have been designated $\mathrm{Ml} / 2$ and $\mathrm{M} 2 / 4$. Band $\mathrm{Ml} / \mathrm{l}$, consistently revealed by the SSC-Giemsa technique was not seen clearly in the present study by the urea-Giemsa method, although Dobel et $a$. reported the presence of this band in $10 \%$ of cases. 
Another two distinct narrow bands are also consistently seen, one on either side of the secondary constriction (Figs. 38 and 39).

(e) Additional Methods Employed in Giemsa Banding

Several other methods reported to induce Giemsa bands were applied in this study, but none elicited clear, reproducible banding. The Arrighi-Hsu technique: NaOH-SSC-Giemsa (employed by Takehisa and Utsumi, 1973) gave poor results. In most cases even a 5-10 sec wash with $0.01 \mathrm{M} \mathrm{NaOH}$ resulted in gross distortion and degradation of the chromosomes.

Dutrillaux and Lejeune's (1971) reverse banding technique (p. 19) resulted in a suggestion of negative bands around the $M$ centromeres and along the arms of some S chromosomes (Fig. 40).

Omission of RNase treatment from Arrighi and Hsu's (1971b) original publication is not held to affect the production of bands RNase and/is now routinely omitted from methods of NaOH-SsC-Giemsa banding.

\section{Lacto-Aceto-Orcein (LAO) Banding}

Kurita's (1958) LAO method (p. 19) produces distorted chromosomes. In clear spreads, however, a new and distinctive pattern of chromosome banding is seen on the M chromosome (Figs. 43, 44 and 5lh). Three negative bands, consistent with acid treatment, occur around the centromere, and in contrast a positively-stained band is present on either side of, and directly adjacent to the secondary constriction. As is commonly the case the length of the secondary constriction varies such that the flanking bands merge: Indeed the two bands are mostly seen as one band (the NOR band) (Fig. 45). The rest of the chromatin is lightly stained. 
Phase contrast microscopy indicates that this banding pattern is produced prior to staining i.e. after $60^{\circ} \mathrm{C}$ acid hydrolysis (Fig. 46). At this stage all chromosome arms are faint but the $\mathrm{M}$ chromosome has a distinct NOR Band. Subsequent orcein staining reveals a general reduction in stain intensity compared to standard fixed/orcein stained chromosomes (see below), while the NOR band is stained normally and hence is obvious.

The faintly stained interphase nuclei each contain two conspicuous chromocenters in contact with the nucleolus (Fig.47a, b).

S chromosomes show no clear differential banding (positive or negative) with this technique.

(i) LAO technique applied to fixed root-tips

Standard fixed root-tips show the M chromosome with the three negative centromeric bands, more apparent as a result of the strong contrast with the now darkly-stained chromosome arms (Figs. 48 and 5li) (ef. acid treatment p. 31). The NOR band is indistinguishable by phase contrast microscopy in preparations of these root-tips prior to staining (Fig. 49).

A negative band can be seen in the short arm of two $\mathrm{S}$ chromosomes (Fig. 48). The long arms of the S chromosomes, however, show no differential banding. Interphase nuclei, unlike "unfixed" preparations, show chromocenters as in standard preparations. 
IV. Temporal Replication of Heterochromatin DNA

The first labelled cells seen at metaphase following a 30 min pulse show some chromosomes with grains distributed over much of their length. In a large proportion of these cells (fixed between 4 and 6 hours after treatment and hence in the last $2 \mathrm{~h}$ of $\mathrm{S}$ at the time of exposure (Webster and Davidson, 1968; MacLeod, 1968)) label is located mainly at regions adjacent to and on either side of the centromere in the $\mathrm{M}$ chromosomes and to bands in the mid-regions of the S chromosomes (Fig. 52). Light labelling occurs in the proximal region of a few $\mathrm{S}$ chromosomes. This pattern of late-labelling is in agreement with the results of Evans (1964) and Woodard, Rasch and Swift (1961). Certain interphase nuclei contain localized label with the grains concentrated over chromocenters (Fig. 53).

In root-tips fixed after a 9-11 h chase, labelled regions were in early $S$ phase at the time of treatment (Webster and Davidson, 1968; MacLeod, 1968). Most c-metaphases show labelling in the distal regions of the $M$ chromosomes and in the short arms or distal regions of the long arms of the $\mathrm{S}$ chromosomes (Fig. 54). The pattern is essentially the converse of latelabelled autoradiographs. Although the entire S phase was monitored, the time of replication of the NOR and/or associated heterochromatin could not be determined unequivocally. After a 9-1l h chase, however, label is distributed along the satellite and M2 arm and may include NOR and associated heterochromatin labelling. No convincing localization of label was seen around the $M$ secondary constriction after labelling of cells in mid and late $\mathrm{S}$.

The discovery late in this study of exclusive nucleolusassociated DNA labelling in interphase nuclei (Fig. 55) was followed by repeat pulse/chase experiments (to determine time of replication) but no exclusive NOR labelling was seen in any c-metaphase chromosomes. 
V. In Situ Hybridization

Tritium-labelled RNA transcribed from $V$. faba total DNA was hybridized successfully to chromosomal DNA in situ. The following features of the reaction indicated that true hybrid molecules were formed. (1) Tests conducted on the transcription product (see App. Ia-c) showed that bona fide high molecular weight RNA had been prepared. (2) The complex of RNA with the chromosomes and nuclei was stable with RNase treatment. (3) The reaction was competed by unlabelled denatured $V$. faba DNA but was unaffected by heterologous $E$. coli RNA.

Autoradiographs of hybridization preparations show silver grains along the chromosome arms (Figs. 56, 57 and 58). Grains are distributed over the entire length of the $\mathrm{M}$ chromosome although there is a reduction or absence of grains around the M centromeres in Fig. 57 whilst Fig. 58 shows an absence of grains at either M chromosome end. A histogram (Fig. 59) compiled from grain counts of $40 \mathrm{M}$ chromosomes (Table 2), indeed shows more grains at the intercalary regions (including the secondary constriction) than around the centromeres and chromosome ends. A $x^{2}$ test on the total regional grain counts (with limitations as mentioned p. 24) supports a heterogeneous distribution of grains (Table 2; $\left.x_{9}^{2}=183.24,0.05>\mathrm{p}\right)$.

Grain location along different $S$ chromosomes is varied. In any one complement most $\mathrm{S}$ chromosomes show grains along their entire length although in some there is a strong suggestion that label is reduced or absent at the chromosome ends and in some proximal regions (Figs. 56, 57 and 58). Fig. 58 also shows in contrast, two s chromosomes (which may represent an homologous pair) with label localized at, or towards, the chromosome ends; this feature, common in many complements, is not clear in Figs.56 and 57 . 
40 .

Table 2. Silver Grain Counts in 10 Regions along each of $40 \mathrm{M}$ Chromosomes after in situ Hybridization

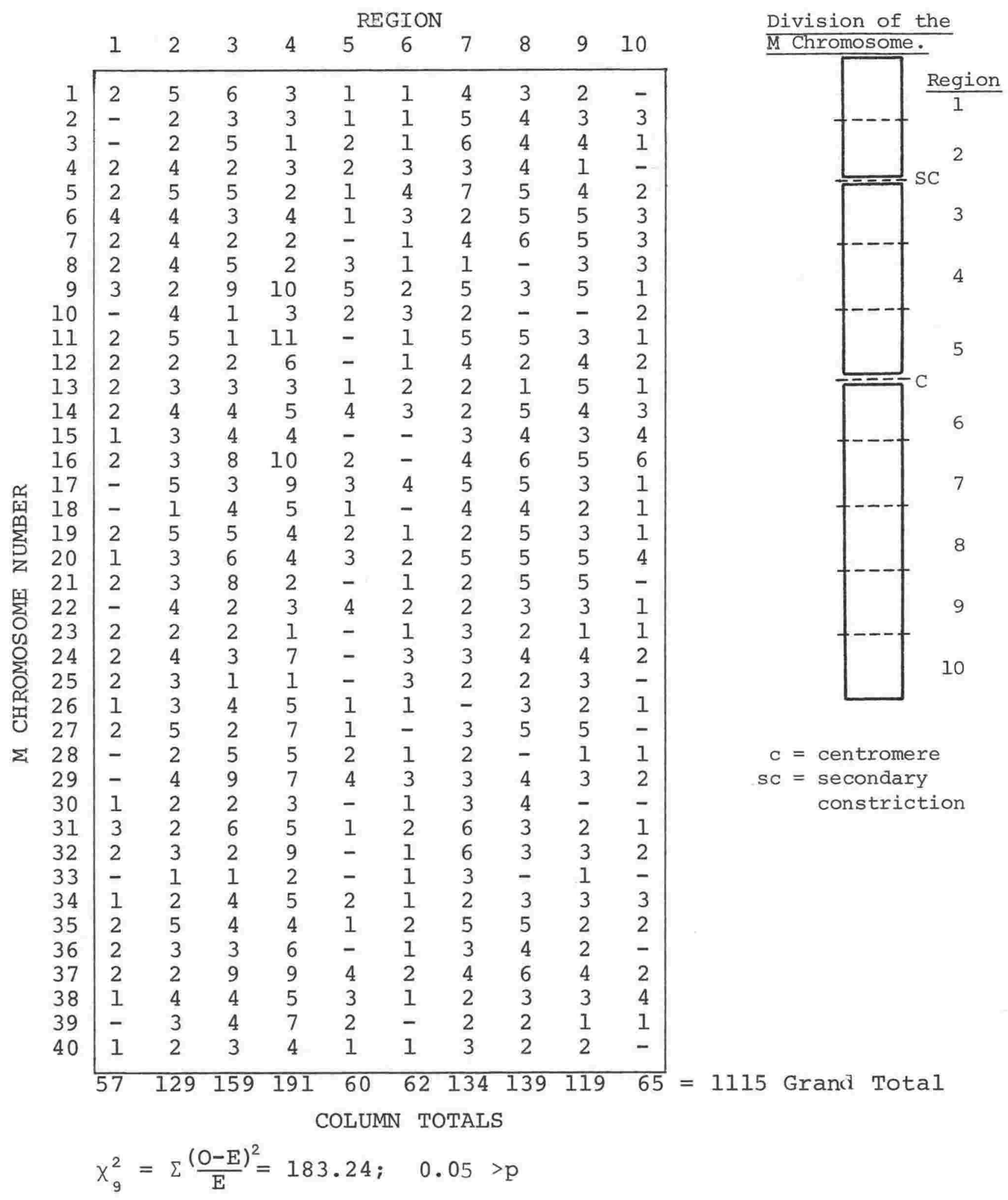

The background count was almost nil and did not affect the analysis. 


\section{DISCUSSION}

\section{Cold Treatment}

The use of cold treatment as a cytological tool may be regarded as the first method to establish reliably the position of heterochromatin along the arms of plant metaphase chromosomes. Experiments in Trizlium and Paris (Darlington and La Cour, 1938, 1940) adequately confirmed the location on chromosomes of heterochromatin previously detected in interphase nuclei.

In the present study, the position of heterochromatic segments in the $\mathrm{M}$ chromosome shown by cold treatment compares favourably with the results of other investigators, although in the diagram published by Evans and Bigger (1961) (Fig. 15b) an additional Ml intercalary band is shown. This band is also suggested in the photograph of Grant and Heslot (1966) (Fig. 15a).

The most significant point arising from the cold treatment study is the non-appearance of the M2 centromeric band M2/2. This band is seen quite clearly, however, following acid treatment (a comparison also noted by Takehisa, 1973) and by nearly all other techniques used to reveal chromosome bands. Band $\mathrm{M} 2 / 2$ is distinguished from the other M centromeric bands by a difference in structure or behaviour as revealed by cold treatment. The mechanism underlying the production of negative bands in chromosomes by cold treatment is still not understood (Takehisa et ar., 1976) so the differences of expression of the H-segments cannot be interpreted in precise terms.

The state of contraction of the chromosomes was seen to influence the appearance of cold bands (p. 30). This feature may account for the varied banding patterns seen within the $\mathrm{S}$ chromosomes not only in this study but also between all four published accounts of H-segment distribution in V. faba (Fig.15a-d). 
42 .

Furthermore, it is not possible to categorize the s chromosomes when they show the greatest number of negative bands as the chromosomes at this stage are in an extended state. It is significant, however, that the position of the more prominent $\mathrm{H}$-segments in the $\mathrm{S}$ chromosomes detected by all investigators, is confined mostly to the intercalary regions. 
II. Temporal Replication of DNA

It has been known for more than a decade that DNA replication in $V$. faba occurs in two waves, being either early or late in $\mathrm{S}$ phase, with only a meagre amount of replication during the middle of $\mathrm{S}$. Late replication during $\mathrm{S}$ is also a common feature of heterochromatin in most organisms, including V. faba (Woodard, Rasch and Swift, 1961; Evans, 1964).

Late-labelling DNA is found around the $M$ centromeres and in the intercalary regions of the $\mathrm{S}$ chromosomes (Fig. 52). These results support those of Evans (1964) and others in showing that heterochromatin, defined as those chromosome regions detected as negative bands in response to cold, is late-replicating. Furthermore, the DNA of an additional band (M2/2) not revealed by cold treatment, but located close to the M centromere most likely replicates late. The time of replication of the achromatic band in the short arm of two $S$ chromosomes is difficult to judge but the presence of grains in the short arm of one or two $\mathrm{s}$ chromosomes may indicate that the DNA of this band replicates in late $\mathrm{S}$. NOR heterochromatin, however, does not replicate late. Indications are that the DNA of this portion of heterochromatin replicates in the first half of $\mathrm{S}$ along with euchromatin. This difference in the timing of DNA synthesis is of note since, as the present study shows, NOR heterochromatin is also known to possess different properties as revealed by the lacto-acetoorcein technique. Thus there are significant differences between NOR heterochromatin and M centromeric heterochromatin, both in the timing of DNA replication and in certain presumably structural features. 
1. Base Content of Early and Late Replicating DNA

A number of pulse-labelling experiments using synchronized cultures of mammalian cells (human, mouse, Chinese hamster and rabbit) and subsequent determination of DNA base composition by ultracentrifugation (Bostock and Prescott, 1971a, b, c; Flamm, Bernheim and Brubaker, 1971; Tobia et al., 1970) have clearly shown that early replicating DNA is relatively GC-rich and latereplicating DNA is relatively AT-rich. The inference is drawn that DNA of heterochromatin (which is largely late-replicating) is relatively AT-rich, whilst the DNA of euchromatin is relatively GC-rich. Indeed, evidence that AT-richness may be a characteristic feature of heterochromatic DNA comes from the study of DNA from highly purified mouse heterochromatin which has a significantly decreased buoyant density (is more AT-rich) (Mattoccia and Comings, 1971). There are exceptions to the rule, however, as for example, quail DNA which has a prominent GC-rich heavy shoulder component enriched in the heterochromatin fraction (isolated by centrifugation) and in the quail much of the heterochromatin is restricted to the late-replicating microchromosomes (Comings and Mattoccia, 1972).

Another exception is in Chinese hamster cells where the very earliest DNA to replicate is relatively AT-rich. This is followed by early replicating euchromatin which is GC-rich and late-replicating AT-rich heterochromatin (Comings, 1972b). As yet there is no cytological information linking this very early replicating DNA fraction with heterochromatin and the author is not aware of any research relating temporal studies with the base composition of DNA in $V$. faba. 
III. Fluorescent Banding with Quinacrine Mustard

Quinacrine mustard dihydrochloride (QM) is a very potent fluorescent agent which selectively binds with particular chromosome regions, thus giving a banded appearance to the chromosomes.

The distribution pattern of the fluorescent bands seen in the $M$ chromosomes in the present study is in agreement with the results of Caspersson et al. (1968) and Vosa (1970). The observed bands coincide in part with the $\mathrm{H}$-segments revealed by cold treatment but correspond even more closely with the bands seen following acid treatment (M1/1, M2/1 and M2/2 - see Fig. 5la, b, c). The QM technique also revealed a third more distal band (M2/3) which although not prominent indicates the presence of an additional band not seen with previous methods.

The presence of fluorescent bands adjacent to the centromere on the long arm of some $\mathrm{S}$ chromosomes but no intercalary bands, is also in agreement with the results of Caspersson et al. (1968). In a later publication, however, Caspersson et al. (1969a) show two $\mathrm{S}$ chromosomes each with a single bright intercalary band on their long arms and another two or more S chromosomes with indistinct banding in the same position.

The distribution of $\mathrm{QM}$ bands around the $\mathrm{M}$ centromere and in the intercalary and proximal regions of some $\mathrm{S}$ chromosomes coincides with those chromosome regions which replicate'in late S. Studies in human chromosomes by Ganner and Evans (1971) and Calderon and Schnedl (1973) have similarly established a correlation between the distribution of Q-bands and late-replicating regions, although the latter investigators noted that the bright Y chromosome band does not replicate late. 
1. Role of Base Content in QM Banding

In an attempt to explain fluorescent banding Caspersson et al. (1968) suggested the observed patterns depend on variations in the guanine content of the DNA in different areas of the chromosome. Several lines of evidence from recent studies suggest that although quinacrine mustard may bind to the guanine moiety (Adkisson, Perrault and Gay, 1971), changes in GC composition are of minor importance in producing the observed fluorescent banding. Although quinacrine mustard contains an alkylating group, which is thought to react with the $\mathrm{N} 7$ atom of guanine, quinacrine dihydrochloride, which lacks the alkylating group, produces the same basic banding patterns, as do other widely varying fluorescent agents $e \cdot g$. ethidium bromide and acriflavine used in some plant tissues.

A number of experiments by Selander and de la Chapelle (1973) have shown that the various nucleic acid polymers in solution affect the intensity of the fluorescence of quinacrine and quinacrine mustard; in all, these workers interpret their data as indicating that the fluorescence of the dyes in solution is more intense with AT-rich than GC-rich DNA. A similar conclusion had been reached previously from cytological experiments by Ellison and Barr (1972) who, using the dipteran Samoaia Zeonensis, compared metaphase figures following continuous labelling with either ${ }^{3} \mathrm{H}$-thymidine or ${ }^{3} \mathrm{H}$-deoxycytidine. Labelling with ${ }^{3} \mathrm{H}-$ thymidine showed that the intensely-fluorescent areas contain late-replicating DNA. Interestingly, these areas show little or no incorporation of ${ }^{3} \mathrm{H}$-deoxycytidine. Thus these workers concluded that the intensely-fluorescent chromosome regions are characterized chemically by an extremely high, if not exclusive, adenine and thymine content. 
The AT-richness of QM fluorescent areas has also been shown in recent biochemical and immunological experiments by schreck et al. (1973). In their studies, antinucleoside antibodies labelled with fluorescein are used to locate regions rich in particular bases. The fluorescein-bright areas rich with anti-A were found to correspond closely with the QM-bright regions along the chromosomes.

Further evidence for the involvement of AT-rich regions in quinacrine banding comes from a study of chromosomal DNA which has been sequentially denatured by heat with the addition of formaldehyde (prevents reassociation) and stained in situ with acridine orange (de la Chapelle et al., 1971, 1973a, b). Strongly fluorescent QM bands denature at a lower temperature than less intensely fluorescent bands; and since AT-rich DNA denatures before GC-rich DNA, AT-richness and bright fluorescence following quinacrine mustard treatment can be coincidently linked.

There is also good correlation between $\mathrm{QM}$ fluorescence and late-replicating DNA (Ganner and Evans, 1971), which studies in many organisms show to be AT-rich rather than GC-rich.

The logical inference from all these data is that differential fluorescence of chromosomes in situ is due to differences in the base content of the chromosomal DNA, with quinacrine mustardbright areas being AT-rich. This hypothesis may be true in essence but some discrepancies exist which indicate that ATrichness/QM banding is not a direct relationship.

Evidence from the study of specific chromosomal regions is known to conflict with the suggestion that AT-rich areas fluoresce brightly. The centromeric regions of mouse chromosomes contain satellite DNA which is richer in AT than the bulk of mouse DNA, yet the quinacrine mustard fluorescence in these regions is less intense than in other regions. Weisblum and de 
Haseth (1973) suggest this may be explained on the basis of "interspersion" of GC base pairs which affects the degree of fluorescence.

Another discrepancy concerns the human chromosomes 1, 9 and 16 whose secondary constrictions contain AT-rich satellite DNA. These regions also show fluorescence, though weakly, with quinacrine derivatives (Caspersson et al., 1970).

Greensher et al. (1971) have reported the fluorescence of the inactive $\mathrm{X}$ chromosome (Barr body) in specialized cells (Wharton-jelly cells) of the umbilical cord in human females and the occasional fluorescence of the Barr body in the other cells. Since the DNA is presumed to be identical in both the staining and non-staining $\mathrm{x}$ chromosomes, this would tend to suggest that composition of the DNA plays no independent role in the fluorescence of the Barr body.

Fraccaro et al. (1971) have reported a Y chromosome/autosome translocation in Drosophiza and noted that the fluorescence intensity of the translocated heterochromatin was subsequently diminished. They reasoned that if the DNA content in this area had remained unchanged following the translocation, this would suggest that factors other than DNA composition are involved in the fluorescence.

A further consideration arises from the work of Comings et al. (1975) who have shown that, with the exception of highly AT-rich satellites, differences in the concentration of quinacrine along the chromosome are capable of producing greater changes in fluorescence intensity than the variations in DNA base composition in any given organism. This is illustrated in a quantitative estimation of the human $\mathrm{Y}$ chromosome fluorescence, which shows an increase of up to 2.2 times the average intensity of the other chromosomes (Comings, 1972a). There is greater 
variation in fluorescence than in base composition since the mean GC content of mammalian DNA is $40 \%$ and even the heavy satellites show a maximum of only 53\% (Arrighi et al., 1970b). This, however, does not refute the hypothesis that differential fluorescence is due to differences in base content since the relationship between binding and degree of fluorescence is not fully known. Comings and Drets (1976) have made certain quantitative estimations on the effect of base composition on quinacrine fluorescence and conclude (p. 199) that "variation in the base content of DNA along the chromosome is sufficient to account for most o-banding, except possibly for some of the extremes of quinacrine fluorescence".

\section{Role of Proteins in QM Banding}

Evidence for the suggestion that chromosomal proteins may affect the fluorescence pattern obtained with acridine dyes comes mostly from Giemsa studies (see p. 66). G-bands, with certain exceptions, occur in the same region as QM bands (reviewed by Hsu, 1973) and it is now widely acknowledged that chromosomal proteins are significantly involved in the production of G-bands. A general extrapolation implies that protein composition, aggregation and interaction with chromosomal DNA may contribute to the banding produced by acridine dyes.

Comings et al. (1975) fluorescent studies in mouse chromosomes support the role of proteins in Q-banding. These workers state that most pale staining regions are due to a decrease in binding of quinacrine and that this inhibition of binding is predominantly due to non-histone proteins. 
3. Single or Double-stranded DNA and QM Banding

Some results obtained by investigators studying the interaction between fluorescent dyes and nucleic acid polymers have indicated that strandedness (i.e. single-stranded or doublestranded) of mammalian DNA also has an effect on fluorescence. The quenching effect of mouse DNA is greater with single-stranded than with double-stranded molecules (Selander and de la Chapelle, 1973). Weisblum and de Haseth (1972) likewise observed a similar result using chick DNA. Could it be, therefore, that differential fluorescence of chromosomes is related to the single or double-strandedness of DNA? The apparent changes in the relative intensity of fluorescence in centromeric and intercalary heterochromatin after denaturation-reassociation procedures could be explained by the variations in such strandedness occurring during the treatment, as already shown with acridine orange (de la Chapelle et al., 1973a, b) and with anti-sera specific for singlestranded DNA (Mace, Tevethia and Brinkley, 1972). It is known, however, from chemical studies (Ris, 1969) as well as from cytological experiments (Schreck et al., 1973; Nash and Plaut, 1964) that the DNA in standard fixed chromosomes is normally in double-stranded form. Hence, variations in the strandedness of the DNA probably contribute little to the production of bands in untreated chromosomes in situ which the QM technique entails.

\section{Repetitive DNA and QM Banding}

The discovery of repetitive DNA prompts the suggestion that repeated sequences play an important role in the production of QM bands. The suggestion initially sounds attractive. A prominent example is the human $Y$ chromosome whose distal end is extremely brightly fluorescent with quinacrine mustard. The DNA of this region is found to be highly repetitive as seen by its 
51.

rapid reassociation in situ. On the other hand human chromosomes 1, 9 and 16, which contain highly repetitive DNA, show little correspondingly bright fluorescence (Caspersson, Lomakka and Zech, 1971).

Again, in mouse chromosomes centromeric DNA is highly repetitive but $Q M$ fluorescence is minimal, and in $V$. faba the widespread distribution of repetitive DNA along the chromosome arms is far in excess of the QM banding pattern seen.

A relationship may exist between repetitive DNA and fluorescence intensity but so far the unpredictability of the fluorescence behaviour of repetitive DNA has introduced a complexity difficult to explain.

\section{A Short Résumé of QM Banding}

The balance of evidence from fluorescence studies suggests that in situ QM banding of chromosomes reflects DNA base content i.e. AT-richness. In some organisms it also reflects the location and perhaps degree of base sequence repetition. 
IV. Giemsa Banding

The technique widely known as Giemsa banding has found a place in cytology for the demonstration of chromosome bands in more precise detail than was possible with any previous technique. A modification of the SSC-Giemsa banding technique used in this study revealed discrete cross-bands along the chromosome arms. Some of the finer bands had not previously been detected as clearly in c-metaphase chromosomes.

The $M$ chromosomes of $V$. faba consistently shows Giemsa bands localized in the positions established by QM fluorescence and late replication studies, and also in part by cold and acid treatments (see Fig. 5la-f). Centromeric band Ml/1 is characteristically conspicuous, whilst bands $\mathrm{M} 2 / 1, \mathrm{M} 2 / 2$ and $\mathrm{M} 2 / 3$ follow the pattern seen with QM fluorescence.

The $\mathrm{S}$ chromosomes have a consistent banding pattern showing bands not identified in detail by previous methods. The Giemsa bands in the mid and proximal regions of the long arms of the S chromosomes correspona in position to some prominent cold bands and late-labelling areas. The pattern of differentially stained areas close to the centromere on the long arm of several subtelocentrics compares with that seen in some fluorescentlystained S chromosomes.

Studies in human chromosomes have similarly established a correlation between the distribution of Q-bands and G-bands (Evans, Buckton and Sumner, 1971), and Q-bands, Giemsa bands and late-replicating regions (Schnedl, 1973). Schnedl (1972) also established a close correspondence in the location of Q-bands, Giemsa bands and late-replicating regions in cattle chromosomes.

Six groups of investigators have published results of Giemsa banding in $V$. faba: Takehisa and Utsumi (1973), Schweizer (1973), Scheid and Traut (1973), Dobel, Rieger and Michaelis (1973), Burger and Scheuermann (1974) and Klasterska and Natarajan (1975) (Fig. 42a-f). (See also Addendum p. 101). 
The last three groups have illustrated the genome in detail with related banding patterns. A comparison of the bands on the $\mathrm{S}$ chromosomes shown in the present study by the SSC-Giemsa method and those illustrated by Dobel et al. (fixed $\rightarrow$ urea $\rightarrow$ Giemsa), Klasterska and Natarajan, and Burger and Scheuermann (fixed $\rightarrow$ $\mathrm{BaOH} \rightarrow \mathrm{SSC} \rightarrow$ Giemsa) reveals minor differences of banding patterns (Figs. 23 and 42d, e, f). The last two groups illustrate C-dots on all the chromosomes and call them C-bands. A major difference in the Giemsa banding pattern produced by the urea and $\mathrm{BaOH} / \mathrm{SSC}$ methods as compared with the SSC method is seen in the M chromosome. Dobel et al., Klasterska and Natarajan, and Burger and scheuermann found a distinct band at the NOR, which is notably absent following SSC-Giemsa treatment as well as with trypsin treatment, and is absent in most cases with NaOH-SSC-Giemsa treatment (Takehisa and Utsumi, 1973). Furthermore, although the $\mathrm{Ml} / \mathrm{l}$ band is mentioned in passing by Dobel et al., it is more prominent by the SSC-Giemsa method.

In the present study a paradox arose following the use of the $6 \mathrm{M}$ urea technique for $V$. faba chromosomes. Contrary to the results of Dobel et al., bands were seen consistently flanking the $\mathrm{M}$ centromere and also the secondary constriction (Figs. 38 and 39). Dobel et al. interpret the NOR band as lying within the constriction although in the text they do state "in, or adjacent to, the secondary constriction" (cf. p. 36). This difference could be discounted on the basis of variation in length of secondary constrictions if it were not for Funaki, Matsui and Sasaki's (1975) discovery of an N-band within the secondary constriction (Fig. 50) which they claim is separate from adjacent NOR heterochromatin, in which case any differences, if real, in secondary constriction banding between that reported by Dobel et $a l$. and the present study with the same technique, would be an enigma (see again p. 72). 
The action of urea on chromosomes is not clearly defined, but it is known to possess properties which include breaking hydrogen bonds and extracting proteins. This is generally attributed to its powerful electro-negative charge. Urea is not known to discriminate between proteins and this may account for bands observed at both the secondary constriction and $\mathrm{M}$ centromeric regions. It does not, however, explain the lack of expression of the $\mathrm{Ml} / \mathrm{l}$ band or the specific banding pattern produced by the urea method in the present study.

The reports using $\mathrm{NaOH}-\mathrm{SSC}-\mathrm{Giemsa}$ (Takehisa and Utsumi, 1973) and BaOH-SSC-Giemsa (Burger and Scheuermann, 1973; Klasterska and Natarajan, 1975) show interesting differences in banding pattern. The bands seen by Takehisa and Utsumi are all centromeric except for a prominent intercalary band in one S chromosome (Fig. 42a). They show two bands on the M chromosome corresponding to cold bands, although they note occasional banding "at both regions adjacent to the secondary constriction". On the other hand, Klasterska and Natarajan (1975) show four M centromeric bands ( $\mathrm{Ml} / 1$ is weakly stained) and a prominent band at the secondary constriction, while Burger and Scheuermann show five $M$ centromeric bands, (including the C-dots) as well as a consistent band at the secondary constriction (Figs. 42e, f). The last two groups show a more detailed pattern of banding in the $\mathrm{S}$ chromosomes than that seen by Takehisa and Utsumi ( $20 \mathrm{c}$. cit.).

These differences may be due to the heavier barium atom perhaps binding to some exposed negatively-charged groups and somehow effecting differential banding, or as is common in this field, the differences may be attributed to the "vagaries of variation in Giemsa banding" (Pearson, 1972) between different laboratories. 
The SSC-Giemsa method employed by the present author and also by Schweizer (Loc. cit.) is milder than the above techniques and $M$ secondary constriction banding has not been observed with this method.

The production of Giemsa bands in $V$. faba is a delicate operation and, not surprisingly, variation of the method results in different banding patterns. Overall, however, the development of suitable Giemsa banding procedures has shown chromosome bands in heterochromatic regions (as defined) in $V$. faba chromosomes more clearly than with previous cytological techniques. The Giemsa band(s) seen at the M secondary constriction is a special case and although not late-replicating, probably represents classical NoR-associated heterochromatin (see again p. 83).

\section{An Assessment of Giemsa Banding}

In recent years techniques of chromosome banding, particularly fluorescent banding and Giemsa banding, have provided cytogeneticists with powerful new tools. Soon after Arrighi and Hsu (1971b) perfected the technique of staining for centromeric heterochromatin, it became apparent that by utilizing a number of modifications it was possible to obtain differential staining along the chromosome arms. The question that followed and is still being pursued in the literature today is: "What causes Giemsa banding?" Modifications have become so numerous and varied, even to the point where reproducibility is particular to certain laboratories, that it is difficult to determine the important factors in the Giemsa banding reaction. Banding
are patterns/produced by a large number of treatments which include, for example, incubation with any one of the following: organic and inorganic salts, bases, chelating agents, various buffers, detergents, protein denaturants, proteolytic enzymes and even an 
oxidizing agent (Kato and Moriwaki, 1972; Kato and Yosida, 1972; Seabright, 1971; Dutrillaux and Lejeune, 1971; Utakoji, 1972). Yet on the other hand the biochemical complexity of procedures permits the crystallization of certain features particular to the banding phenomenon.

The question of the biochemical basis behind Giemsa banding may be partially equated with the inherent difference between euchromatin and heterochromatin, thus the following section is concerned primarily with establishing the biochemical nature of Giemsa bands and elucidating the conditions responsible for their formation.

For clarity, each of five possibilities may be the prime cause of Giemsa banding:

1. Inherent longitudinal differences in concentration of chromosome material.

2. The presence of DNA with a different base composition.

3. The presence of repetitive DNA with the staining being due to differential renaturation.

4. The selective disruption of band regions or interband chromosomal material by banding agents.

5. DNA-protein or protein-protein modifications. Each of these possibilities will be considered individually.

\section{Inherent Longitudinal Differences in Concentration of}

Chromosome Material

An analysis by McKay (1973) of G and C-banding supports the view that banding is a consequence of differential chromatin condensation. - This conclusion is based primarily on his discovery that potential G-bands can be observed by phase contrast microscopy, by gold/palladium shadowed surface topography, or by U.V. microscopy without any post-fixation 
treatment or staining. Moreover he maintains that fixation in ethanol-acetic acid does not play an essential role in banding since chromosomes stabilized in uranyl acetate also show phase contrast bands, and although the fixation procedure may contribute to their appearance, the evidence is most easily explained if the bands are present in vivo and not induced by the preparation treatment. All subsequent treatments which may give rise to G-banding patterns are regarded as modifying methods only.

McKay's photographs are convincing and whatever technique one employs, the appearance of Giemsa bands must be a manifestation of some form of inherent differences. But it is difficult to reconcile McKay's observations with those of numerous investigators who have shown or stated that fixed Giemsastained chromosomes stain uniformly. Phase contrast and bright field microscopy of fixed unstained and stained $V$. faba root-tip preparations by the present author revealed no structural or staining differences along the chromosome arms where Giemsa bands are located, which is in agreement with the majority of observations.

Whole mount electron microscopy of treated and especially untreated chromosomes provides some evidence of inherent differential coiling of chromatin into bands along the chromosome arms (Comings et al., 1973) yet these workers reject differential chomatin condensation as a cause of banding on account of finding uniform Feulgen staining of mouse chromosomes after Giemsa banding treatment. These results are contrary to those of Kato and Moriwaki (1972), Rodman and Tahiliani (1973) and Meisner, Chuprevich and Inhorn (1973) who all showed that Feulgen staining of either SSC or trypsin-digested Giemsastained and destained chromosomes maintains the banded pattern. 
Yet like Comings et al., these investigators lean towards conformational changes of nucleoprotein as being a prime requisite of banding.

In agreement with inherent differential chromatin condensation are some observations of chromomeric patterns in mitotic and meiotic prophase chromosomes resembling the G-banding pattern of metaphase chromosomes. This is seen in the present study in $V$. faba chromosomes and has been observed in human material by Hungerford et al. (1972) and Utakoji (1972). Also, the G-banding pattern shown by Utakoji (Zoc. cit.) corresponds to the spiral structure of mitotic chromosomes (Ohnuki, 1968). Thus McKay's advance of the differential condensation hypothesis might have some merit in explaining the Giemsa banding phenomenon. Indeed it may in future prove to be an important factor. The hypothesis, however, does not satisfy biochemical evidence which clearly implicates the Giemsa banding reaction with primary characteristic differences within chromatin. It is this latter aspect which presents a more detailed understanding of Giemsa bands.

\section{Giemsa Banding and Differences in DNA Composition Along the Chromosome Arms}

From buoyant density, satellite composition, and renaturation kinetic studies of DNA in mammalian and avian heterochromatin, Comings and Mattoccia (1972) suggest there are several different types of DNA which may be localized in centromeric heterochromatin. These include the following:

(i) Repetitive satellite DNA which is (a) AT-rich, (b) GC-rich, or (c) same density as main band DNA.

(ii) Repetitive main band DNA. 
(iii) Non-repetitive DNA: (a) GC-rich heavy shoulder DNA, (b) AT-rich main band DNA.

It seems, therefore, that centromeric heterochromatin can be either AT-rich, GC-rich, or neutral and still produce C-bands and thus it is questionable whether base composition is a prime requisite for banding in these areas.

As previously shown, however, most studies of the relationship between chromosome banding and base composition have been done in relation to quinacrine labelling. And since QM and G-banding are generally similar in distribution, these studies are pertinent. Evidence from the previous section on fluorescence and base composition is relevant to this discussion and in brief reiteration most quinacrine-bright areas are convincingly AT-rich. But there is sufficient evidence to suggest that AT-rich base composition may be a modifying factor in the banding process, rather than the primary cause of quinacrine labelling. This is highlighted in studies by de la Chapelle et a. . (1973a, b), Weisblum and de Haseth (1973) and Greensher et al. (1971) where fluorescence is not always seen to be directly related to base composition. Indeed, if base composition is an important factor in Giemsa banding the relationship is not linear since the amount of positively-stained regions is far greater than that allowed by the relatively narrow range of base composition (AT/GC ratio). A clear example is seen in human chromosomes where Giemsa bands constitute approximately half the genome.

\section{Preferential Renaturation of Repetitive DNA}

When Giemsa bands were first detected around the centromeres of mouse chromosomes and found to coincide with the localization of highly repetitive DNA, the conclusion generally accepted at the time was that the banded areas represented regions on the 
60.

chromosome whose DNA had rapidly reassociated and stained positively with Giemsa. Further investigation has since shown that the situation is not well defined and certain facts would tend to refute this claim:

(a) Giemsa banding can be induced along the chromosome arms as well as in the centromere region without the use of any recognised DNA denaturant, $i . e$. positive bands can be produced by omitting the $\mathrm{NaOH}$ step and merely immersing the slide in SSC buffer before staining.

(b) According to acridine orange ( $\mathrm{AO}$ ) experiments, fixation and air drying of the chromosome preparation does not denature the DNA (Comings et al., 1973).

(c) Acridine orange experiments also indicate that once the denaturing conditions are removed, the DNA around the centromere renatures almost instantly (within seconds) and the DNA of the arms soon follows uniformly (de la chapelle, schroder and selander, 1971). These experiments provide no evidence for preferential denaturation or renaturation within the arms of the chromosomes. (d) $2 \times \mathrm{SSC}$ (at $65^{\circ} \mathrm{C}$ overnight), which is accepted as the medium in which reassociation is allowed to proceed, actually re-denatures the DNA (Comings et al., 1973).

(e) Intense centromeric banding can be seen in chromosomes in which apparently (i) both centromeric DNA and arm DNA are double-stranded, (ii) both centromeric DNA and arm DNA are single-stranded, (iii) centromeric DNA is double-stranded and arm DNA is single-stranded (iv) centromeric DNA is single-stranded and arm DNA is double-stranded (Comings et al., 1973).

(f) Very gentle digestion methods such as treatment with 0.005\% trypsin for 10 seconds, can produce excellent Giemsa banding in mouse chromsomes without denaturing DNA (Comings et ar., 1973). 
(g) Excellent Giemsa bands can be induced in human chromosomes using actinomycin D prior to harvest (Shafer, 1973) and this agent is not known to possess DNA denaturing properties. Doubt was first cast on the rapid reassociation/Giemsa bands hypothesis when the omission of $\mathrm{NaOH}$ from the method produced not only clear C-bands but G-bands as well. If SSC was allowing reassociation to take place then the whole system seemed to be illogical. However, Comings et al. (1973) maintain SSC treatment actually denatures rather than renatures the DNA, with reassociation of the centromeric areas occurring immediately the denaturing conditions are removed. It follows that to some degree the original idea may be upheld.

Even if preferential renaturation does occur, however, it is not clear whether this is the cause of differential staining or is merely a coincidental phenomenon. Perhaps a stronger case can be advanced for preferential renaturation of repetitive DNA being a prime requisite in C-banding rather than G-banding, in testimony to the rapid selective reassociation of DNA around the centromere. But if one accepts the evidence from AO experiments, differences in strandedness which can occur suggest that preferential renaturation of repetitive DNA is unrelated to the ability of chromosomes to show C-bands. This is consistent with previous studies in Chinese hamster cells which suggest that centromeric banding may be seen in heterochromatin that is not excessively enriched in repetitive DNA (Comings and Mattoccia, 1972).

Adding to the negation of the preferential reassociation hypothesis is the observation by Stockert and Lisanti (1972) that post-fixation of mouse chromosomes with $10 \%$ formaldehyde in $0.4 \mathrm{x} \mathrm{SSC}$, followed by careful washing, does not affect the ability of the DNA to denature and renature, but does prevent the differential staining of the centromeric regions. And a 
particularly strong argument against denaturation-reassociation being a prime factor in band production is the use of actinomycin D on living cells as a band-producing agent (Shafer, 1973). Of all the chemicals used to reveal bands this one is known to be unlinked to DNA denaturation.

On the basis of in situ hybridization there is little question that at least part of the staining of centromeric heterochromatin is related to its content of highly repetitive DNA but it is debatable whether all Giemsa bands are a direct consequence of preferential renaturation of repetitive DNA sequences. It is significant in this respect to note that in human chromosomes Giemsa bands constitute approximately half the genome while there is only 30-35\% repetitive DNA (Saunders et al., 1972).

In situ hybridization studies in $V$. faba by the present author and by Timmis, Deumling and Ingle (1975), on the other hand, show far more repetitive DNA along the chromosome arms than Giemsa bands. Such evidence indicates that repetitive DNA and Giemsa bands do not form a unique relationship, which militates against accepting selective reassociation as playing a major role in Giemsa band production.

\section{Selective Disruption of Band or Non-band Chromosomal Material}

It is possible that the various treatments inherent in producing Giemsa bands might either remove or disperse band or interband material, and indeed compelling evidence that this is so comes from six sources:

(a) Phase contrast microscope studies in the present study showed phase lucent bands in regions on the chromosome arms after SSC treatment (Fig. 28a) suggesting the removal or rearrangement of chromosome material prior to Giemsa staining. The exposure of specific chromosomal sites could lead to selective banding by 
the thiazine group of Giemsa to free DNA phosphate groups. Comings and Okada (1975) on the other hand attribute the nonstaining of interband regions to the dispersal of the protein covering the DNA phosphate groups.

Selective disruption of the chromosome arms is difficult to expain. It is perhaps interesting to reflect that nearly all Giemsa banding techniques incorporate an agent capable of removing divalent metal ions somewhere in the banding procedure. SSC is an effective chelating agent in the presence of the divalent cation calcium at pH 7.0 (Johnston, 1956). Cohn (1961, p. 596) has noted the "increasing evidence that divalent metallic ions are critical for the integrity of the chromosomes" and has shown the metal chelator $2.2^{\prime}$ bipyridine (which chelates iron at biological pH without affecting ions higher up in the MellorMaley series (Albert, 1951)) to cause breaks in heterochromatic regions in $V$. faba chromosomes (around the $M$ centromere and in mid-regions of the $S$ chromosomes). He emphasizes the possible role of iron in maintaining structural stability. If specific chromosome regions were susceptible to chelation these data could explain selectivity in band production.

(b) In contrast to SSC-Giemsa studies, trypsin digestion studies (p.35) have shown the selective removal of non-band material and the retention of Giemsa banded regions. The "chromosome ghosts" that appear are probably peripheral pools of breakdown products. Burkholder (1975) and Bath (1976) have independently examined the ultrastructure of trypsin-banded chromosomes by whole mount electron microscopy which also appears to indicate the removal of interband material.

(c) The radioisotope findings of Comings et al. (1973) show that the complete Arrighi-Hsu technique in Chinese hamster cells removes, on average, $60 \%$ of chromosomal DNA and that this DNA is 
preferentially extracted from all but the regions containing C-bands. It is also significant that the Arrighi-Hsu technique removes up to $30 \%$ of total chromosomal protein. G-band techniques, however, remove less than $9 \%$ of Chinese hamster chromosomal DNA and only 5\% of chromosomal protein (even with methods using trypsin).

(d) Meisner et al. (1973) and Rodman and Tahiliani (1973) clearly show that Feulgen staining of either $\mathrm{NaOH}$ or trypsin digested, Giemsa stained and destained chromosomes maintains the banded pattern. Both groups claim that conformational change of nucleoprotein structure gives rise to banding which may be true but does not discount selective removal of chromosomal material from the interband or band regions depending on the technique. Microdensitometry studies of Feulgen stained C-banded chromosomes by Comings et al. (1973) indicate the removal of large quantities of non-centromeric DNA, whilst as mentioned before (p. 57), Feulgen stained G-banded chromosomes, by the same method, showed no significant variations in the density of DNA along the arms.

(e) Analytical ultracentrifugation studies by Comings et al. (1973) of Chinese hamster DNA obtained from NaOH-SSC treated slides and untreated slides, tend to confirm these authors' radioisotope and Feulgen findings that the non-satellite (noncentromeric) DNA is preferentially extracted by the Arrighi-Hsu method.

(f) Electron microscopy of alkali-treated whole mount preparations shows widespread chromatin dispersal in the chromosome arms while that in the centromere region is more resistant to destruction(McKay, 1973). A similar effect is observed using trypsin treatment with perhaps a suggestion of differential condensation in the arms after mild digestion (Burkholder, 1974). 
These data indicate that chromosomal material is selectively disrupted in band formation. This is clearly seen in the present ssC-Giemsa and trypsin studies in $V$. faba. Although selective disruption or removal of chromosomal material is a plausible explanation of Giemsa banding, the fact that trypsin is an effective banding agent introduces further discussion as follows.

\section{DNA-Protein or Protein-Protein Modifications}

The many observations that proteolytic agents produce excellent Giemsa bands (Seabright, 1971; Burkholder, 1974; Comings et al., 1973) provide strong evidence that either DNAprotein or protein-protein modifications are an important factor in this type of banding. Thus differential staining could arise either through protein loss, physicochemical modifications, or conformational changes.

Shafer (1973) incubated live human cells in actinomycin D, a drug which has been shown to affect chromosome condensation. After fixation and staining with Giemsa, banding patterns were observed which appeared to be the same as those produced by post-fixation techniques. Since the treatment occurs in living cells, the observed banding more clearly reflects natural chromosome structure. Furthermore, actinomycin D is thought to bind specifically at guanine bases in DNA (Muller and Crothers, 1968) and to compete for protein-attachment sites (Kleiman and Huang, 1971). Shafer claims this supports the involvement of protein displacement in the light-staining bands; thus the banding effect may be related to the relative content or distribution of adenine/thymine versus guanine/cytosine basepairs in the dark and light regions respectively. Evidence supporting base specificity has already been mentioned. 
66.

Considered together, these findings suggest an interrelationship between base composition and protein organisation.

Quinacrine mustard fluorescence and Giemsa bands coincide in distribution in most cases (Hsu, 1973). The fluorescence technique does not, however, include a protein extraction, nor even, so far as is known, a protein-dye interaction. But it is believed in some quarters that the accessibility of the DNA to quinacrine is "determined by the steric relations between the DNA and chromosomal proteins" (Caspersson et $\alpha$ l., 1972). Fluorescence patterns, therefore, might be directed by the position, concentration and molecular structure of proteins, whereas Giemsa banding patterns might be dependent upon the removal or displacement of possibly the same proteins. The fact that all of the Giemsa staining techniques include a step that by evidence or rational conjecture could result in selective extraction of chromosomal proteins gives weight to the hypothesis that the differential staining of Giemsa bands is related to the removal or redistribution of chromosomal proteins. This also implies base specific and to some degree repetitive DNA specific, protein associations and necessitates an examination of the types of protein (acidic and/or basic) as a requisite for evaluating their genetic function.

There are several factors which tend to support the presence of each type of protein in the banded regions.

(a) Although information is not extensive it is currently held that the distribution of Giemsa bands is species specific and not, at least in animal chromosomes, tissue specific (QM bands in $V$. faba are species specific (Caspersson et al., 1972)). As some acidic proteins are known to vary in different tissues (Wang, 1971) there is a possibility that if any proteins characterise Giemsa bands then these may be of the histone type. 
(b) Histone involvement in banded regions is also indicated by immunofluorescence studies. Desai et al. (1972), working with polytene chromosomes from the salivary gland cells of second instar larvae of Drosophila melanogaster, treated the preparations with fluorescein-bound histone antisera and found fluorescence in areas corresponding to known QM bands. Of further significance was anti-serum from the argenine-rich histone fraction which could be considerably diluted before any appreciable diminution of fluorescence was noted.

(c) Since trypsin requires a free basic amino acid for hydrolysis of a polypeptide (Simpson, 1972) cleavage would not be expected when the basic group is complexed to nucleic acid. Not unexpectedly, Simpson subsequently found that tryptic digestion of proteins bound to nucleic acids did not occur at those sites where there was an electrostatic linkage of lysine or argenine-rich histones to nucleic acid phosphate. Upon extrapolation it is not unlikely that trypsin banding of chromosomes differentiates between protein types with the positive bands representing lysine or argenine-rich histones.

Some evidence, however, would ascribe Giemsa bands to the localization of acidic proteins. Giemsa staining of HCl-treated metaphase chromosomes in situ shows no apparent morphological effect, or at the most a slight decrease in the stain intensity of G-bands (Meisner, Chuprevich and Inhorn, 1973) which would seem to support the positive Giemsa band/acidic protein theory. Furthermore, the fact that chromosome morphology is unaffected after the $\mathrm{HCl}$ treatment, which is assumed to extract total histone and non-histone acid soluble protein, contradicts the many studies which demonstrate these proteins to be a major determinant of chromosome coiling and structure, and, in so far as proteins are involved, would appear to attribute metaphase morphology entirely to acid and residual proteins. 
68.

Alkaline or trypsin treatment after exposure to $\mathrm{HCl}$, however, can still induce Giemsa bands (Chuprevich et al., 1973). Some techniques (Bobrow, Madan and Pearson, 1972) use a pH of 11.5 to produce G-bands, and this is not consistent with persistence of acid protein.

In an attempt to clarify the matter fully Meisner et al. (1973) treated slides of fixed human chromosomes with a pH 12.0 solution for $30 \mathrm{~min}$, followed by a $30 \mathrm{~min}$ immersion in $0.2 \mathrm{~N} \mathrm{HCl}$, both at room temperature. This treatment gives uniformly stained chromosomes. (Application of this alkaline-acid wash to V. faba preparations, however, results in grossly distorted chromosomes). Yet if this treatment is followed by trypsin digestion $(0.6 \%$ at $\mathrm{pH} 8.0$ for one to five $\mathrm{min}$ ) before Giemsa staining, both $\mathrm{G}$ and C-bands can be produced, regardless of the alkaline-acid washes which, it was reasoned, should have removed all proteins both basic and acidic!

Accepting trypsin as a bona fide proteolytic agent a protein must, therefore, still remain complexed on the chromosomes despite the harsh pretreatment. Indeed, Pothier et al. (1975) have since reported that even a four hour extraction with $0.2 \mathrm{~N}$ $\mathrm{HCl}$ does not extract all histone 2al. The most important stabilizing forces in nucleohistones are the non-specific ionic bonds between the positive residues on the histone and the phosphate groups on the DNA (Walker, 1965).

In studying the titration properties of the nucleo-histones Walker found that their stereochemical arrangements on the DNA helix are in fixed positions, and that lysine and argenine residues are the main groups involved in the complexing. 
Furthermore, the charge distribution along the polypeptide chain of the nucleohistone appears to be non-uniform, producing an effect which suggests that the lysine and argenine residues are grouped close together. Most significant was his discovery that only $80 \%$ of the lysine and argenine residues titrated at pH 12.0 and he concluded that the remaining moieties are still firmly linked by ionic bonds to the phosphate of the DNA. This could mean that lysine and/or argenine-rich histone residues are the only proteins on the chromosomes which survive the conditions imposed in the banding process, and modification of these by trypsin gives rise to Giemsa bands. This would add further weight to the significance of the immunofluorescence studies and to Simpson's work in emphasizing the role of histones in chromosome banding.

In testimony to the controversial nature of the issue, Comings and Avalino (1974) had published results at variance with Pothier et al. (1975). They claimed that all histones were removed from the chromosomes in a $0.2 \mathrm{~N} \mathrm{HCl}$ wash for 4 hours as shown by polyacrylamide gel electrophoresis. Upon producing Giemsa bands thereafter with trypsin, Comings and Avalino concluded that non-histone proteins were the important proteins in chromosome banding. In a recent publication, Comings and Harris (1975) report a number of non-histone proteins that are unique to or present in greater quantity in constitutive heterochromatin.

Ample evidence implicates the role of proteins in association with DNA as a requisite for Giemsa banding. This evidence is divisive, however, in indicating what type of protein is involved. Although the author would tend to favour a histone-type protein playing a major role, this conjecture is tempered with caution whilst the entire field attends the weight of confirming results. 


\section{Lacto-Aceto-Orcein Banding}

Application of Kurita's (1958) lacto-aceto-orcein method revealed a banding pattern not seen with previous techniques. of prime note was the discovery of a positively-stained NoR band and negatively-stained centromeric bands in each $\mathrm{M}$ chromosome. The three centromeric bands coincide in location with those $M$ centromeric bands seen after acid treatment. Replication studies did not give clear results as to when the NOR band replicates. It does not, however, replicate in late $\mathrm{S}$, which supports Burger and Scheuermann's (1974) conclusion and is in agreement with the photographic evidence of late-labelled chromosomes shown by Evans (1964). Early labelling studies suggest that the NoR band replicates in early $\mathrm{S}$.

NOR band chromatin is resistant to acid hydrolysis whilst centromeric band chromatin is sensitive, which implies some structural difference between the two regions elicited by this particular technique. Furthermore, it is because chromosomal material has been removed that the structural differences are manifested rather than a qualitative change in these two regions alone.

If the banding pattern on the $M$ chromosome is manifested as a result of removal of chromosomal material, what material is being removed? Because strong acids are involved, the effect could be related to protein complexes and their binding to DNA, in which case a histone-type protein may be removed (Phillips, 1962; Holtzman, 1965). Histones play an important role in maintaining chromosome structure (Bonner and Garrard, 1974) and their removal may account for the distortion witnessed by this technique without standard fixation procedure. Should any proteins remain, one might therefore expect the NOR band to be constructed of acidic proteins or a histone-type protein resistant to the acid procedure possibly of the 
lysine or argenine-rich variety mentioned in the previous section.

Mattingly (1963) discovered lysine-rich areas on perinucleolar chromatin in $V$. faba. She deduced that because the nuclear histones are known to have greater stability than the residual proteins and because a major constituent of the histone proteins is lysine, there is a possibility that the lysine fraction is a part of the histone moiety in this portion of the genome. If Mattingly's reasoning is true and if it applies to the NOR band, then this histone-type protein must be of the acid resistant kind and be bound in a very tight manner. But also if it were true, one must reconcile this view with the argument that all Giemsa bands are composed of resistant histone-type proteins. Therefore, why are the M centromeric bands not positive with Kurita's technique as they are with the urea-Giemsa technique (not distinctive in this study but shown clearly by Dobel et ar., 1973)?

There is the remaining possibility that the centromeric bands contain a different histone type not resistant to acid, though this may appear, with regard to the discovery by Pothier et al. (1975) of an acid resistant histone fraction, to be contrary to Meisner, Chuprevich and Inhorn's (1973) results who showed that Giemsa bands could be revealed on human chromosomes after $0.2 \mathrm{~N} \mathrm{HCl}$ treatment.

An effect that could equally give rise to differential banding is selective removal of divalent metal ions, a proposal advanced as a possible cause of Giemsa banding. This may or may not be related to protein types. The proposal is tenable in the light of Cohn's (1961) results on the effect of the ironchelator 2.2' bipyridine on the structural stability of heterochromatic regions in $V$. faba chromosomes i.e. around the $\mathrm{M}$ centromere and intercalary regions of the s chromosomes. 
72.

The first report of differential staining around the NOR in metaphase M chromosomes in V. faba was by Rattenbury (1952). He noted the occasional presence of this structure in preparations connected with nucleolar studies (pers. comm.). Apart from recent Giemsa banding studies, the only other note of its presence is a brief report by Takehisa (1969). Both Rattenbury's and Takehisa's methods were applied by the author to $V$. faba var. C.E.D. without success. The acquiring of the variety Takehisa used (Nagasaya Soramame) and subsequent experimentation also produced fruitless results. Both these investigators used formaldehyde somewhere in the treatment. Formaldehyde acts chiefly by denaturing proteins (Sharma and Sharma, 1965) which offers a clue to its possible action in manifesting the NOR band, but as well, this chemical is known for its unpredictability in its treatment of chromosomes which may account for the present author's lack of success with the above experimenters' techniques.

A recent report of $\mathrm{N}$-banding in $V$. faba by Funaki, Matsui and Sasaki (1975) shows a positively-stained band within the secondary constriction of the M chromosome (Fig. 50) which the authors regard as being distinct from heterochromatin adjacent to the NOR as shown by the TCA-Feulgen reaction (Takehisa, 1969). They do not, however, compare the location of this band with the results of Dobel et al. (20c. cit), although in the present study the urea-Giemsa technique revealed distinct bands adjacent to the NOR.

The NOR band in Fig. 45 is similar to the N-band shown by Funaki et $a l$. and a distinction between the two structural features cannot be drawn with certainty from these photographs. Fig. 43, however, shows the NOR band as segments flanking the secondary constriction and it is most likely that Fig. 45 represents the merging of these segments. Should there be, however, two distinct structures at the $M$ secondary constriction 
(adjacent heterochromatin and an N-band), then the "band" in this position in Fig. 41 (Gll method) could possibly be interpreted as an N-band. Funaki et al., moreover, claim that Nbands represent certain structural non-histone proteins specifically linked to nucleolar organizers.

The function of the NOR band is no doubt connected with nucleolus formation. Berns and Cheng (1971) used a laser microbeam to irradiate regions outside and inside the constriction of No chromosomes. Irradiation immediately adjacent to the constriction consistently resulted in the loss of nucleolar organizing capacity, whereas irradiation $2 \mu \mathrm{m}$ away from the secondary constriction and direct irradiation of the secondary constriction did not alter the ability of the cell to form nucleoli. These results show that sites adjacent to the constriction are involved in nucleolus formation.

No differential banding was seen in the $\mathrm{S}$ chromosomes by the LAO technique. Whereas the NOR band is resistant to this method, and M centromeric band chromatin very sensitive, S chromosome heterochromatin (known to be located in the intercalary regions of the long arms) is indistinguishable from all the remaining chromatin and tolerably resistant to acid hydrolysis enough to contribute towards chromosome recognition. That $\mathrm{S}$ chromosome heterochromatin should behave in this fashion complicates speculation on its properties. Being heterochromatin, one might expect it to behave like $M$ centromeric band chromatin. This suggestion is based on cold treatment and late labelling observations of heterochromatin expression and behaviour in $V$. $f a b a$. It is perhaps surprising that acid treatment or the LAO technique should be discriminating in not showing any $\mathrm{S}$ chromosome bands (apart from the small arm band). One can only reflect that whereas M centromeric band chromatin and NOR band chromatin possess different properties as manifested by the LAO 
method, s chromosome heterochromatin has, with respect to this treatment, similar properties to euchromatin.

\section{A Short Résumé of Lacto-Aceto-Orcein Banding}

The LAO banding technique used in this study has revealed two types of bands in the $M$ chromosome of $V$. faba: the NOR band and the M centromeric bands. Unlike all previous banding techniques this method produces positively-stained cross-bands and negatively-stained cross-bands simultaneously and on the same chromosome. HCl and acetic acid are known to extract histone proteins from chromosome preparations (Phillips, Zoc. cit.; Holtzman, Zoc. cit.), therefore it is proposed, on balance, that the LAO procedure selectively removes certain histone-type constituents thus giving rise to differential staining along the chromosomes. 
VI. In Situ Hybridization

The widespread distribution of grains over the M chromosome seen in autoradiographs indicates that both heterochromatin (as defined by cold treatment and late-replicating regions) and euchromatin contain repetitive DNA. The dispersion of grains along the S chromosomes results in the same conclusion, although in some instances the grain distribution corresponds closely with intercalary heterochromatin location. Diffuse labelling and labelling at both ends of many $s$ chromosomes, however, clearly indicate that in the $V$. faba genome, a considerable amount of euchromatin as well as heterochromatin comprises repetitive DNA. These results are similar to the findings of Timmis, Deumling and Ingle (1975) who showed diffuse labelling over all the $V$. faba chromosomes and interphase nuclei upon performing hybridization with RNA transcribed from a $\mathrm{Ag}^{+} / \mathrm{Cs}_{2} \mathrm{SO}_{4}$ satellite DNA component. (A light satellite component is present in $V$. faba total DNA (see App. II). Although the satellite is not specified by Timmis et al., it is assumed this was the fraction used in their studies). These investigators state "The satellite sequences appear to be more generally spread over

cne'nuclei and over the chromosomes. There is a suggestion that the ends of the chromosome arms are unlabelled and in addition, certain proximal regions". The same sugaestion is seen_in_tbe

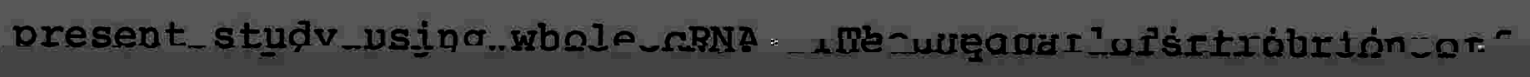
grains along the $M$ chromosome shown in Fig. 59 , especially the reduction in grain count around the centromere, would seem reievant" to cnfomosome banding. The grain count data would 
highly repetitive sequences were hybridized (see below)). Nevertheless, the reduction in grain count around the $M$ centromere which in $V$. faba is known to comprise heterochromatin, is contrary to many results in other organisms which show heterochromatic regions to be specially rich in repetitive DNA sequences.

The light satellite DNA fraction in $V$. faba comprises only approximately $3-5 \%$ of the total DNA. Thus RNA produced from this DNA is potentially able to hybridize with the equivalent percentage of chromosomal DNA. RNA from total DNA, however, should theoretically hybridize to $100 \%$ of chromosomal DNA. Under the conditions in the present study, $c_{0} t$ values ranging from $10^{-1}$ to $10^{-2}$ mole $\mathrm{x}$ secs/litre were achieved. This implies according to reassociation kinetics (see App. III), that only 5-20\% of the total $V$. faba DNA (i.e. highly repetitive sequences) is potentially detectable by in situ hybridization. Cot values, however, offer only a rough guide in estimating the actual percentage of RNA-DNA hybridization in situ; it is not possible to determine accurately whether more chromosomal DNA was bound by the whole cRNA than satellite band cRNA.

Transcripts from whole DNA must have included a variety of different RNA molecules and hence would not be as pure as satellite band CRNA. It is most likely that several families of repeated sequences hybridized with chromosomal DNA giving rise to the widespread grain pattern. The occurrence of heavy labelling in euchromatic regions is in contrast with previous studies which have shown that euchromatic regions either lack label or show light labelling whereas heterochromatin is intensely rich in repetitive DNA (see pages 13 and 14 of the Historical survey). The result of Timmis et al., hybridizing satellite band CRNA, is perhaps more surprising. It is unusual to find non-localization of a satellite DNA component on the chromosomes of higher 
organisms; Scilla sibirica satellite DNA, for example, is strongly localized on the chromosomes (Timmis et al., Zoc. cit.)

The diffuse location of satellite DNA along $V$. faba chromosomes may be related to the evolution of these sequences. Walker (1971) has offered possibly the most plausible arguments on the evolution of satellite DNA sequences whereby a selective advantage is conferred on a chromosome to preserve a certain sequence which arises from ribosomal spacer DNA, multiplied rapidly, and is then translocated to other sites on the same and other chromosomes. Multiplication, according to Walker, probably occurs over a short period ("saltation") faster than the rate of pase substitution, with the exchange to other chromosomal sites occurring over a longer period. If a high rate of translocation occurred in $V$. faba, it could explain the widespread distribution of satellite DNA sequences throughout the genome.

Burger and Scheuermann (1974) and Scheuermann and Knallman (1975) hybridized V. faba ribosomal RNA (fractions 4 and 5S, 18S and 25S prepared from root-tips incubated in ${ }^{3} \mathrm{H}$-uridine) to chromosomal DNA of root-tip preparations. After seven months exposure time, fractions $18 \mathrm{~S}$ and $25 \mathrm{~S}$ (fraction 4 and $5 \mathrm{~S}$ results were not reported) showed localization of grains around the secondary constriction of the M chromosome. These investigators, therefore, clearly established the localization of certain ribosomal cistrons in $V$. faba chromosomes.

One of the interesting problems is to determine whether repetitive DNA in $V$. $f a b a$ is transcribed into RNA in vivo. The data of Flamm, Walker and McCallum (1969) suggest that mouse satellite DNA is not transcribed. Available evidence regarding the sequence of bases in satellite DNA's suggests that they cannot code for a meaningful polypeptide, although this does not negate the possibility of their transcription; certain nucleotide 
sequences may possess functions other than those involving translation. Evidence has been obtained that homopolymers of purine ribonucleotides (poly A) are present in the nucleus and cytoplasm of various organisms (Lim, Canellakis and Canellakis, $1970 a$, b). Poly A sequences are now known to be attached to most eukaryotic mRNA's yet despite intensive research the function of these sequences remains obscure (Hamlyn, 1975). This introduces the question of functions of different repetitive DNA fractions. Discussion on the topic has ranged from their possible role as gene regulators or initiators of transcription to no attributable function (labelled as "junk DNA"). For reviews see Walker (1971), Rae (1972), Ursprung, (1972), Hennig (1973).

Although evidence from molecular biology studies indicates that at least some repetitive DNA sequences are transcribed (saturation hybridization studies by Soeiro and Darnell (1969) have shown that about 5\% of total nuclear DNA can be bound by in vivo synthesized RNA at low $\left.C_{0} t\right)$ information with respect to V. faba is lacking. It is now possible to estimate the contributions of transcripts from various families of DNA sequences to the populations of heterogeneous nuclear RNA (HnRNA) and mRNA. This is done by incubating small amounts of radioactively labelled $\mathrm{Hn}$ - or mRNA in solutions of reannealing DNA under conditions such that the RNA participate in the annealing reaction without seriously affecting the kinetics of DNA-DNA annealing. The fraction of RNA complementary to DNA of various degrees of repetition can then be measured by assaying for radioactivity bound to DNA, after separating double from singlestranded molecules on a hydroxyapatite column when various $\mathrm{C}_{0} t$ values have been reached (Gelderman, Rake and Britten, 1971; Greenberg and Perry, 1971). These experiments have shown that the bulk of both Hn and mRNA is transcribed from the unique 
79.

sequence fraction of DNA, but that some messenger and HnRNA's are transcribed from all but the most highly repetitive sequences (which in mouse cells is satellite DNA).

Experiments by hybridization competition have also shown in mammalian nucleic acids that some of the RNA transcribed from the rapidly reannealing DNA fractions is tissue specific (Hennig, 1968) as well as developmental-stage specific (Church and McCarthy, 1967; Davidson, Crippa and Mirsky, 1968). It would be meaningful as an extension to the present study to pursue this avenue of research in $V$. faba in conjunction with DNA and RNA fractionation/chromosome localization studies. 
VII. Chromosome Bands and Heterochromatin

Many techniques were used or developed in this study to visualize chromosome bands on metaphase chromosomes. A central question in such an investigation is whether these bands demonstrate the presence of heterochromatin.

If the bands shown by a new chromosome banding technique coincide in location with established heterochromatic regions, and if this is substantiated in a number of investigations in various organisms, then that technique can be said to demonstrate the presence of heterochromatin and it then becomes another criterion for defining heterochromatin. Furthermore, the technique may offer contributions to explaining the nature of this portion of chromatin.

On the other hand if a new band does not coincide with established heterochromatic regions then that band is a "chromosome band" and not a "heterochromatic band" until the new technique is accepted as a method for showing heterochromatin. The following section sets the criteria for detecting heterochromatin and questions the heterochromatic character of chromosome bands shown by the various banding techniques used in the present study.

Methods for detecting heterochromatin include the following:

(1) direct visualization by staining. Those chromosome regions which demonstrate heteropycnosis (differential condensation) are judged to be heterochromatic. These regions are seen as chromocenters in interphase nuclei or differentially condensed areas in prophase chromosomes. Ohno, Kaplan and Kinosita (1957) clearly recognised heterochromatin in the proximal regions of mouse prophase chromosomes by this method.

(2) use of cold treatment; seen as negatively-stained cross-bands in metaphase chromosomes. 
(3) use of autoradiography to detect late DNA-replicating regions.

Heterochromatin is known to possess other attributes as mentioned in the historical survey, and not unexpectedly, there are exceptions in behaviour to some of the above features (Lima-de-Faria, 1969). It is upon a combination of these criteria, however, that a chromosome band may be judged as being heterochromatic.

The C-dots observed in this study seem comparable to the deeply stained paired dots seen at the centromeres of AZlium cepa chromosomes by stack and Clarke (1973) who used a modified C-banding technique ( $i . e$. a modified NaOH-SSC-Giemsa technique). Stack (1974) extended this work to include several plants (Ornithogalum sp., Tradescantia sp. and Rhoeo sp.) and he distinguishes between the terms "centromere" and"kinetochore". The term "kinetochore" is reserved for structures within the centromere, or primary constriction, to which microtubules attach and by which chromosomes are moved during cell division. Pericentromeric heterochromatin, seen as C-bands or constitutive heterochromatin in mammalian chromosomes is considered to be distinct from the centromere. Stack concludes that the paired dots represent differential kinetochore staining and that their uncommon observation in other organisms may be due largely to their being obscured by the large masses of centromeric heterochromatin that characterize animal chromosomes. Ultrastructural examination of the dots is apparently in progress (Stack, 1974).

The present study is in agreement with the above observations and Stack's interpretations seem most plausible. C-dots should not be viewed as representing heterochromatin but regarded as distinct functional units. 
Bostock and Christie (1974) conducted a detailed study into the heterochromatic characters of $\mathrm{C}, \mathrm{G}$ and $\mathrm{Q}$ bands in kangaroo rat chromosomes. Their results are somewhat complex. Q-bands correspond to G-bands which are located in the chromosome arms. C-bands are located not only in the pericentromeric regions but also along the chromosome arms alternating with G-bands. Centromeric C-bands contain late-replicating DNA whereas noncentromeric C-bands, Q-bands and G-bands contain earlyreplicating DNA. From these studies Bostock and Christie suggest there are several different states or degrees of heterochromatin. A similar conclusion was reached by Yamasaki (1971) in his studies of Trizlium and cypripedium chromosomes. The evidence from $V$. faba supports this view. Bands $M 1 / 1$ and $M 2 / 1$ may represent the extreme case of heterochromatin shown by nearly all techniques, whereas $\mathrm{Ml} / 2, \mathrm{M} 2 / 2, \mathrm{M} 2 / 3$ and $\mathrm{M} 2 / 4$ may represent different classes of heterochromatin revealed only by specialized techniques.

That the latter group of bands (M1/2 to $\mathrm{M} 2 / 4)$ are not shown by cold treatment, may reflect more on the inadequacies of this technique as a criterion for defining all heterochromatin. This would seem true for band $M 2 / 2$ which is shown by most other banding techniques. Furthermore, in the V. faba M chromosome, QM bands, acid treatment bands, and Giemsa bands (as shown by the various regimes used in this study), are all localized within the late-replicating region (except for the NOR band). Therefore, given that there are differences of band expression within this limited region with specialized techniques, all the $\mathrm{M}$ centromeric bands revealed (M1/1, M1/2, M2/1, M2/2, M2/3 and M2/4) are judged to represent the position of heterochromatin. The centromere region of the $M$ chromosome is not, however, especially enriched with repetitive DNA. 
The negatively-stained band seen on the small arm of one or two $\mathrm{S}$ chromosomes after acid treatment is also seen after cold treatment. And in most $S$ chromosomes there appears to be a correlation between the position of discrete Giemsa bands in the intercalary and proximal regions of their long arms and the location of cold bands which in turn correspond to the location of late-replicating DNA. Caspersson et al. (1969a) also show QM bands (more convincingly than in the present study) exclusively in these regions. Those bands seen in the $\mathrm{s}$ chromosomes by acid treatment, $Q M$ fluorescence and Giemsa banding are also judged to represent the position of heterochromatin.

The distribution of repetitive DNA in the $\mathrm{S}$ chromosomes is varied. Most $\mathrm{S}$ chromosomes in the genome have grains along their entire length indicating a widespread distribution of repetitive DNA, although in some $\mathrm{S}$ chromosomes there is a suggestion that label is localized at intercalary heterochromatin regions. In contrast, the common observation of grains at the ends of two $\mathrm{S}$ chromosomes in the genome (Fig. 58) suggests repetitive DNA in these two $\mathrm{S}$ chromosomes is localized at euchromatic regions, at least for the long arm end. The short arm may contain the heterochromatic band seen above but this was not determined in in situ hybridization preparations.

The NOR band is one of the classical examples of nucleolusassociated heterochromatin described by Heitz (1928, 1929) and later studied by Caspersson and Schultz (Caspersson, 1950). This was seen most convincingly in Fig. $47 \mathrm{a}$, b where the two chromocenters of each nucleus associated with the nucleolus represent the NOR heterochromatin from the two M chromosomes. NOR heterochromatin in $V$. faba differs from the rest of the heterochromatin in not replicating late (also reported by Burger and Scheuermann, 1974), and being located on either side of the secondary constriction it would escape detection by cold 
treatment. However, Fig. 59 indicates that NOR heterochromatin may house repetitive DNA sequences even though these sequences are generally spread along the M2 arm.

The phase-dense regions at some chromosome ends probably represent condensed chromosome areas. Therefore they would share a characteristic of heterochromatin as first defined by Heitz (Zoc. cit.). The lack of phase density in these regions in less-contracted chromosomes, however, suggests they are not highly condensed at interphase. Furthermore, the chromosome ends do not otherwise manifest heterochromatic behaviour (although, as above, negative cold bands would not be detected). Therefore these particular regions are not regarded as being heterochromatic.

All the chromosome bands revealed in this study by acid treatment, $\mathrm{QM}$ fluorescence, Giemsa banding and orcein banding are judged to represent the position of heterochromatin and the techniques accepted as methods which show heterochromatin in Vicia faba chromosomes. Furthermore, the variable expression of different bands with particular banding techniques testifies to certain differences between banded regions which is interpreted as indicating the existence of several classes of heterochromatin. 
VIII. Summary of Findings with Comparison to Other Studies

The present study, unlike previous studies in Vicia faba, presents a comparison of band distribution by several banding techniques, and demonstrates the coincidence of these bands with the position of heterochromatin as shown by cold treatment and late DNA-replication. The study also compares the distribution of heterochromatin with the location of repetitive DNA sequences. In situ hybridization results show that these sequences are widespread in the $V$. faba genome.

During the course of investigation certain results were achieved that have not been reported previously in $V$. faba chromosomes, viz. the illustration of both C-dots and phaselucent cross-bands immediately after SSC treatment, the appearance of "chromosome ghosts" after trypsin treatment, nucleolus-associated DNA labelling discovered during temporal replication studies (this feature requires intensive investigation), and the location of repetitive DNA sequences transcribed from total DNA.

Similar comparative studies have been conducted mainly in mammalian chromosomes asmentioned in the discussion (pp. 45, 52, 82). Most reports of chromosome banding in Vicia faba, many published during the course of the present study, are not comparative studies but individual reports of bands produced by a particular technique. However, the finding in the present study that two different banding patterns are produced around the $\mathrm{M}$ centromere by cold treatment and acid treatment is a comparison also reported by Takehisa (1973). Burger and Scheuermann (1974) likewise compared and established Giemsa band locations coinciding with late-replicating regions (except for the Giemsa band at the M secondary constriction), and also established the location of certain ribosomal subunits at the NOR. 
86.

The conclusion arising from the present study that a number of classes of heterochromatin exist, has been independently reached by Vosa (1970), Vosa and Marchi (1972a), Yamasaki (1971), Takehisa (1973) and Bostock and Christie (1974). A recent publication by Vosa (1976) classifies V. faba heterochromatin and a publication by Friebe (1976) describes Giemsa banding in $V$. faba but the present author had not seen either report at the time the manuscript was typed. 
This study investigated the distribution of bands along root-tip chromosomes of Vicia faba "Coles Early Dwarf" as seen by acid treatment, quinacrine mustard fluorescence, various forms of Giemsa banding and orcein banding. These bands reveal the position of heterochromatin, indicated by their coincidence with cold treatment bands and late-replicating regions. The NOR band, however, is not late-replicating (evidence suggests it replicates in early $S$ ) but was judged to represent classical nucleolus-associated heterochromatin.

Most of the observed bands were not exclusive to one treatment, but could be recognized in chromosomes prepared by several methods, yet their variable expression with different banding techniques testifies to certain differences between banded regions and emphasizes the existence of several classes of heterochromatin.

Heterochromatin in the $M$ chromosome is located in two areas, (a) around the centromere and (b) adjacent to the secondary constriction. Fig. 51 (a-i) illustrates the variation in banding patterns in these areas with specialized techniques. Heterochromatin in the $S$ chromosomes is located in the intercalary and proximal areas of their long arms and in the short arm of two chromosomes.

In situ molecular hybridization of labelled complementary RNA to chromosomal DNA indicates the presence of repetitive DNA in both euchromatin and heterochromatin of the $V$. faba genome.

Factors involved in Giemsa banding were considered in detail with the role of proteins judged to be of prime importance.

A major difference, probably in protein content or architecture, was seen between M centromeric heterochromatin and NOR heterochromatin as revealed by the lacto-aceto-orcein technique. 
88.

It is proposed that the procedure selectively removes certain basic histone proteins thus giving rise to differential staining of the $\mathrm{M}$ chromosome. 


\section{ACKNOWLEDGEMENTS}

I express my sincere appreciation to Dr G.K. Rickards, Botany Department, V.U.W., whose advice and criticism during this study was of considerable value. Special thanks are also extended to Dr W.D. Sutton, Plant Physiology Division, D.S.I.R., Palmerston North, for his guidance in solving difficulties encountered with DNA transcription. I acknowledge that the ultracentrifugation analysis in App. II showing $V$. faba satellite DNA was conducted by Dr sutton.

To Professor H.D. Gordon, Botany Department, V.U.W., I express my gratitude for his valuable criticisms, particularly of the final written work.

I would also like to thank Professor J.K. Heyes, Botany Department, V.U.W., for his valuable comments and discussion, Mr W. Armstrong, Mathematics Department, V.U.W., for his statistical advice, Miss Cathi Balog for her assistance with the draft, and Mrs olga Vincent for typing the script.

Special thanks arealso given to the technical staff of the Botany Department, V.U.W., in particular Mr Ron Hoverd, Miss Margaret Priday and Mr Herb Christophers, all whose willingness to supply items of equipment and chemicals contributed towards a smoother running of the experimental work.

To many others who have been less specifically but equally helpful to me during this study I express my sincere appreciation. 
ADKISSON, K.P., PERREAULT, W.J. and GAY, H. (1971). Differential fluorescent staining of Drosophila chromosomes with quinacrine mustard. Chromosoma 34, 190-205.

ALBERT, A. (1951). "Selective Toxicity". Methuen \& Co. Ltd., London.

ARRIGHI, F.E. and HSU, T.C. (1971a). Distribution of constitutive heterochromatin in mammalian chromosomes. Chromosoma 34, 243-253.

(1971b). Localization of heterochromatin in human chromosomes. Cytogenetics 10, 81-86.

ARRIGHI, F.E.,HSU, T.C., SAUNDERS, P. and SAUNDERS, G.F. (1970a). Localization of repetitive DNA in the chromosomes of Microtus agrestis by means of in situ hybridization. Chromosoma 32, 224-236.

ARRIGHI, F.E., MANDEL, M., BERGENDAHL, J. and HSU, T.C. (1970b). Buoyant densities of DNA of mammals. Biochem. Genet. 4, 367-376.

BAKER, J.R. and CALLAN, H.G. (1950). Heterochromatin. Nature, Lond. 166, 227-228.

BARR, M.L. and BERTRAM, E.G. (1949). A morphological distinction between neurones of the male and female, and the behaviour of the nucleolar satellite during accelerated nucleoprotein synthesis. Nature, Lond. 163, 676-677.

BATH, D.W. (1976). Surface ultrastructure of trypsin-banded chromosomes. Expl. Cell Res. 98, 262-268.

BENTZER, B., BOTHMER, R.V., ENGSTRAND, L., GUSTAFSSON, M. and SNOGERUP, S. (1971). Some sources of error in the determination of arm ratios of chromosomes. Bot. Notiser 124, 65-74.

BERNS, M.W. and CHENG, W.K. (1971). Are chromosome secondary constrictions nucleolar organizers? A re-examination using a laser microbeam. Exp Z. Cell Res. 69, 185-192.

BOBROW, M., MADAN, K. and PEARSON, P.L. (1972). Staining of some specific regions of human chromosomes, particularly the secondary constriction of number 9. Nature New Biol. 238, 122-124.

BONNER, J. and GARRARD, W.J. (1974). Biology of the histones. Life Sci. $14,209-221$.

BOOTHROYD, E.R. (1953). The reaction of Trillium pollen tube chromosomes to cold treatment during mitosis. J. Hered. 44, 2-9.

BOOTHROYD, E.R. and LIMA-DE-FARIA, A. (1964). DNA synthesis and differential reactivity in the chromosomes of Trillium at low temperatures. Hereditas 52, 122-126.

BOSTOCK, C.J. and CHRISTIE, S. (1974). Chromosome banding and DNA replication studies on a cell line of Dipodomys merriami. Chromosoma 48, 73-87.

BOSTOCK, C.J. and PRESCOTT, D.M. (1971a). Buoyant density of DNA synthesized at different stages of the S phase of mouse L cells. Expl. CeZl Res. 64, 267-274. 
BOSTOCK, C.J. and PRESCOTT, D.M. (1971c). Shift in buoyant density of DNA during the synthetic period and its relation to euchromatin and heterochromatin in mammalian cells. J. molec. Biol. 60, 151-162.

BRITTEN, R.J. and KOHNE, D.E. (1966). Nucleotide sequence repetition in DNA. Camegie Inst. Wash. Year Book 65, 78-106.

Camegie Inst. Wash. Year Book 66, 73-88.

Science, N.Y. 161, 529-540.

BRITTEN, R.J. and WARING, M. (1965). "Renaturation" of the DNA of higher organisms. Camegie Inst. Wash. Year Book 64, 316-333.

BROWN, S.W. (1966). Heterochromatin. Science, N.Y. 151, 417-425.

BUONGIORNO-NARDELLI, M. and AMALDI, F. (1970). Autoradiographic detection of molecular hybrids between rRNA and DNA in tissue sections. Nature, Lond. 225, 946.

BURGER, E.-C. and SCHEUERMANN, W. (1974). Giemsa-Banden und heterochromatische Regionen bei Metaphasechromosomen von Vicia faba.

Cytobiologie 9, 23-35.

BURKHOLDER, G.D. (1974). Electron microscopic visualization of chromosomes banded with trypsin. Nature, Lond. 247, 292-294.

(1975). The ultrastructure of $\mathrm{G}-$ and $\mathrm{C}-$ banded chromosomes. Expl. Cell Res. 90, 269-278.

CALDERON, D. and SCHNEDL, W. (1973). A comparison between quinacrine fluorescence banding and ${ }^{3} \mathrm{H}$-thymidine incorporation patterns in human chromosomes. Humangenetik 18, 63-70.

CASPERSSON, T.O. (1950). "Cell Growth and Cell Function". A cytochemical study. Norton, New York.

CASPERSSON, T., de la CHAPELLE, A., SCHRODER, J. and ZECH, I. (1972). Quinacrine fluorescence of metaphase chromosomes. Identical patterns in different tissues. Expl. CelZ Res. 72, 56-59.

CASPERSSON, T., FARBER, S., FOLEY, G.E., KUDYNOWSKI, J., MODEST, E.J., SIMONSSON, E., WAGH, U. and ZECH, L. (1968). Chemical differentiation along metaphase chromosomes. Expl. Cell. Res. 49, 219-222.

CASPERSSON, T., LOMAKKA, G. and ZECH, L. (1971). The 24 fluorescence patterns of the human metaphase chromosomes - distinguishing characters and variability. Hereditas 67, 89-102.

CASPERSSON, T., ZECH, L., JOHANSSON, C. and MODEST, E.J. (1970). Identification of human chromosomes by DNA-binding fluorescent agents. Chromosoma 30, 215-227.

CASPERSSON, T., ZECH, L., MODEST, E.J., FOLEY, G.E., WAGH, U. and SIMONSSON, E. (1969a). Chemical differentiation with fluorescent alkylating agents in Vicia faba metaphase chromosomes. Expl. Cel2 Res. 58, 128-140.

CASPERSSON, T., ZECH, L., MODEST, E.J., FOLEY, G.E., WAGH, U. and SIMONSSON, E. (1969b). DNA-binding fluor_ochromes for the study of the organization of the metaphase nucleus. Expl. CelZ Res. 58, 141-151. 
CHUPREVICH, T.W., MEISNER, L.T., INHORN, S.L. and INDRIKSONS, A. (1973). Chromosomal protein and C-banding. Lancet (i), 1453-1454.

CHURCH, R.B. and MCCARTHY, B.J. (1967). Ribonucleic acid synthesis in regenerating and embryonic liver. J. molec. Biol. 23, 459-475.

COHEN, M. (1976). Ectopic Pairing and evolution of 5S ribosomal RNA genes in the chromosomes of Drosophita funebris. Chromosoma 55, 349-357.

COHN, N.S. (1961). The effect of chelation on the production of chromatid aberrations in Vicia faba. Expl. Cell Res. 24, 596-599.

COMINGS, D.E. (1972a). The structure and function of chromatin. Adv. Hum. Genet. (N.Y.) 3, 237-431.

(1972b). Replicative heterogeneity of mammalian DNA. Expl. Cell Res. 71, 106-112.

COMINGS, D.E. and AVELINO, E. (1974). Mechanisms of chromosome banding. II. Evidence that histones are not involved. Expl. Cell Res. $86,202-206$.

COMINGS, D.E., AVELINO, E., OKADA, T.A. and WYANDT, H.E. (1973). The mechanism of $\mathrm{C}-$ and G-banding of chromosomes. Expl. Cell Res. 77 , 469-493.

COMINGS, D.E. and DRETS, M.E. (1976). Mechanisms of chromosome banding. IX. Are variations in DNA base composition adequate to account for quinacrine, Hoechst 33258 and daunomycin banding? Chromosoma 56, 199-211.

COMINGS, D.E. and HARRIS, D.C. (1975). Nuclear Proteins. I. Electrophoretic comparison of mouse nucleoli, heterochromatin, euchromatin and contractile proteins. Expl. Cell Res. 96, 161-179.

COMINGS, D.E., KOVACS, B.W., AVELINO, E. and HARRIS, D.C. (1975). Mechanisms of chromosome banding. V. Quinacrine banding. Chromosoma 50, 111-145.

COMINGS, D.E. and MATTOCCIA, E. (1972). DNA of mammalian and avian heterochromatin. Expl. Cel2 Res. 71, 113-131.

COMINGS, D.E. and OKADA, T.A. (1975). Mechanisms of chromosome banding. VI. Whole mount electron microscopy of banded metaphase chromosomes and a comparison with pachytene chromosomes. Expl. Cell Res. 93, 267-274.

COOPER, K.W. (1959). Cytogenetic analysis of major heterochromatic elements (especially $\mathrm{x}_{\mathrm{h}}$ and $\mathrm{Y}$ ) in Drosophila melanogaster, and the theory of "heterochromatin". Chromosoma 10, 535-588.

DARLINGTON, C.D. and LA COUR, L.F. (1938). Differential reactivity of the chromosomes. Ann. Bot. 2, 615-625.

chromosomes in Trillium. J. Genet. 40, 185-213.

DAVIDSON, E.H., CRIPPA, M. and MIRSKY, A.E. (1968). Evidence for the appearance of novel gene products during amphibian blastulation. Proc. natn. Acad. Sci. (U.S.A.). 60, 152-159. 
DEAVEN, L.L. and PETERSEN, D.F. (1973). The chromosomes of CHO, an aneuploid Chinese hamster cell line: G-band, C-band and autoradiographic analyses. Chromosoma 41, 129-144.

de la CHAPELLE, A., SCHRODER, J. and SELANDER, R-K. (1971). Repetitious DNA in mammalian chromosomes. Hereditas 69, 149-153.

localization and characterization of different classes of chromosomal DNA: Acridine orange and quinacrine mustard fluorescence. Chromosoma 40, 347-360.

de la CHAPELLE, A., SCHRODER, J., SELANDER R-K. and STENSTRAND, K. Differences in DNA composition along mammalian metaphase chromosomes. Chromosoma 42, 365-382.

DESAI, L.S., POTHIER, L., FOLEY, G.E. and ADAMS, R.A. (1972). Immunofluorescent labelling of chromosomes with antisera to histones and histone fractions. Expl. Cell Res. 70, 468-471.

DOBEL, P., RIEGER, R. and MICHAELIS, A. (1973). The Giemsa banding patterns of the standard and four reconstructed karyotypes of Vicia faba. Chromosoma 43, 409-422.

DRETS, M.E. and SHAW, M.W. (1971). Specific banding patterns of human chromosomes. Proc. natn. Acad. Sci. (U.S.A.) 68, 2073-2077.

DUTRILLAUX, B. and LEJEUNE, J. (1971). Sur une nouvelle technique d'analyse du caryotype humain. C.R. Acad. Sci. Paris 272, 2638-2640.

ECKHARDT, R.A. and GALI, J.G. (1971). Satellite DNA associated with heterochromatin in Rhynchosciara. Chromosoma 32, 407-427.

EIBERG, H. (1974). New selective Giemsa technique for human chromosomes, Cd staining. Nature, Lond. 248, 55.

ELLISON, J.R. and BARR, H.J. (1972). Quinacrine fluorescence of specific chromosome regions. Late replication and high $\mathrm{A}: \mathrm{T}$ content in Samoaia Zeonensis. Chromosoma 36, 375-390.

EVANS, H.J. (1961) . Chromatid aberrations induced by gamma irradiation. I. The structure and frequency of chromatid interchanges in diploid and tetraploid cells of Vicia faba. Genetics 46, 257-275.

(1964). Uptake of ${ }^{3} \mathrm{H}$-thymidine and patterns of DNA replication in nuclei and chromosomes of Vicia faba. Expl. Cell Res. 35, 381-393.

EVANS, H.J. and BIGGER, T.R.L. (1961). Chromatid aberrations induced by gamma irradiation. II. Non-randomness in the distribution of chromatid aberrations in relation to chromosome length in Vicia faba root-tip cells. Genetics 46, 277-289.

EVANS, H.J., BUCKTON, K.E. and SUMNER, A.T. (1971). Cytological mapping of human chromosomes: results obtained with quinacrine fluorescence and the Acetic-Saline-Giemsa techniques. Chromosoma $35,310-325$.

EVANS, H.J. and SCOTT, D. (1964). Influence of DNA synthesis on the production of chromatid aberrations by $\mathrm{x}$-rays and maleic hydrazide in Vicia faba. Genetics $49,17-38$. 
FLAMM, W.G., BERNHEIM, N.J. and BRUBAKER, P.E. (1971). Density gradient analysis of newly replicated DNA from synchronized mouse lymphoma cells. Expl. Cell Res. 64, 97-104.

FLAMM, W.G., WALKER, P.M.B. and MCCALLUM, M. (1969). Some properties of the single strands isolated from the DNA of the nuclear satellite of the mouse (Mus musculus). J. molec. Biol. 40, 423-443.

FRACCARO, M., TIEPOLO, L., ZUFFARDI, O., BARIGOZZI, C. and DOLFINI, S. (1971). Fluorescence and $\mathrm{Y}$ translocation in XX males. Lancet (i), 858.

FRENSTER, J.H., ALLFREY, V.G. and MIRSKY, A.E. (1963). Repressed and active chromatin isolated from interphase lymphocytes. Proc. natn. Acad. Sci. (U.S.A.) 50, 1026-1032.

FRIEBE, B. (1976). Differential Giemsa staining of heterochromatic regions in the chromosomes of Vicia faba, Allium cepa, and Paeonia tennuifolia. Theor. and Appl. Genet. 47(6), 275-283.

FUNAKI, K., MATSUI, S. and SASAKI, M. (1975). Location of nucleolar organizers in animal and plant chromosomes by means of an improved N-banding technique. Chromosoma 49, 357-370.

GAGNE, R. and LABERGE, C. (1972). Specific cytological recognition of the heterochromatic segment of number 9 chromosome in man. Expl. Cell Res. 73, 239-242.

GALI, J.G., COHEN, E.H. and POLAN, M.L. (1971). Repetitive DNA sequences in Drosophiza. Chromosoma 33, 319-344.

GALI, J.G. and PARDUE, M.L. (1971). Nucleic acid hybridization in cytological preparations. In "Methods in Nucleic Acids". ( $L$. Grossman and K. Moldave, eds.), Meth. Enzym. 21, 470-480.

GANNER, E. and EVANS, H.J. (1971). The relationship between patterns of DNA replication and of quinacrine fluorescence in the human chromosome complement. Chromosoma 35, 326-341.

GELDERMAN, A.H., RAKE, A.V. and BRITTEN, R.J. (1971). Transcription of non-repeated DNA in neonatal and fetal mice. Proc. natn. Acad. Sci. (U.S.A.) 68, 172-176.

GRANT, C.J. and HESLOT, H. (1966). Chromosome aberrations and the chromosome cycle in Vicia faba after treatments with nitromethyl urethane and nitroso-ethyl urethane. Chromosomes Today, 1, 118-127. (Eds. Darlington C.D. and Lewis K.R.) Oliver and Boyd. London.

GREENBERG, J.R. and PERRY, R.P. (1971). Hybridization properties of DNA sequences directing the synthesis of messenger RNA and heterogeneous nuclear RNA. J. Cell Biol. 50, 774-786.

GREENSHER, A., GERSH, R., PEAKMAN, D. and ROBINSON, A. (1971). Fluorescence of the $\mathrm{Y}$ and Barr body in human interphase cells. Lancet (i), 920-921.

GUTHERZ, S. (1907). Zur Kenntnis der Heterochromosomen. Arch. mikrosk. Anat. EntwMech. 69, 491-514.

HAMLYN, P. (1975). Non-coding regions of messenger RNA. Nature, Lond. 253, 235-236. 
HANNAH, A. (1951). Localization and function of heterochromatin in Drosophiza melanogaster. Adv. Genet. 4, 87-125.

HEITZ, E. (1928). Das Heterochromatin der Moose I. Jb. wiss. Bot. 69, $762-818$.

(1929). Heterochromatin, Chromocentren, Chromomeren. Ber. Deut. Bot. Ges. 47, 274-284.

HENNIG, W. (1968). Ribonucleic acid synthesis of the Y-chromosome of Drosophila hydei. J. molec. Biol. 38, 227-239.

(1973). Molecular hybridization of DNA and RNA in situ. Int. Rev. Cytol. 36, 1-44.

HENNIG, W., HENNIG, I. and STEIN, H. (1970). Localization of repeated DNA sequences in chromosomes. Chromosoma 32, 31-63.

HOLTMAN, E. (1965). A cytochemical study of the solubilities of the histones of fixed Necturus Iiver. J. Histoch. Cytochem. 13, 318-327.

HSU, T.C. (1973). Longitudinal differentiation of chromosomes. Ann. Rev. Genet. 7, 153-176.

HUNGERFORD, D.A., ASHTON, F.T., BALABAN, G.B., LABADIE, G.U., MESSATZIA, L.R., HALLER, G. and MILLER, A.E. (1972). The C-group pachytene bivalent with alocus characteristic for parachromosomally situated particulate bodies (parameres): a provisional map in human males. Proc. natn. Acad. Sci. (U.S.A.) 69, 2165-2168.

JOHANSEN, D.A. (1940). "Plant Microtechnique". McGraw-Hill, New York.

JOHN, H.A., BIRNSTIEL, M.L. and JONES, K.W. (1969). RNA-DNA hybrids at the cytological level. Nature, Lond. 223, 582-587.

JOHNSTON, H.W. (1956). Chelation between calcium and organic anions. N.Z. JZ. Sci. Technol. 37, 522-537.

JONES, K.W. (1970). Chromosomal and nuclear location of mouse satellite DNA in individual cells. Nature, Lond. 225, 912-915.

JONES, K.W. and ROBERTSON, F.W. (1970). Localization of reiterated nucleotide sequences in Drosophila and mouse by in situ hybridization of complementary RNA. Chromosoma 31, 331-345.

KATO, H. and MORIWAKI, K. (1972). Factors involved in the production of banded structures in mammalian chromosomes. Chromosoma 38, 105-120.

KATO, H. and YOSIDA, T.H. (1972). Banding patterns of Chinese hamster chromosomes revealed by new techniques. Chromosoma 36, 272-280.

KIHLMAN, B.A. (1957). Experimentally induced chromosome aberrations in plants. I. The production of chromosome aberrations by cyanide and other heavy metal complexing agents. J. biophys. biochem. Cytol. 3, 363-380.

(1959). On the radiomimetic effects of cupferron and potassium cyanide. J. biophys. biochem. Cytol. 5, 351-353. 
KIT, S. (1961). Equilibrium sedimentation in density gradients of DNA preparations from animal tissues. J. molec. Biol. 3, 711-716.

(1962). Species differences in animal deoxyribonucleic acids as revealed by equilibrium sedimentation in density gradients. Nature, Lond. 193, 274-275.

KLASTERSKA, I. and NATARAJAN, A.T. (1975). Distribution of heterochromatin in the chromosomes of Nigella damascena and Vicia faba. Hereditas $79,154-156$.

KLEINMAN, L. and HUANG, R.C. (1971). Binding of actinomycin D to calf thymus chromatin. J. molec. Biol. 55, 503-521.

KURITA, M. (1958). Heterochromaty in the AZZium-chromosomes. Mem. Ehime Univ. Sect. II Science Vol. III, 23-28.

LA COUR, L.F. (1951). Heterochromatin and the organisation of nucleoli in plants. Heredity, Lond. 5, 37-50.

LIM, L. and CANELLAKIS, E.S. (1970a). Adenine-rich polymer associated with rabbit reticulocyte messenger RNA. Nature, Lond. 227, 710-712.

LIM, L., CANELIAKIS, Z.N. and CANELLAKIS, E.S. (1970b). Metabolism of naturally occurring homopolymers. I. The isolation and metabolism of adenine-rich polynucleotides of mouse liver. Biochim. biophys. Acta 209, 112-127.

LIMA-DE-FARIA, A., (1969). Ed ., "Handbook of Molecular Cytology". NorthHolland Publ. Amsterdam.

LITTAU, V.C., ALLFREY, V.G., FRENSTER, J.H. and MIRSKY, A.E. (1964). Active and inactive regions of nuclear chomatin as revealed by electron microscope autoradiography. Proc. natn. Acad. Sci. (U.S.A.) 52, 93-100.

LYON, M.F. (1962). Sex chromatin and gene action in the mammalian Xchromosome. Am. J. hum. Genet. 14, 135-148.

MACE, jun., M.L., TEVETHIA, S.S. and BRINKIEY, B.R. (1972). Differential immunofluorescent labelling of chromosomes with antisera specific for single strand DNA. Expl. CeZl Res. 75, 521-523.

MacLEOD, R.D. (1968). Changes in the mitotic cycle in lateral root meristems of Vicia faba following kinetin treatment. Chromosoma 24, 177-187.

MANNING, J.E., HERSHEY, N.D., BROKER, T.R., PELLEGRINI, M., MITCHELI, H.K. and DAVIDSON, N. (1975). A new method of in situ hybridization. Chromosoma 53, 107-117.

MARMUR, J. (1961). A procedure for the isolation of deoxyribonucleic acid from micro-organisms. J. molec. Biol. 3, 208-218.

MATTINGLY, S.A. (1963). Nuclear protein synthesis in Vicia faba. Expl. Cell Res. 29, 314-326.

MATTOCCIA, E. and COMINGS, D.E. (1971). Buoyant density and satellite composition of DNA of mouse heterochromatin. Nature New Biol.229, 175-176. 
MCKAY, R.D.G. (1973). The mechanism of $\mathrm{G}$ and $\mathrm{C}$ banding in mammalian metaphase chromosomes. Chromosoma 44, 1-14.

MCLEISH, J. (1953). The action of maleic hydrazide in Vicia. Heredity (Supp1.) 6, 125-147.

MEISNER, L.F., CHUPREVICH, T.W. and INHORN, S.L. (1973). Giemsa banding specificity. Nature New Biol. 245, 145-147.

MICHAELIS, A. and RIEGER, R. (1971). New Karyotypes of Vicia faba. Chromosoma 35, 1-8.

MIILER, G.L., BERLOWITZ, L. and REGELSON, W. (1971). Chromatin and histones in mealy bug cell explants: activation and decondensation of facultative heterochromatin by a synthetic polyanion. Chromosoma $32,251-261$.

MOAR, M.H., PURDOM, I.F. and JONES, K.W. (1975). Influence of temperature on the detectability and chromosomal distribution of specific DNA sequences by in situ hybridization. Chromosoma 53, 345-359.

MULLER, H.J. and PAINTER, T.S. (1932). The differentiation of the sex chromosomes of Drosophiza into genetically active and inert regions. Z. indukt. Abstomm. $-u$. VererbLehre 62, 316-365.

MULLER, W. and CROTHERS, D.M. (1968). Studies of the binding of actinomycin and related compounds to DNA. J. molec. Biol. 35, 251-290.

NASH, D. and PLAUT, W. (1964). On the denaturation of chromosomal DNA in situ. Proc. natn. Acad. Sci. (U.S.A.) 51, 731-735.

OHNO, S., KAPLAN, W.D. and KINOSITA, R. (1957). Heterochromatic regions and nucleolus organizers in chromosomes of the mouse, Mus musculus. Expl. Cell Res. 13, 358-364.

OHNUKI, Y. (1968). Structure of chromosomes. I. Morphological studies of the spiral structure of human somatic chromosomes. Chromosoma $25,402-428$.

PARDUE, M.L. and GALL, J.G. (1969). Molecular hybridization of radioactive DNA to the DNA of cytological preparations. Proc. natn. Acad. Sci. (U.S.A.) 64, 600-604. satellite DNA. Science, N.Y. 168, 1356-1358.

PARDUE, M.L., GERBI, S., ECKHARDT, R.A. and GALL, J.G. (1970). Cytological localization of DNA complementary to ribosomal RNA in polytene chromosomes of Diptera. Chromosoma 29, 268-290.

PATAU, K. (1960). The identification of individual chromosomes in man. Am. J. hum. Genet. 12, 250-276.

PEARSON, P.I. (1972). Chromosomes have stripes. New Scient. 53, $371-372$.

PEARSON, P.L., BOBROW, M. and VOSA, C.G. (1970). Technique for identifying $\mathrm{Y}$ chromosomes in human interphase nuclei. Nature, Lond. 226, 78-80.

PHILIIPS, D.M.P. (1962). The histones. Prog. Biophys. biophys. Chem. 12, 211-280. 
POTHIER, L., GALLAGHER, J.F., WRIGHT, C.E. and LIBBY, P.R. (1975). Histones in fixed cytological preparations of Chinese hamster chromosomes demonstrated by immunofluorescence. Nature, Lond. 255, 350-352.

PRENSKY, W., STEFFENSEN, D.M. and HUGHES, W.L. (1973). The use of iodinated RNA for gene localization. Proc. natn. Acad. Sci. (U.S.A.) 70, 1860-1864.

RAE, P.M.M. (1972). The distribution of repetitive DNA sequences in chromosomes. Adv. Cell \& Mol. Biol. 2, 109-149.

RATTENBURY, J. (1952). Specific staining of nucleolar substance with aceto-carmine. Stain Technol. 27, 113-120.

RIS, H. (1969). "The Molecular Organization of Chromosomes". In Handbook of Molecular Cytology (ed. A. Lima-de-Faria), 222-250. NorthHolland Publ. Amsterdam.

RODMAN, T.C. and TAHILIANI, S. (1973). The Feulgen banded karyotype of the mouse : analysis of the mechanism of banding. Chromosoma 42, 37-56.

SASAKI, M. (1961). Observations on the modification in size and shape of chromosomes due to technical procedure. Chromosoma 11, 514-522.

SAUNDERS, G.F., SHIRAKAWA, S., SAUNDERS, P.P., ARRIGHI, F.E. and HSU, T.C. (1972). Populations of repeated DNA sequences in the human genome. J. molec. Biol. 63, 323-334.

SCHEID, W. and TRAUT, H. (1973). Banding in trypsin-treated chromosomes of Vicia faba. Z. Naturforsch. 28c, 357.

SCHEUERMANN, W. and KNALLMAN, M. (1975). Localization of ribosomal cistrons in metaphase chromosomes of Vicia faba (L). Expl. Cell Res. 90, 463-465.

SCHNEDL, W. (1972). Giemsa banding, quinacrine fluorescence and DNA replication in chromosomes of cattle (Bos taurus). Chromosoma 38, 319-328.

(1973). Analysis of the human karyotype by the recent banding techniques. Arch. Genet. 46, 65-98.

SCHRECK, R.R., WARBURTON, D., MILLER, O.J., BEISER, S.M. and ERLANGER, B.F. (1973). Chromosome structure as revealed by a combined chemical and immunochemical procedure. Proc. natn. Acad. Sci. (U.S.A.) 70, 804-807.

SCHWEIZER, D. (1973). Differential staining of plant chromosomes with Giemsa. Chromosoma 40, 307-320.

SEABRIGHT, M. (1971). A rapid banding technique for human chromosomes. Lancet (ii), 971-972.

SELANDER, R-K. and de la CHAPELLE, A. (1973). The fluorescence of quinacrine mustard with nucleic acids. Nature New Biol. 245, 240-244.

SHAFER, D.A. (1973). Banding human chromosomes in culture with actinomycin D. Lancet (i), 828-829.

SHARMA, A.K. and SHARMA, A. (1965). "Chromosome Techniques". Theory and Practice. Butterworths. London. 
SIMPSON, R.T. (1972). Modification of chromatin by trypsin. The role of proteins in maintenance of deoxyribonucleic acid conformation. Biochemistry N.Y. 11, 2003-2008.

SJODIN, J. (1971). Induced translocations in Vicia faba L. Hereditas 68, 1-33.

SNOW, R. (1963). Alcoholic HCl-carmine as a stain for chromosomes in squash preparations. Stain Technol. 38, 9-13.

SOEIRO, R. and DARNELI, J.E. (1969). Competition hybridization by "presaturation" of Hela cell DNA. J. molec. Biol. 44, 551-562.

STACK, S.M. (1974). Differential Giemsa staining of kinetochores and nucleolus organizer heterochromatin in mitotic chromosomes of higher plants. Chromosoma 47, 361-378.

STACK, S.M. and CLARKE, C.R. (1973). Pericentric chromosome banding in higher plants. Can. J. Genet. Cytol. 15, 367-369.

STEFFENSEN, D.M. and WIMBER, D.E. (1972). Hybridization of nucleic acids to chromosomes. Result. \& Probl. Cell Different. 3, 47-63.

STOCKERT, J.C. and LISANTI, J.A. (1972). Acridine-orange differential fluorescence of fast- and slow-reassociating chromosomal DNA after in situ DNA denaturation and reassociation. Chromosoma 37, 117-130.

STRAUS, N.A. (1972). Reassociation of bean DNA. Camegie Inst. Wash. Year Book 71, 257-259.

STRICKBERGER, M.W. (1968). "Genetics". The Macmillan Co., N.Y.

SUMNER, A.T., EVANS, H.J. and BUCKLAND, R.A. (1971). A new technique for distinguishing between human chromosomes. Nature New Biol. 232, $31-32$.

SYBENGA, J. (1959). Some sources of error in the determination of chromosome length. Chromosoma 10, 355-364.

TAKEHISA, S. (1969). Positively heterochromatic segment in mitotic metaphase chromosomes of Vicia faba. Experientia 25, 1340.

(1973). Two types of negative heterochromatin in Vicia faba as related to non-random distribution of chemically induced chromosome aberrations. Mutat. Res. 17, 267-269.

(1976). Negative heterochromatin, positive heterochromatin, and chromosome condensation in Vicia faba. Experientia 32, 303-304.

TAKEHISA, S., DOBEL, P., RIEGER, R. and MICHAELIS, A. (1976). Differential response to cold and HCl-acetic acid treatment of heterochromatin in reconstructed Vicia faba karyotypes. Chromosoma 54, 165-173.

TAKEHISA, S. and UTSUMI, S. (1973). Visualization of metaphase heterochromatin in Vicia faba by the denaturation - renaturation Giemsa staining method. Experientia 29, 120-121.

TIMMIS, J.N., DEUMLING, B. and INGLE, J. (1975). Localization of satellite DNA sequences in nuclei and chromosomes of two plants. Nature, Lond. 257, 152-155.

TOBIA, A.M., SCHILDKRAUT, C.L. and MAIO, J.J. (1970). DNA replication in sychronized cultured mammalian cells. I. Time of synthesis of molecules of different average $\mathrm{G}+\mathrm{C}$ content. J. molec. Biol. 54, 499-515. 
URSPRUNG, H., (1972). Ed., "Nucleic acid hybridization in the study of cell differentiation". Result. \& Probl. Cell Different. 3.

UTAKOJI, T. (1972). Differential staining patterns of human chromosomes treated with potassium permanganate. Nature, Lond. 239, 168-170.

VOSA, C.G. (1970). Heterochromatin recognition with fluorochromes. Chromosoma 30, 366-372.

(1976?). Heterochromatin classification in Vicia faba and Scilla sibirica. Chromosomes Today. 5.

VOSA, C.G. and MARCHI, P. (1972a). Quinacrine fluorescence and Giemsa staining in plants. Nature New Biol. 237, 191-192.

(1972b). On the quinacrine fluorescence and Giemsa staining patterns of the chromosomes of Vicia faba.

Giom. Bot. ItaZ. 106, 151-159.

WALKER, I.O. (1965). Electrometric and spectrophotometric titration of histone and deoxyribonucleohistone. J. molec. Biol. 14, 381-398.

WALKER, P.M.B. (1971). Repetitive DNA in higher organisms. Prog. Biophys. \& Mol. Biol. 23, 145-190.

WANG, T.Y. (1971). Tissue specificity of non-histone chromosomal proteins. Expl. Cell Res. 69, 217-219.

WEBSTER, P.I. and DAVIDSON, D. (1968). Evidence from thymidine- ${ }^{3} \mathrm{H}-$ labelled meristems of Vicia faba of two cell populations. J. cell Biol. 39, 332-338.

WEISBLUM, B. and DE HASETH, P.L. (1972). Quinacrine, a chromosome stain specific for deoxyadenylate-deoxythymidylate-rich regions in DNA. Proc. natn. Acad. Sci. (U.S.A.) 69, 629-632.

(1973). Nucleotide specificity of the quinacrine staining reaction for chromosomes. Chromosomes Today. 4. $35-51$.

WHITE, M.J.D. (1940). The heteropycnosis of sex chromosomes and its interpretation in terms of spiral structure. J. Genetics 40, 67-82.

WILSON, G.B. and BOOTHROYD, E.R. (1944). Temperature-induced differential contraction in the somatic chromosomes of Trizlium erectum $\mathrm{L}$. Can. J. Res. Sec. C. 22, 105-119.

WIMBER, D.E., DUFFEY, P.A., STEFFENSEN, D.M. and PRENSKY, W. (1974) Localization of the 5S RNA genes in Zea mays by RNA-DNA hybridization in situ. Chromosoma 47, 353-359.

WOLF, B.E. (1968). Structure and function of alpha- and beta-heterochromatin - results on Phryne cincta. The Nucleus (Calcutta) seminar on Chromosomes 145.

WOODARD, J., GOROVSKY, M. and SWIFT, H. (1966). DNA content of a chromosome of TrilZium erectum : effect of cold treatment. Science, N.Y. 151, 215-216.

WOODARD, J., RASCH, E. and SWIFT, H. (1961). Nucleic acid and protein metabolism during the mitotic cycle in Vicia faba. J. Biophys. biochem. Cytor. 9, 445-462. 
WOODARD, J. and SWIFT, H. (1964). The DNA content of cold treated chromosomes. Expl. Cell Res. 34, 131-137.

YAMASAKI, N. (1971). Karyotypanalyse an Hand des Färbungsmusters der Metaphasechromosomen von Cypripedium debile und Trillium kamtschaticum. Chromosoma 33, 372-381.

\section{ADDENDUM}

The author has just recently seen the report by Vosa and Marchi (1972b) published in the Italian journal Giorn. Bot. Ital.

Vosa and Marchi show a correlation between the distribution of quinacrine fluorescent bands and Giemsa bands ( $\mathrm{BaOH} \rightarrow \mathrm{SSC} \rightarrow$ Giemsa) in the M chromosome whilst in the S chromosomes "quinacrine treatment shows more regularly those bands which are located very near to the centromere [on the long arm] whereas the BaOH-SSC-Giemsa technique shows more or less the same pattern plus other bands in [intercalary regions of] the long arms". These banding patterns are similar to the results achieved in the present study.

Vosa and Marchi further note, as seen in this study, "a third very fine fluorescent band in the short arm of the M [chromosome]".

(See Fig. 42g). 
Measured bar represents $10 \mu \mathrm{m}$ in all figures where shown.

Fig. 1. Normal somatic chromosome complement of Vicia faba.

Fig. 2. Reproduction of Evans' (1961) diagrammatic representation of the haploid chromosome set of Vicia faba. 

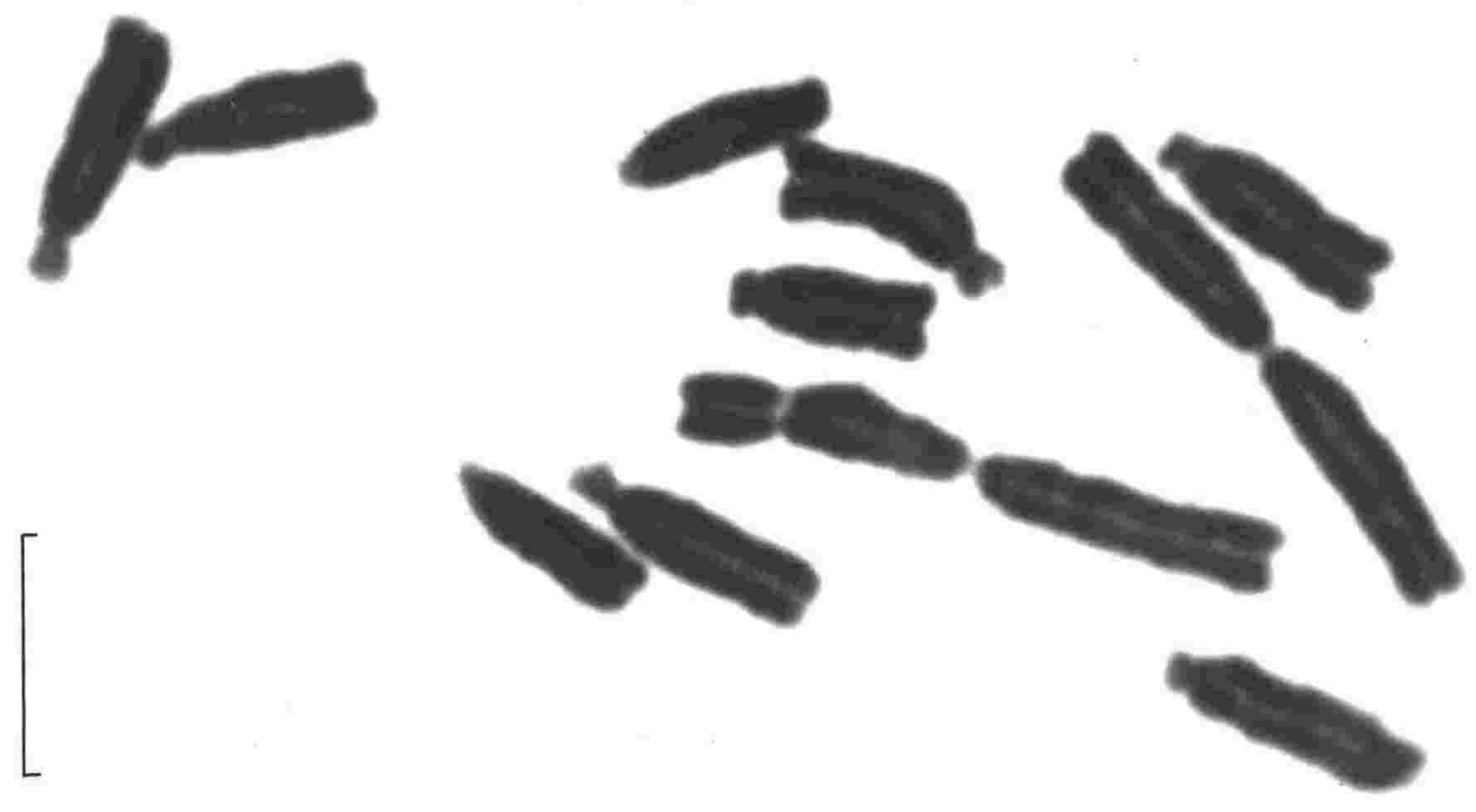

Fig 1
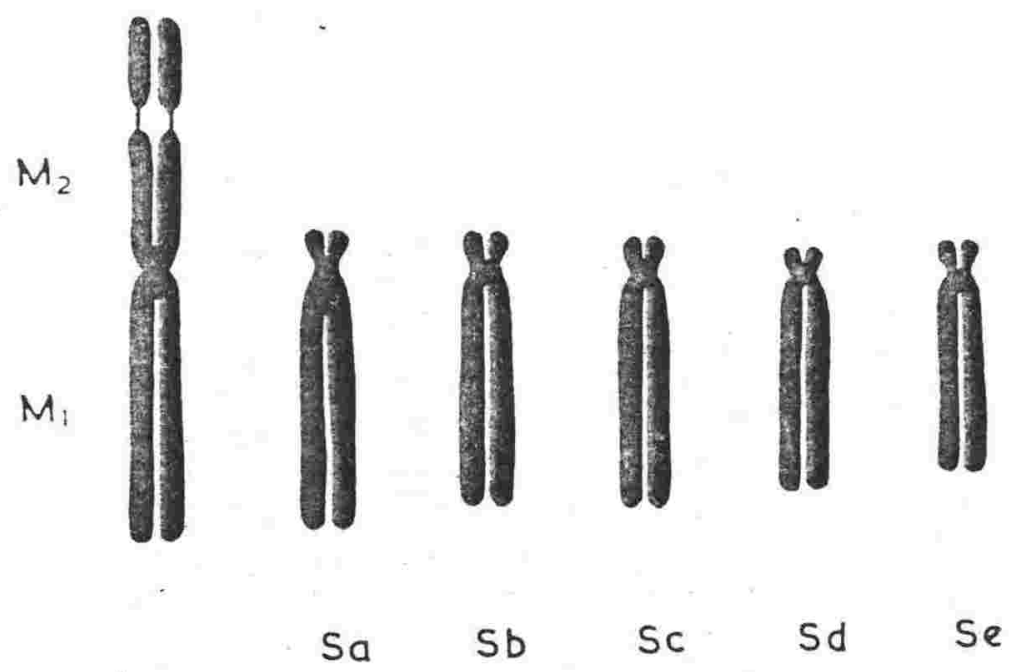

FigURE 3.-Diagrammatic representation of the haploid chromosome set of Vicia faba (Sutton's Prolific Longpod).

Fig 2 
104.

Fig. 3. Karyogram of the standard chromosome complement of Vicia faba. 

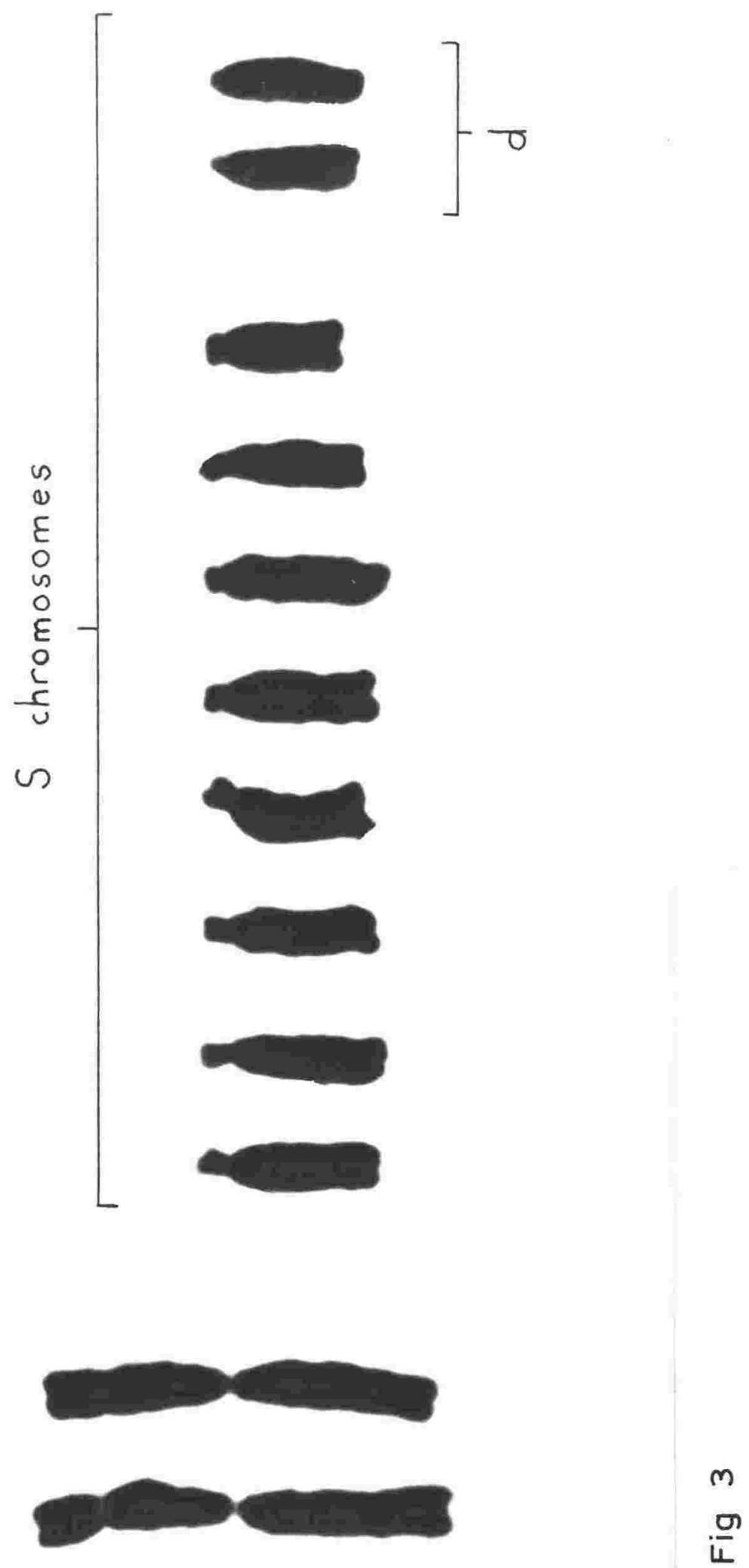

$\sum \quad \Sigma$ 
Fig. 4a. Unstained fixed root-tip squash showing uniform phase density of the chromosome lengths. (Phase contrast microscopy).

Fig. 4b. Unstained fixed root-tip squash showing phasedense regions adjacent to the centromeres and at the chromosome ends (only 10 chromosomes of a complement are present; phase contrast microscopy). 


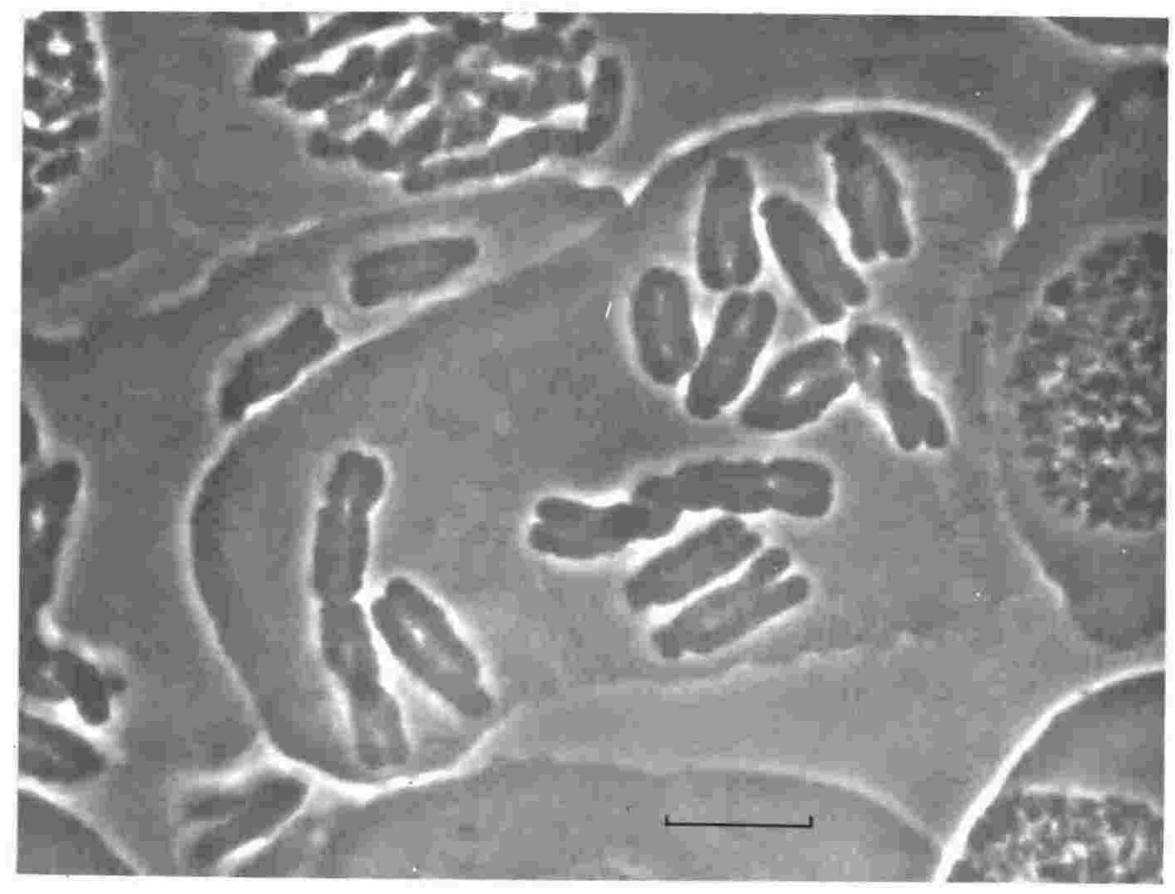

Fig $4 a$

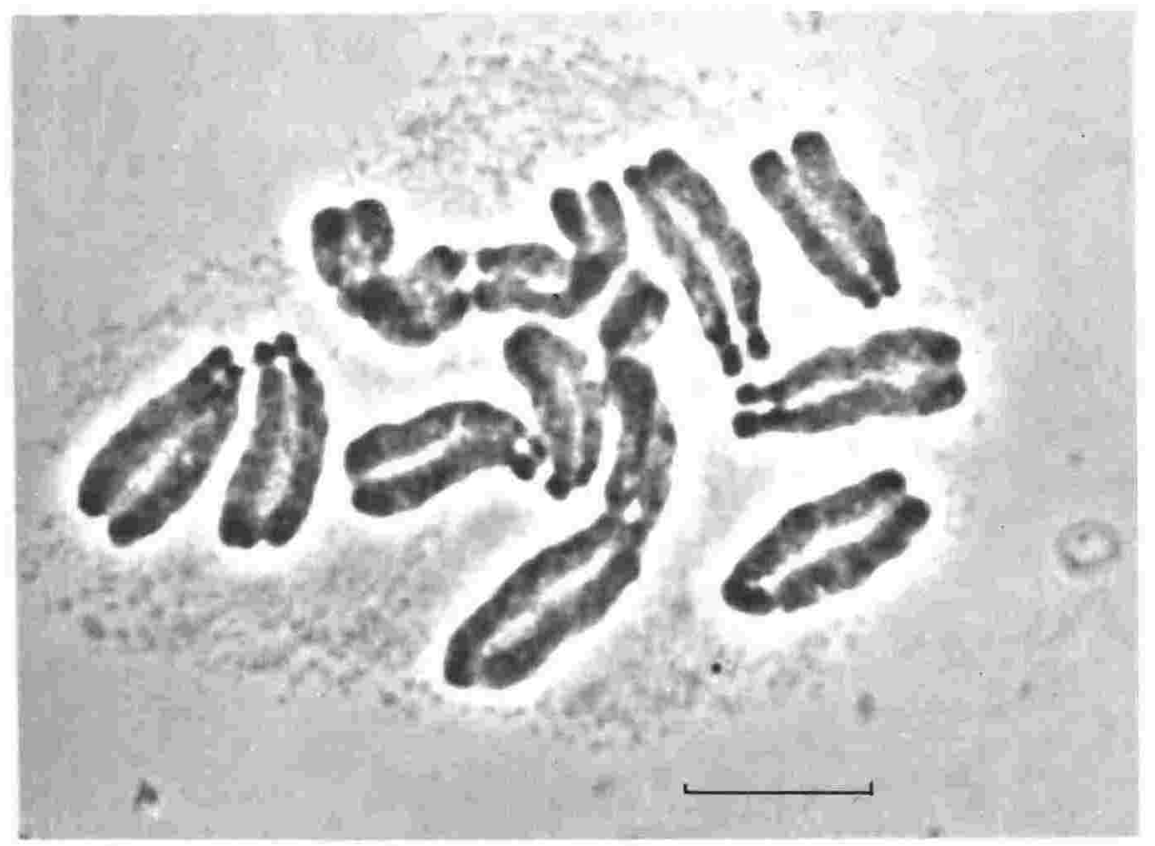

Fig $4 b$ 
Fig. 5a-e. Interphase nucleus at successive levels of focus from a series of root-tip sections showing prominent chromocenters (arrows). Note in (b) the association of a chromocenter with the nucleolus. (Haematoxylin stain).

Fig. 6a, b. Interphase nucleus as in Fig. 5 showing prominent chromocenters (arrows). 


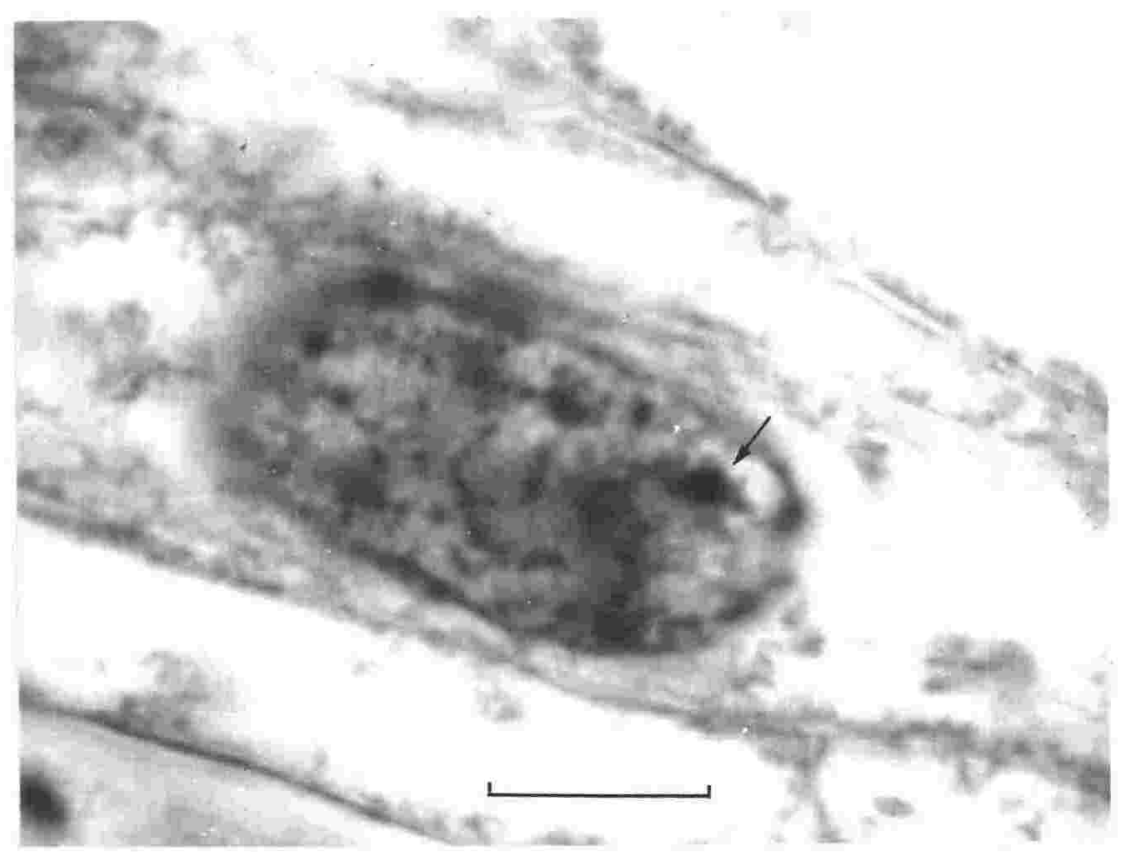

Fig $5 a$

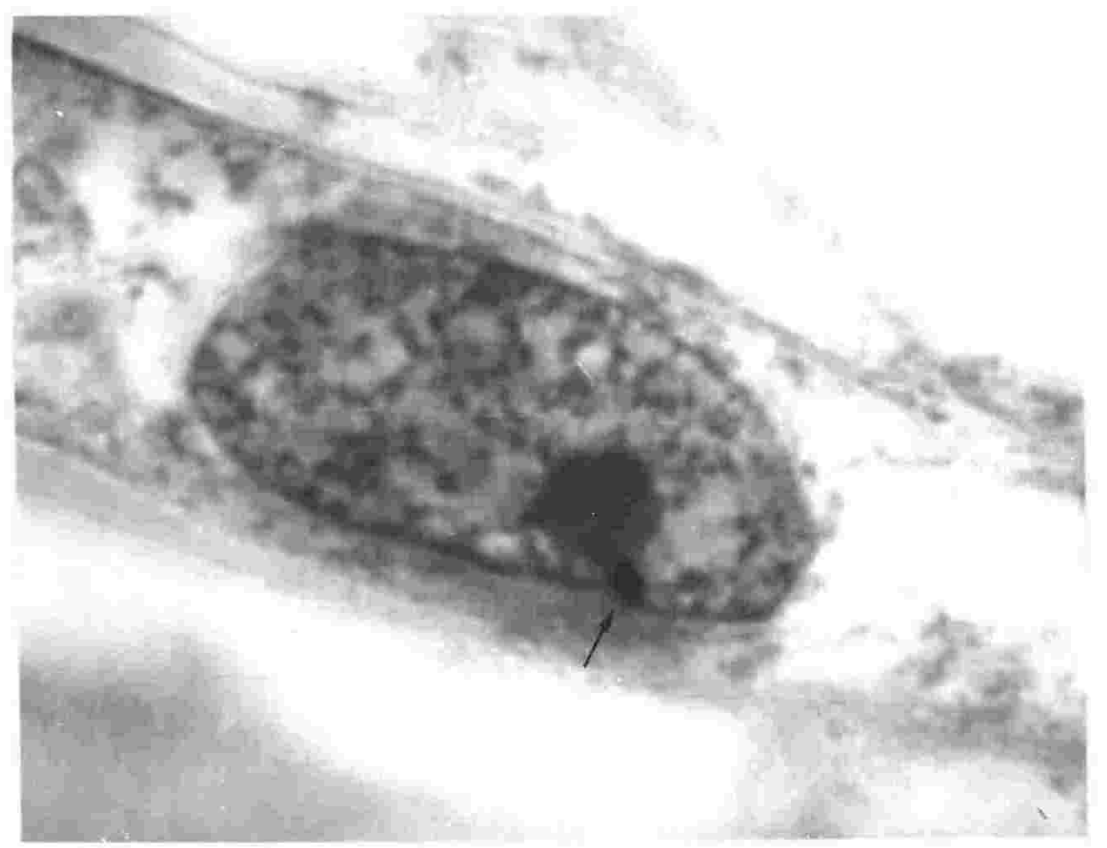

Fig $5 b$

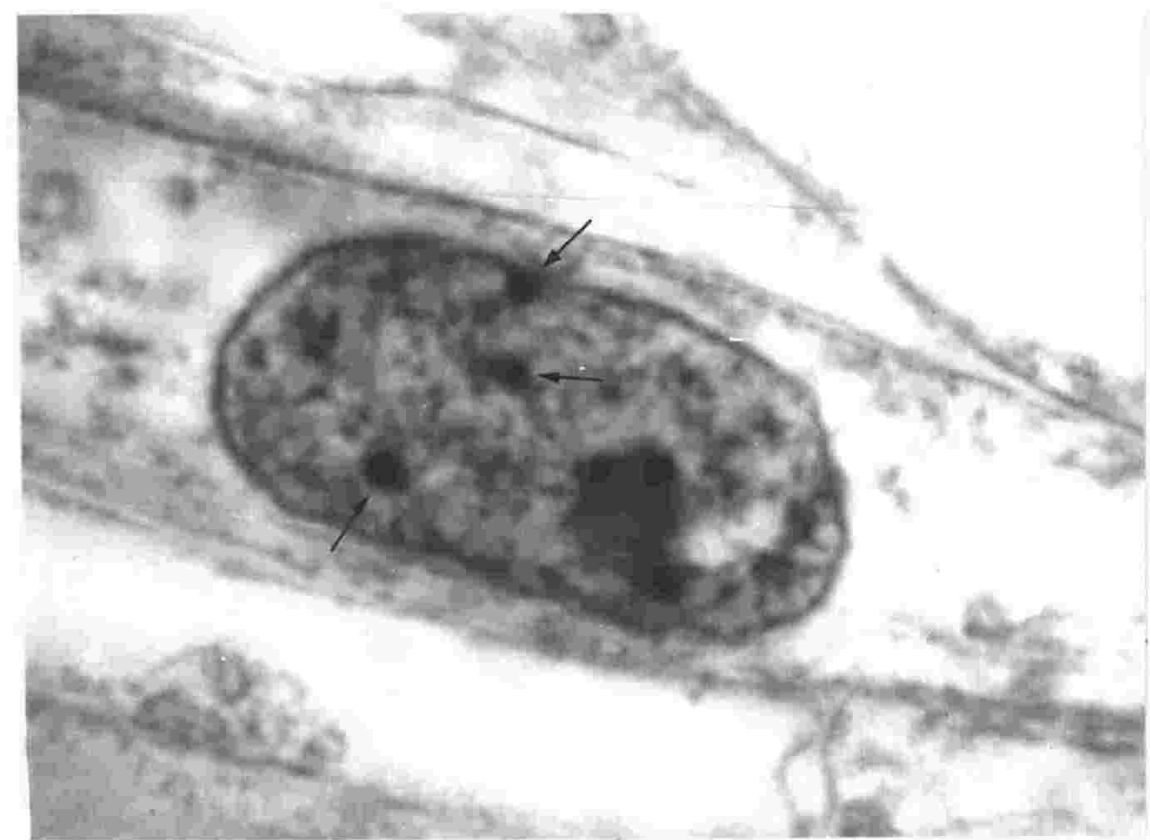

Fig $5 c$ 


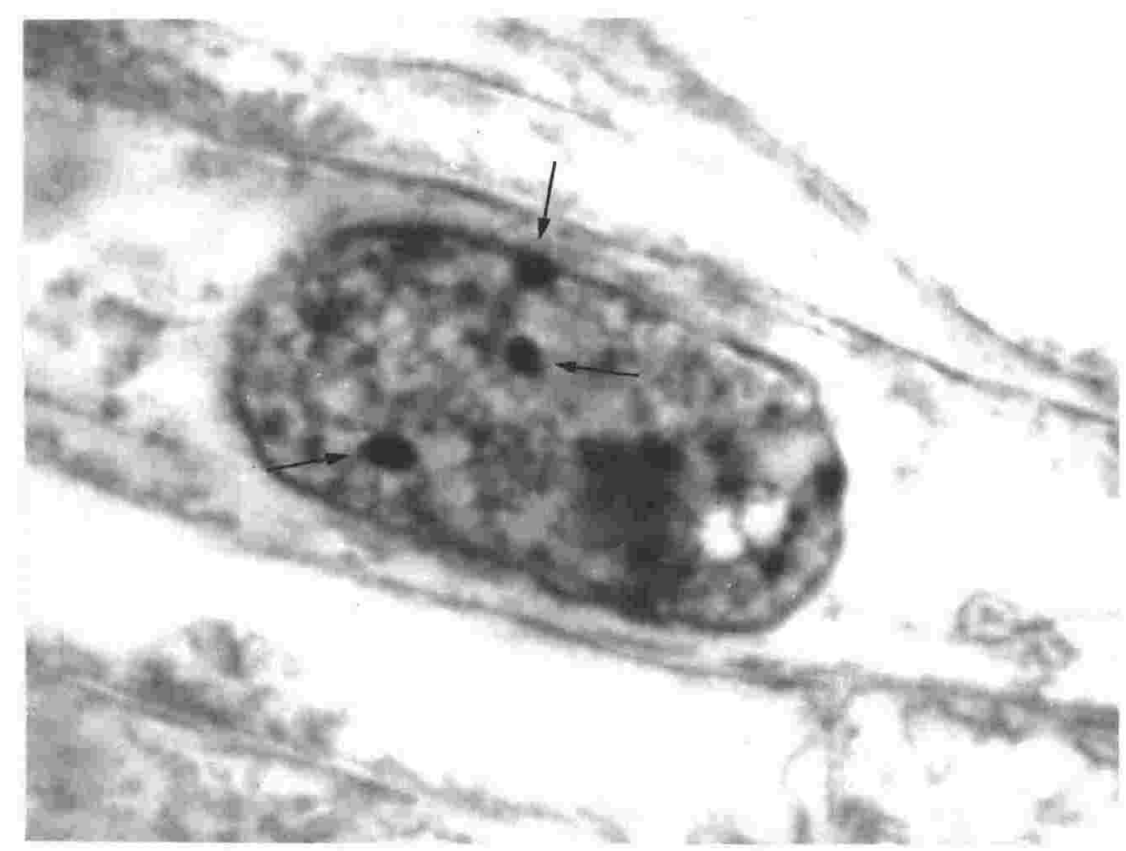

Fig $5 d$

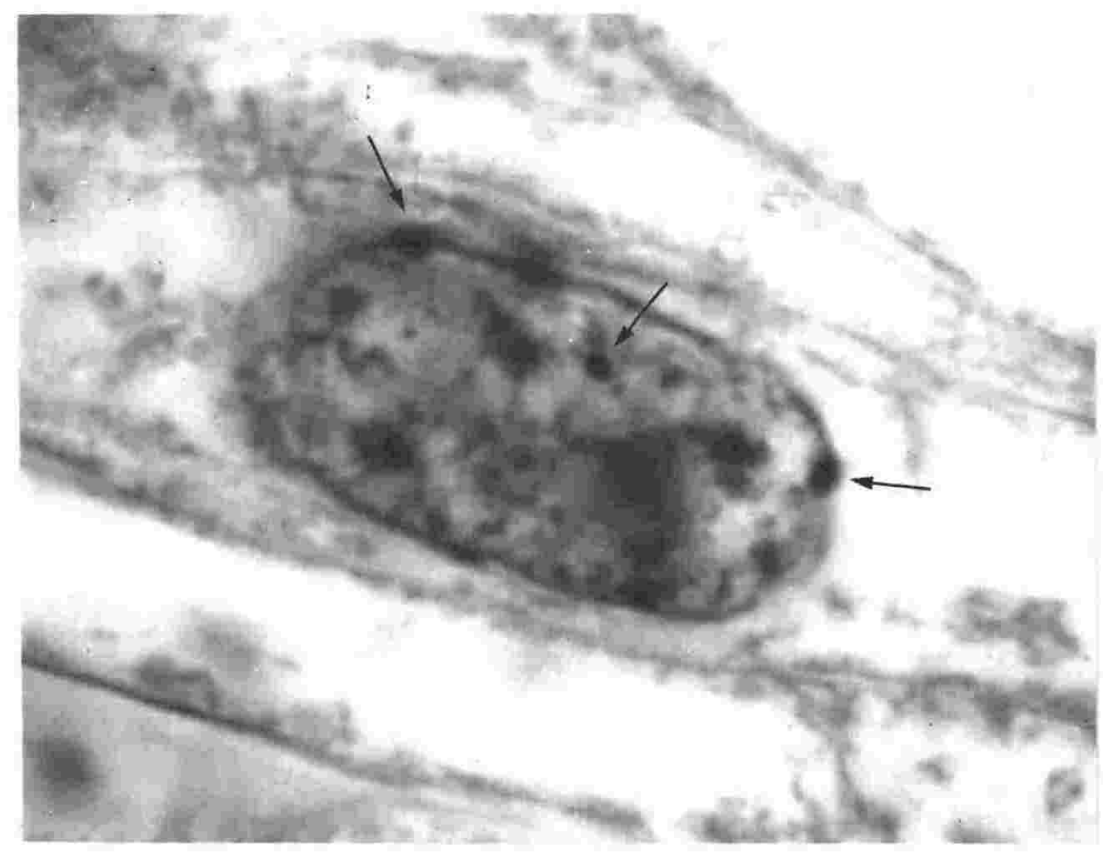

Fig $5 e$ 


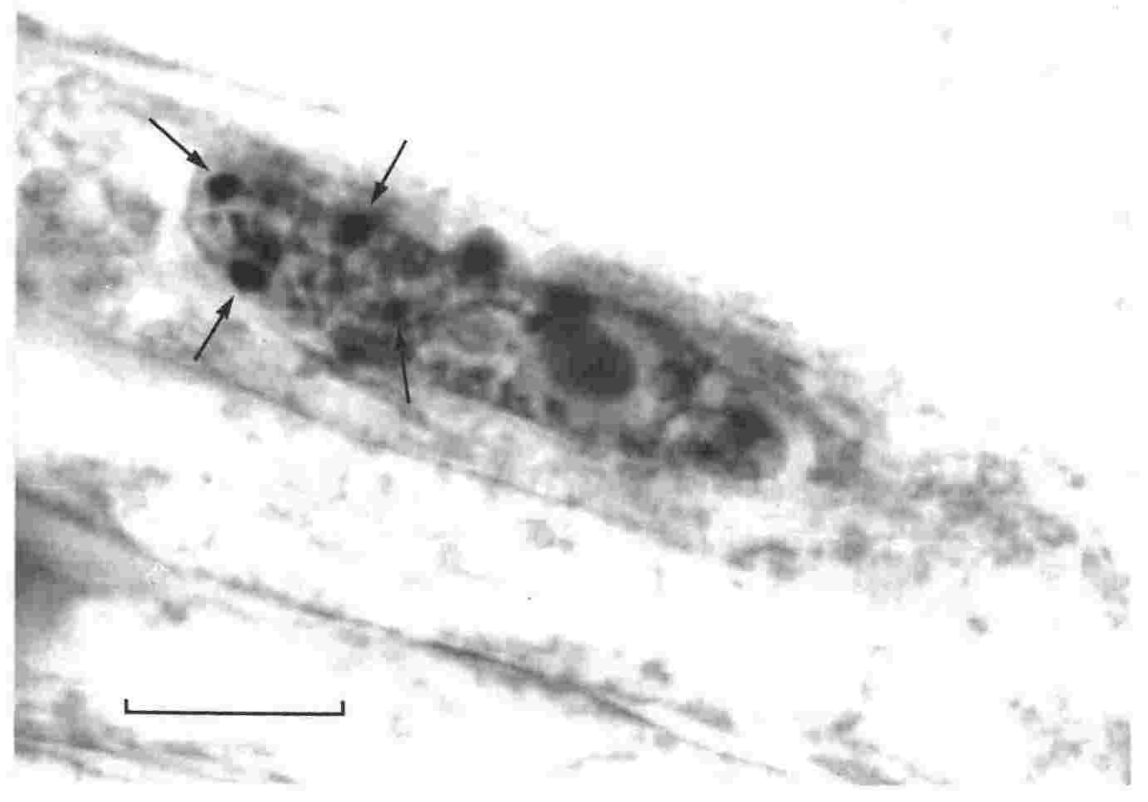

Fig $6 a$

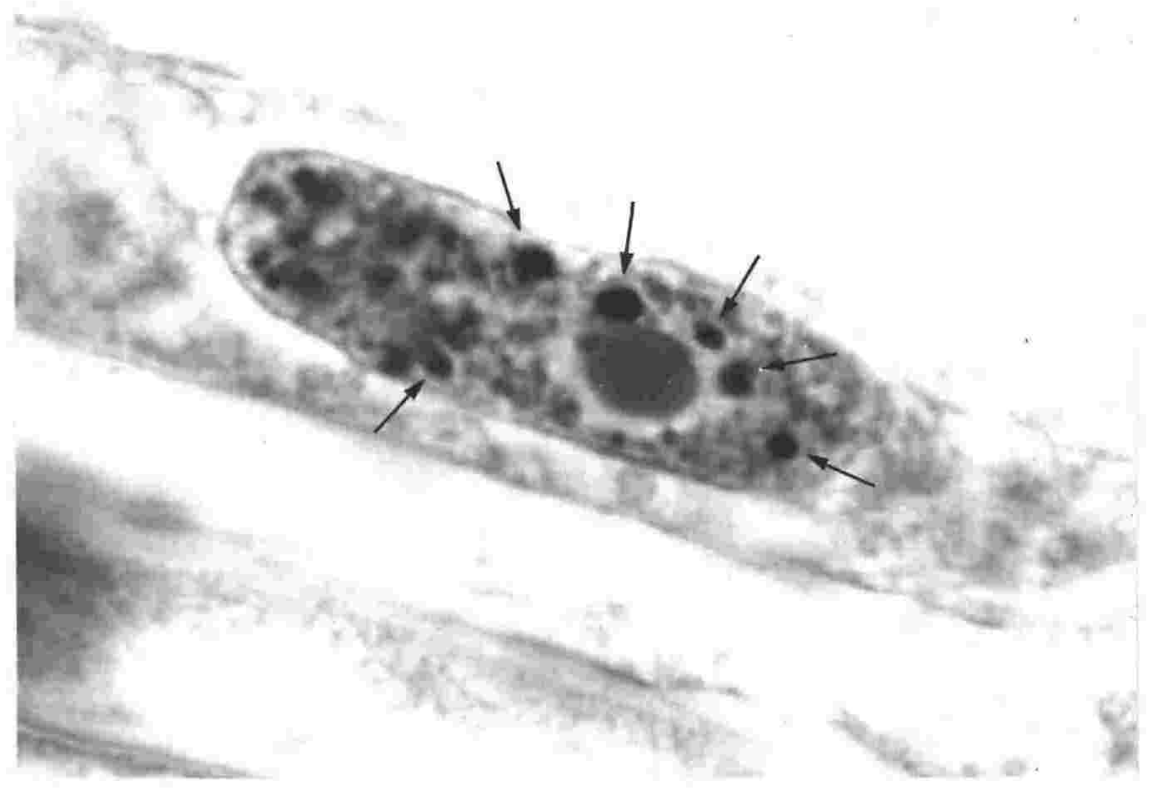

Fig $6 b$ 
Fig. 7. Range in number of chromocenters $\$ 0.5 \mu \mathrm{m}$ in diameter in interphase nuclei of Vicia faba root-tip sections.

(a) meristematic tissue.

(b) differentiated tissue. 
Fig 7

(a)

mean (no. of chromocenters) $=8.52$

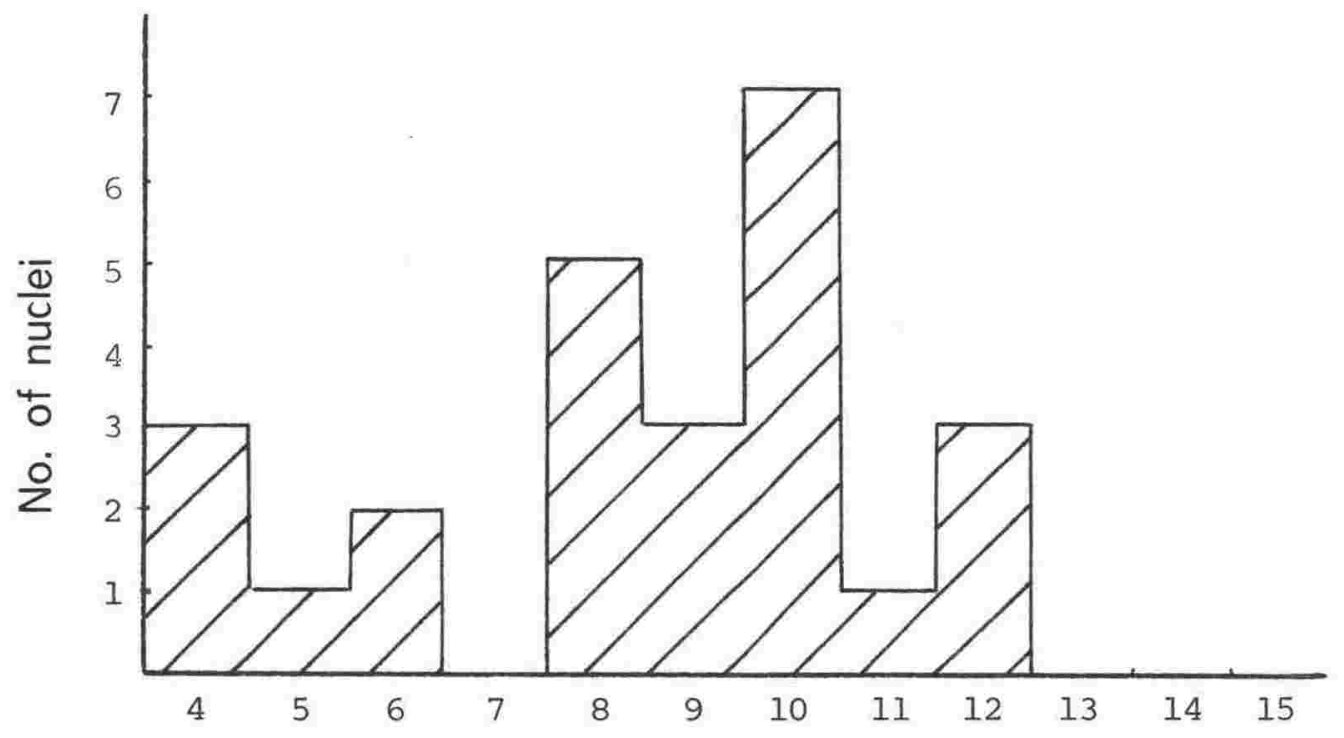

No. of chromocenters $>0.5 \mu \mathrm{m}$ diam/interphase nucleus.

(b)

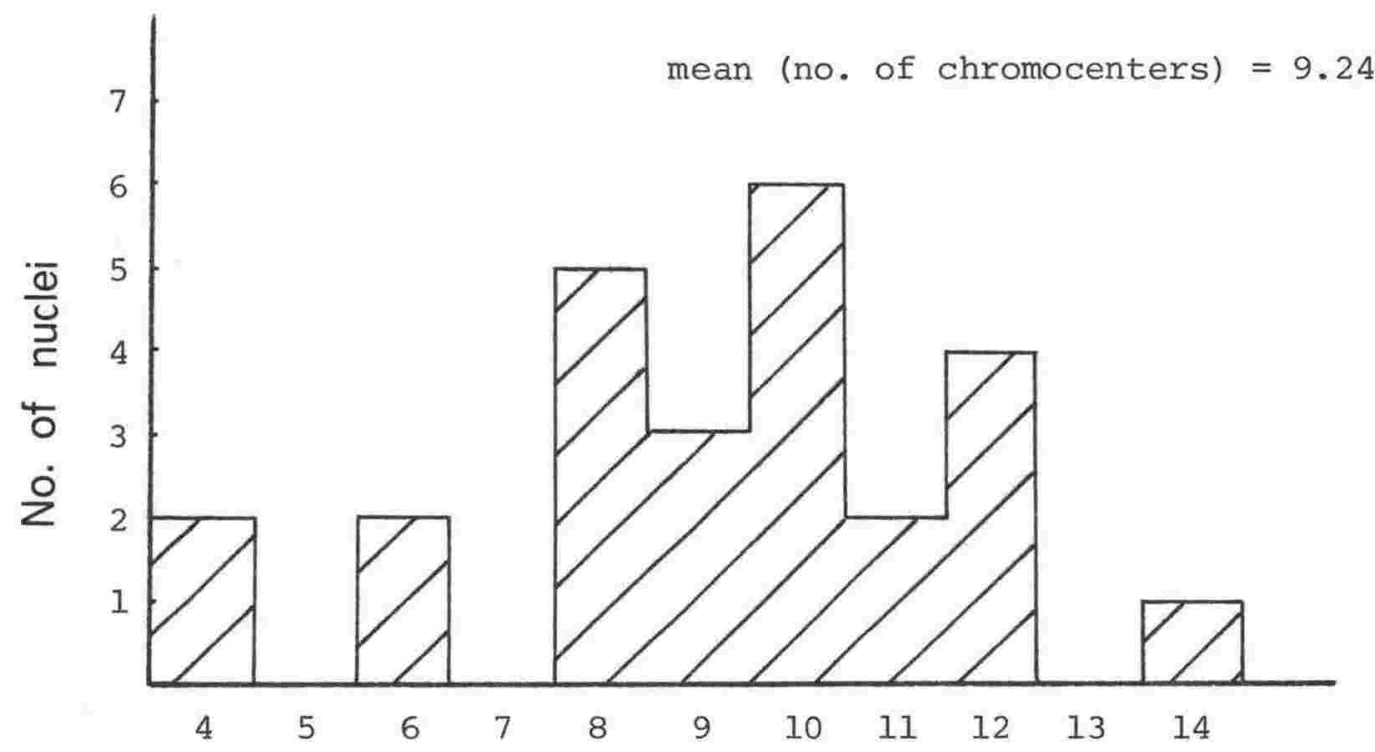

No. of chromocenters $>0.5 \mu \mathrm{m}$ diam/interphase nucleus. 
Figs. 8-14. Cold-treated, Feulgen-stained Squashes

Fig. 8. Achromatic bands ( $M I / I$ and $M 2 / 1)$, one on either side of each centromere (c). Dotted lines attach each satellite to the appropriate M2 arm.

Fig. 9. Non-colchicine anaphase stage showing an M centromere (c) directed towards the pole with the achromatic bands (arrows) on the trailing chromosome arms. 
gestix
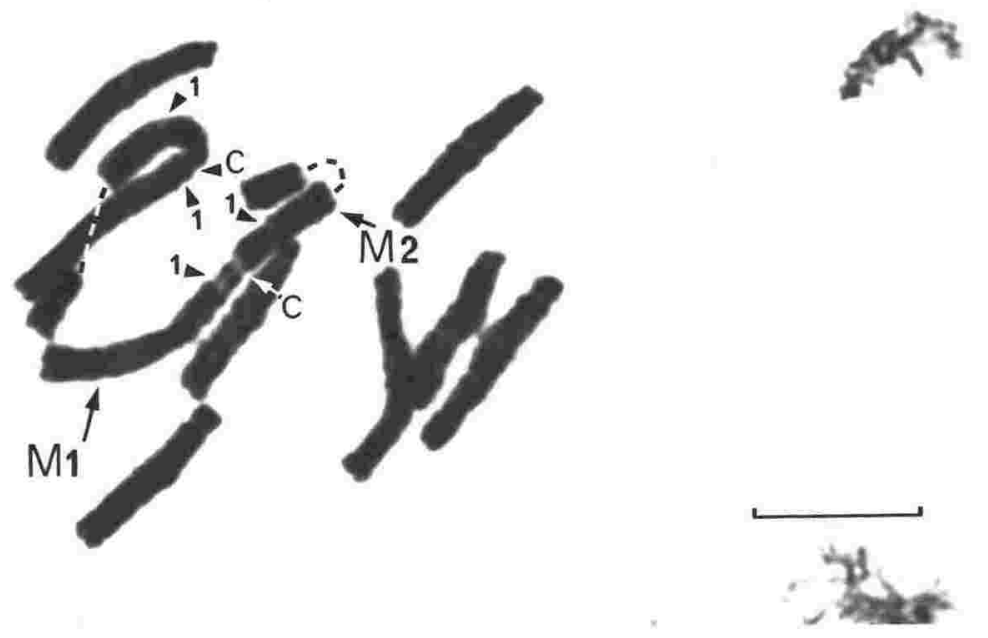

Fig 8
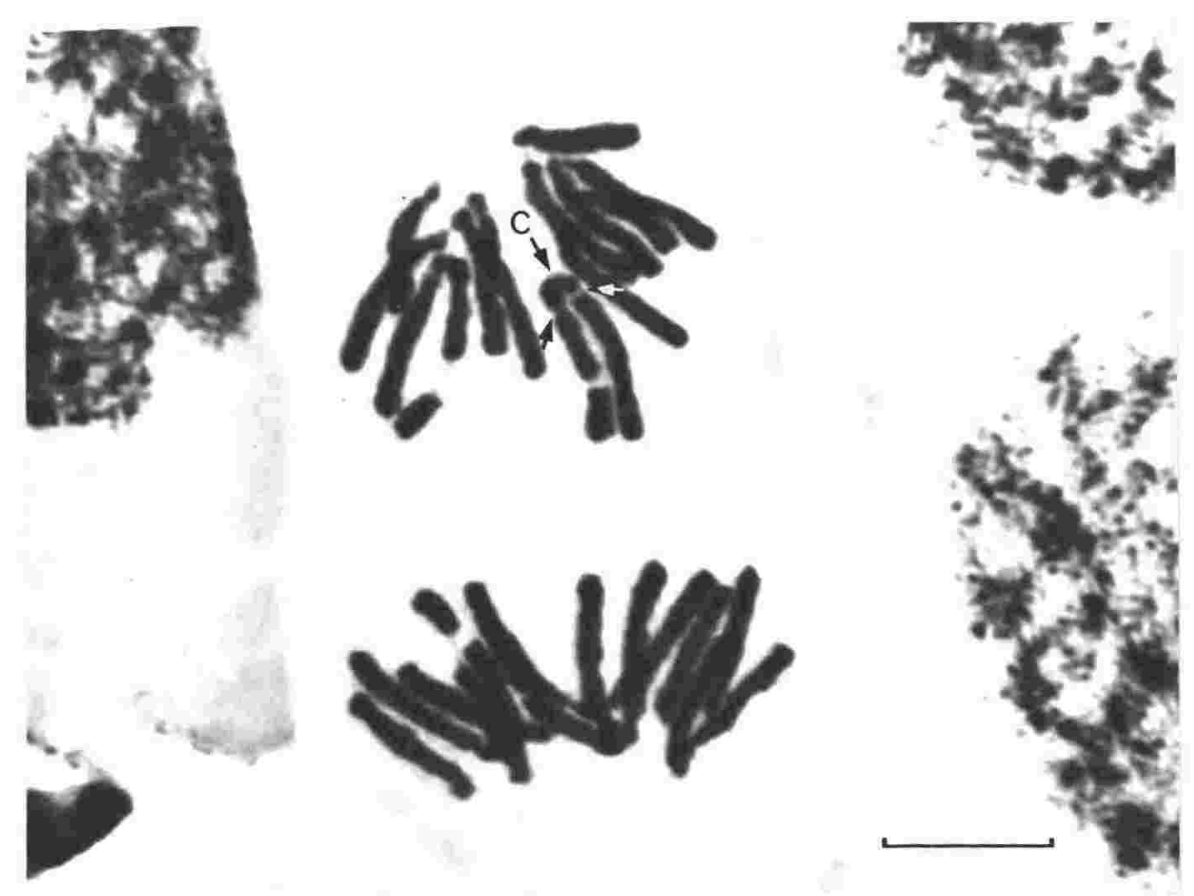

Fig 9 
Cold-treated, Feulgen-stained Squashes (cont.)

Figs. 10 and 11. Less contracted complements with many achromatic regions along the chromosome arms. Identifiable bands are arrowed in Fig. 10.

Satellites attached as in Fig. 8. 


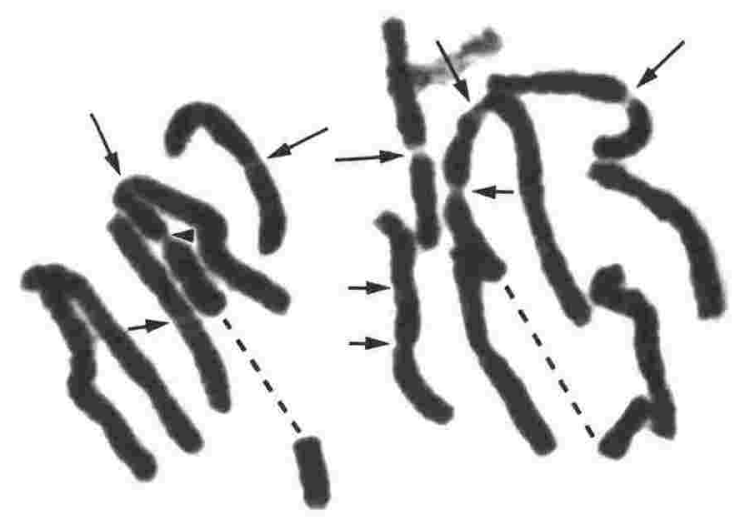

Fig 10

Sulaty
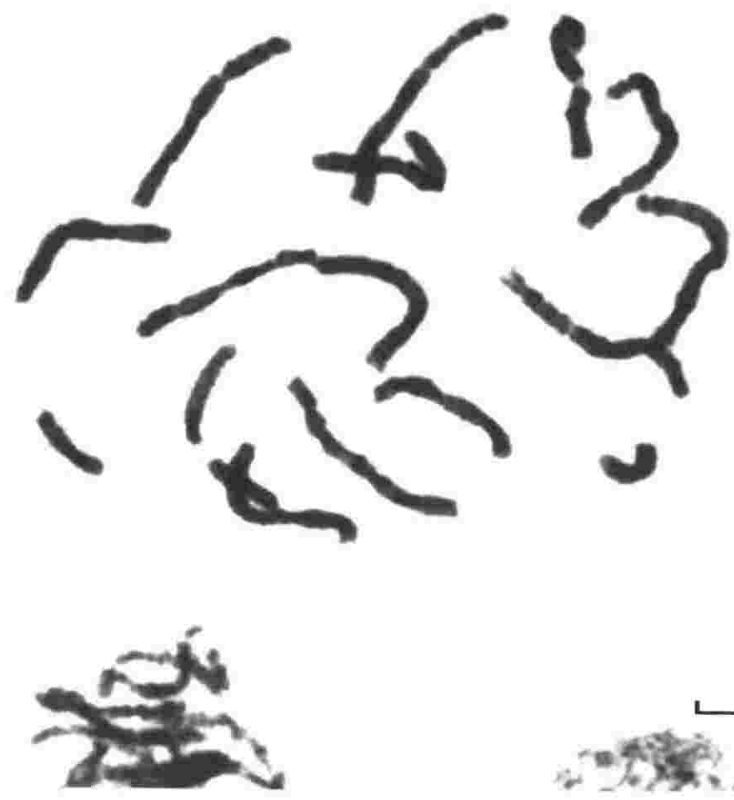

Fig 11 


\section{Cold-treated, Feulgen-stained Squashes (cont.)}

Fig. 12. Well contracted complement with prominent single mid-bands (arrows) on some $\mathrm{S}$ chromosomes; note swellings (arrowheads in three examples).

Fig. 13. Illustrates achromatic bands on the short arm of two $\mathrm{S}$ chromosomes (arrows). 


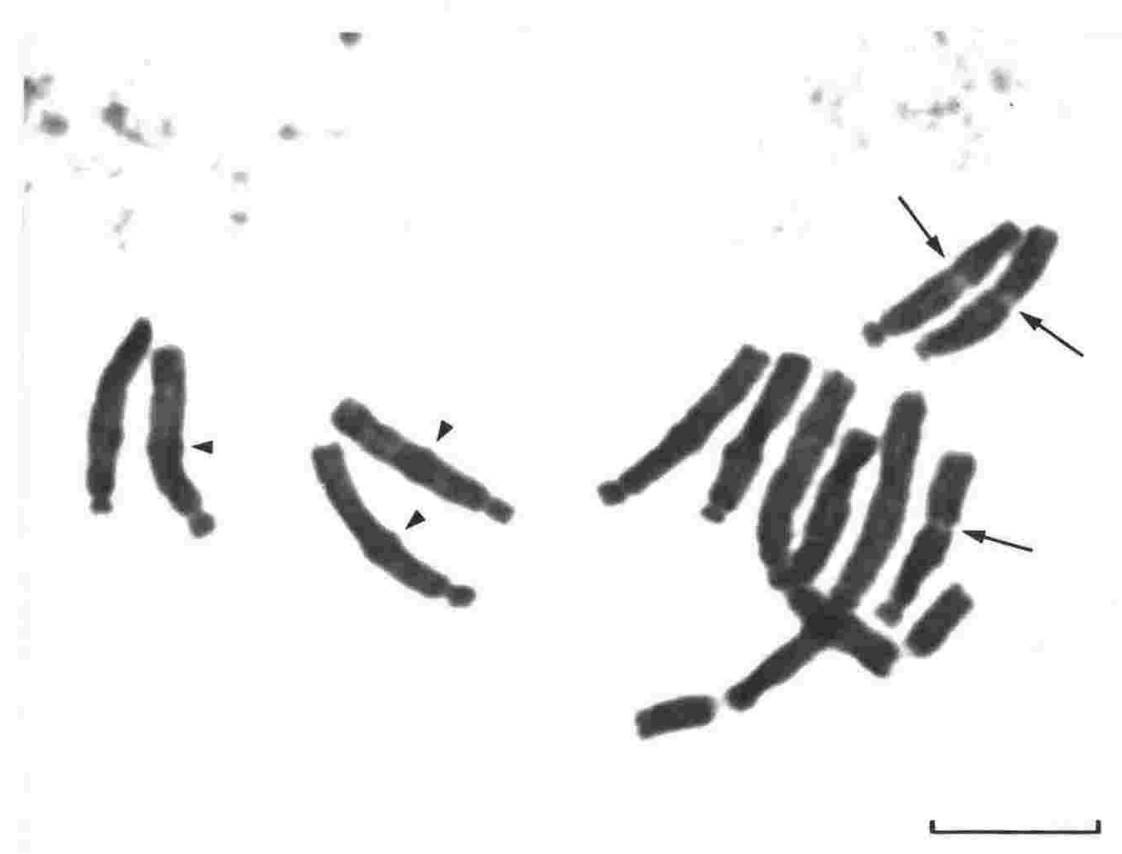

Fig 12

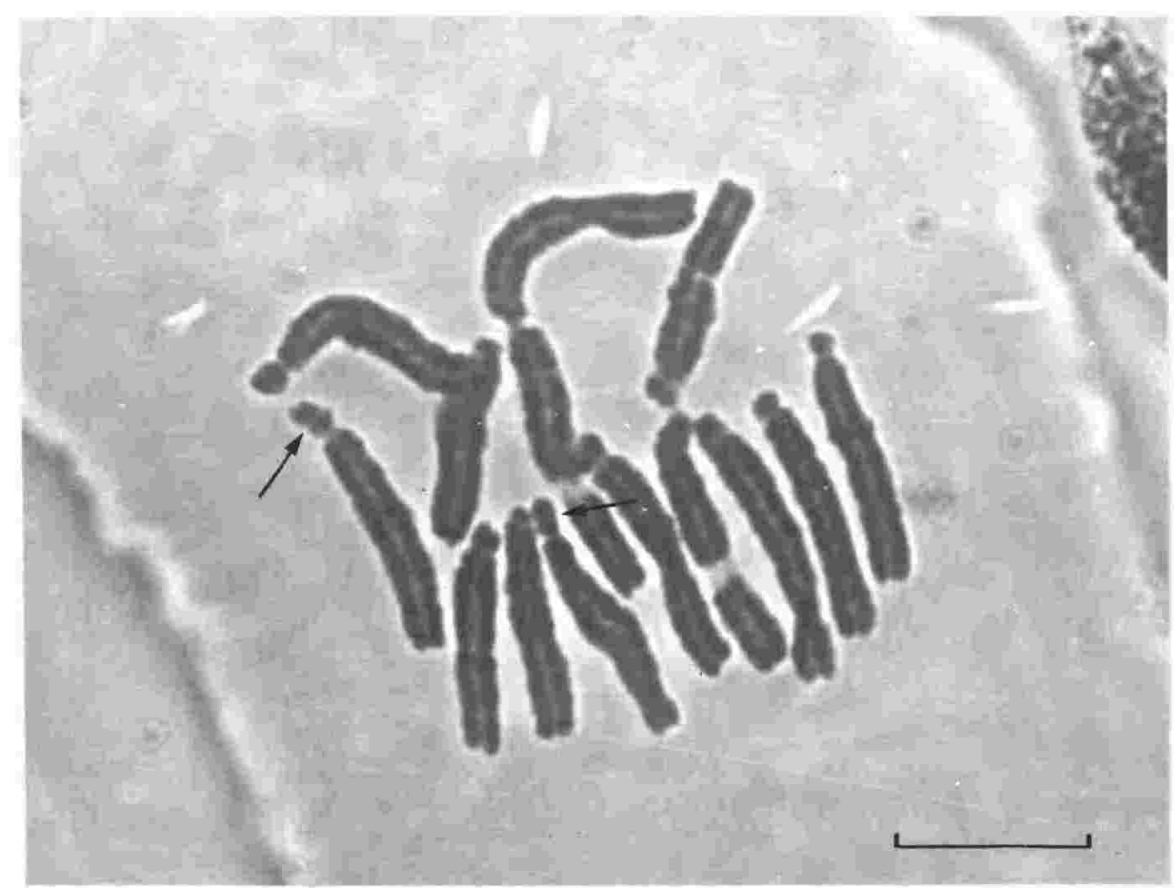

Fig 13 
Cold-treated, Feulgen-stained Squashes (cont.)

Fig. 14a, b. Unstained, cold-treated and fixed squashes showing phase-lucent bands.

(a) Note a single band on either side of each $\mathrm{M}$ centromere $(=\mathrm{c})$.

(b) Identifiable bands are arrowed. ( $s$ = satellite; phase contrast microscopy). 


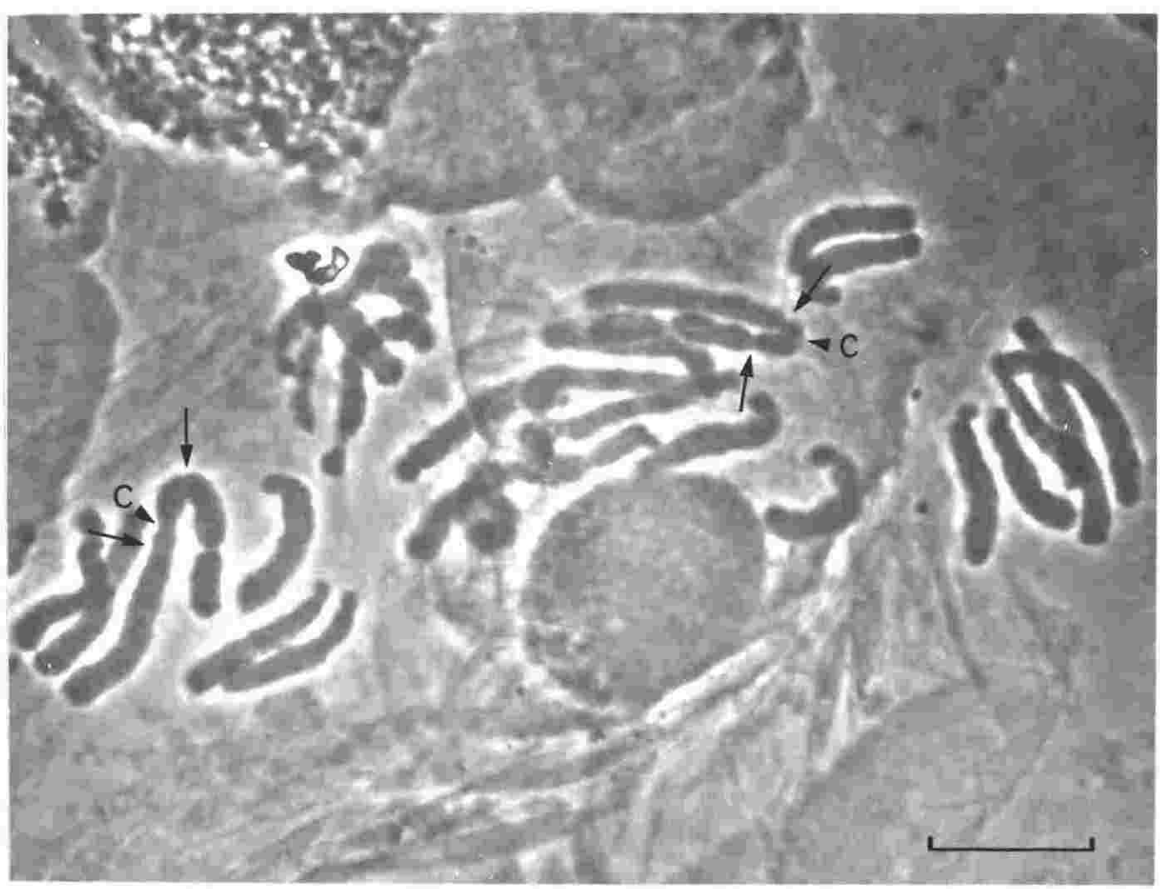

Fig 14a

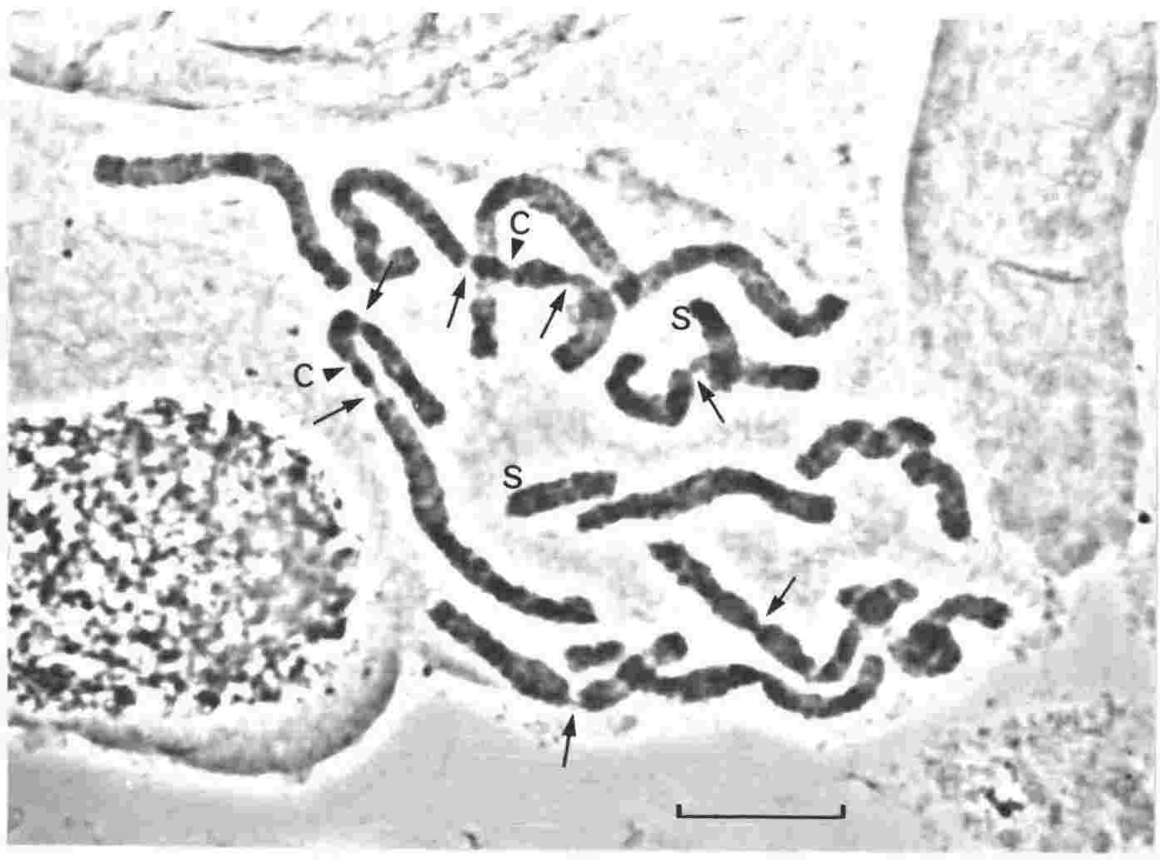

Fig $14 b$ 
Fig. 15a-d. Reproductions of illustrations showing the distribution of cold-induced bands by
(a) Grant and Heslot (1966)
(b) Evans and Bigger (1961)
(c) McLeish (1953)
(d) Ia Cour (1951) 


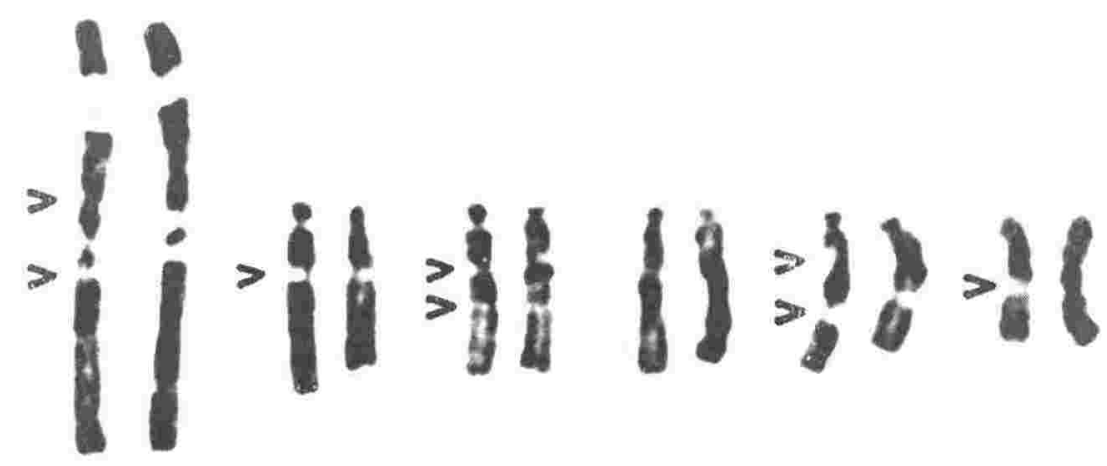

Fig 15a

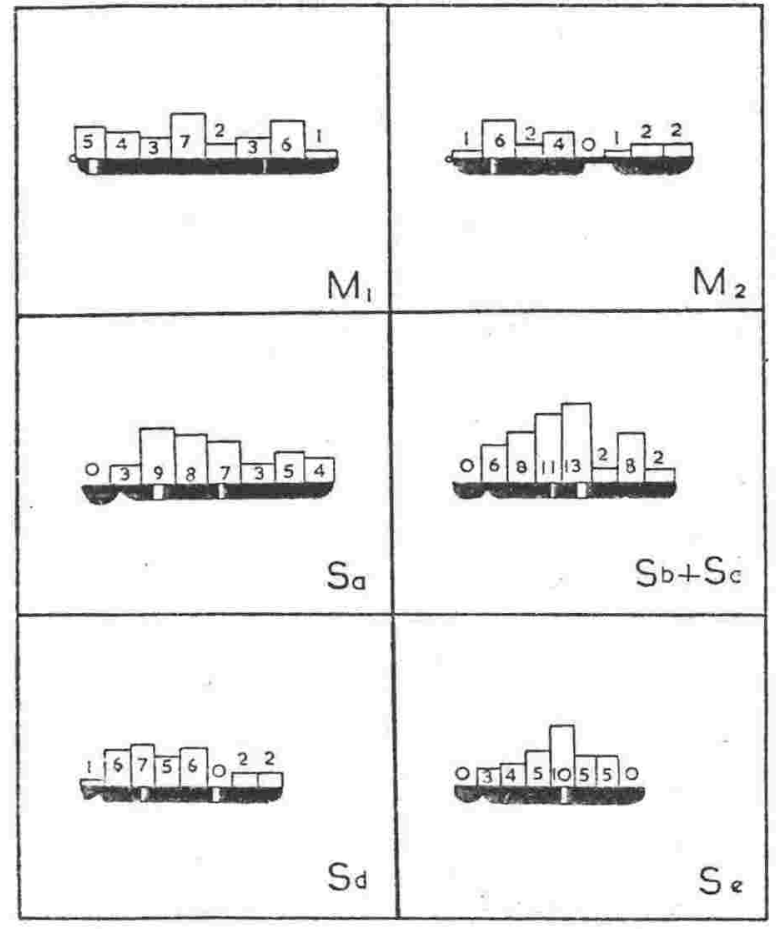

Figtre 3.-Frequency distribution of 100 interchanges in tetraploid cells. The positions of hetarochromatic regions are indicated by the white regions on the chromosomes.

Fig $15 b$ 


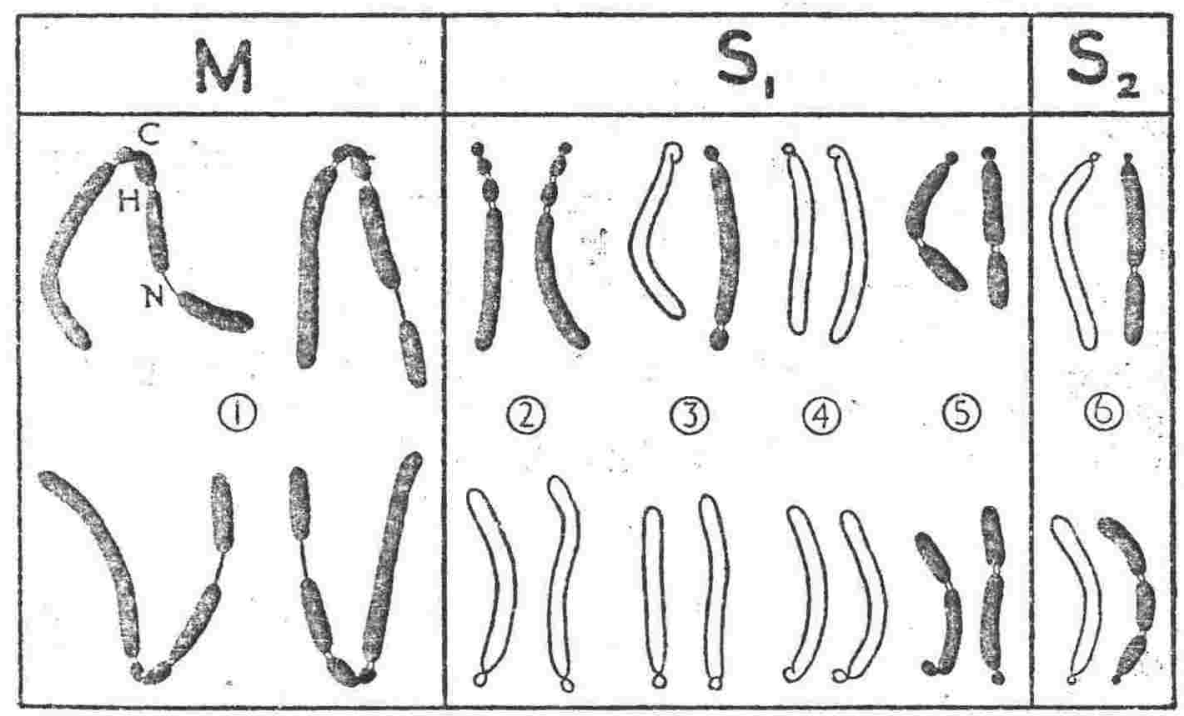

F19. 1.- Araphase chromatids from a root-tip cell of Vicia faba after 4 days at $7^{\circ} \mathrm{C}$. $\mathrm{C}=$ centromere ; $\mathrm{H}=$ heterochromatin; $\mathrm{N}=$ nucleolar organiser. Chromosome pairs of $\mathrm{MI}, \mathrm{S}_{1}$ and $\mathrm{S}_{2}$ types numbered I-6. Starvation is irregular and outline chromosomes fail to show it. All figures $\times 2200$.

Fig $15 c$

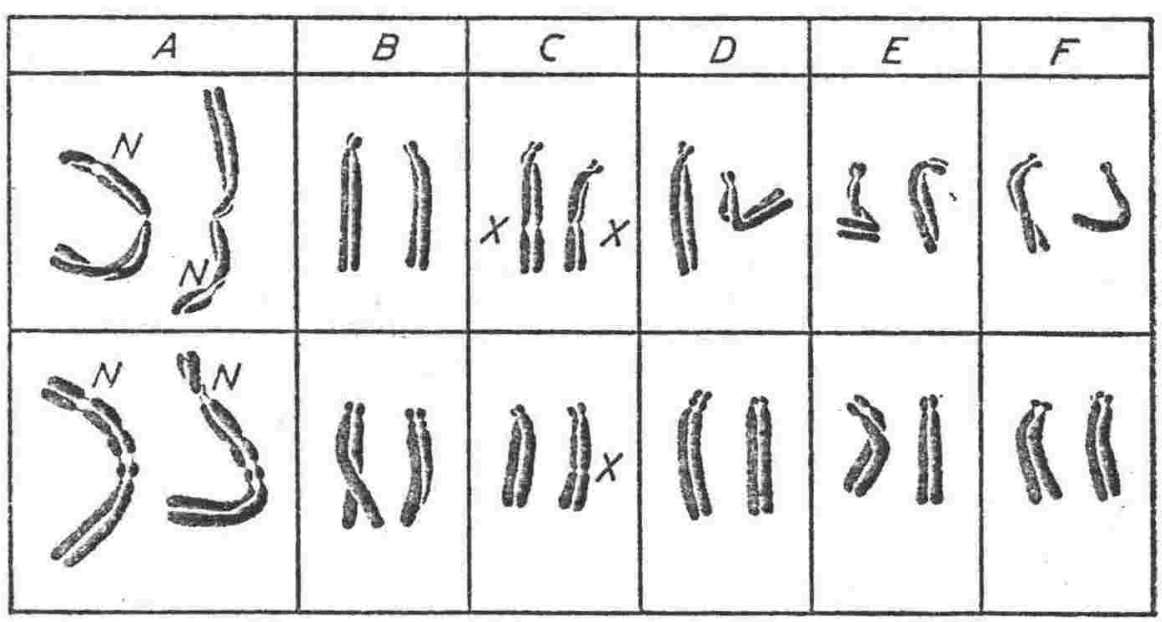

FI3. 4.--Vicia faba, above after normal temperature, below with heterochromatin as revealed by cold. There is difficulty in interpreting differences within pairs because of similarity in the types B-F. $\times 1370$.

Fig $15 d$ 
Figs. 16-18. Acid-treated, Feulgen-stained Squashes

Figs. 16 and 17. Three achromatic bands (M/1/, M2/1 and $\mathrm{M} 2 / 2$ ) neighbour the $\mathrm{M}$ centromere, clear on one $\mathrm{M}$ chromosome in each Fig. (Treatment $4(a)$ in methods, p. 17).

Fig. 18. Prolonged maceration squash showing band $\mathrm{Ml} / 1$, a band on the M2 arm of the homologue and bands on the short arm of two s chromosomes. 

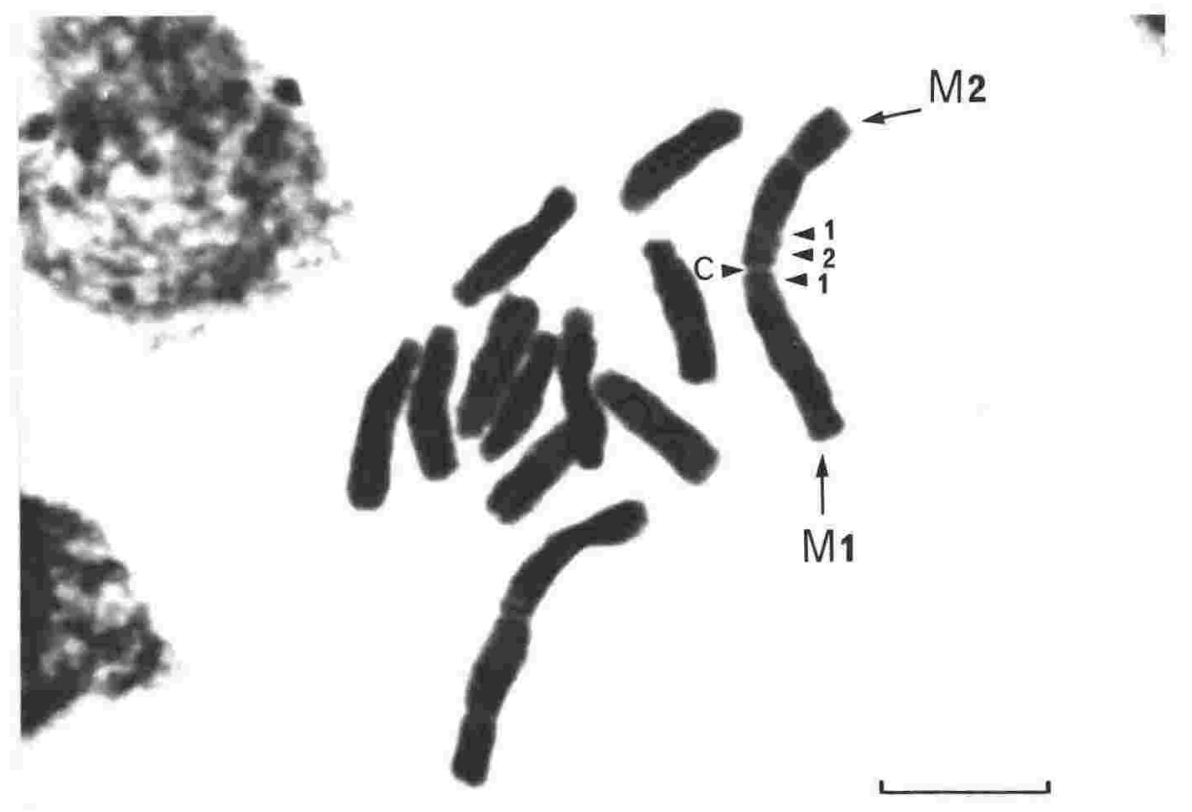

Fig 16

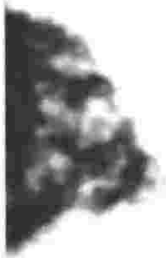

M1

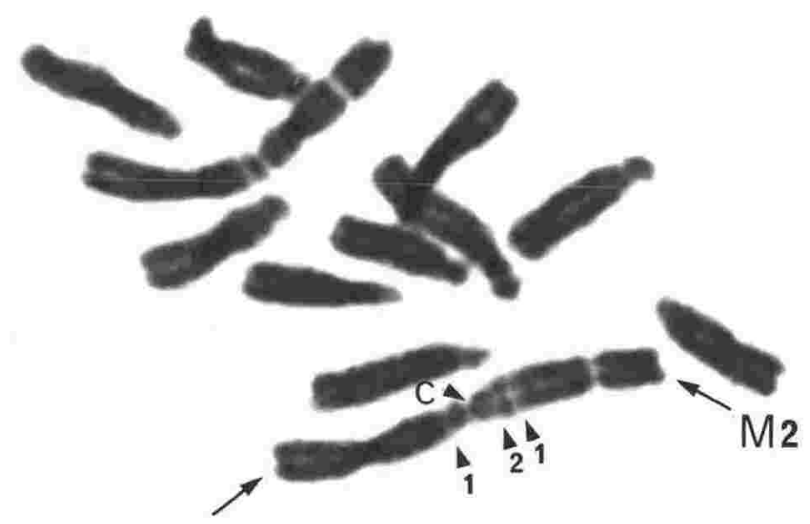

M1
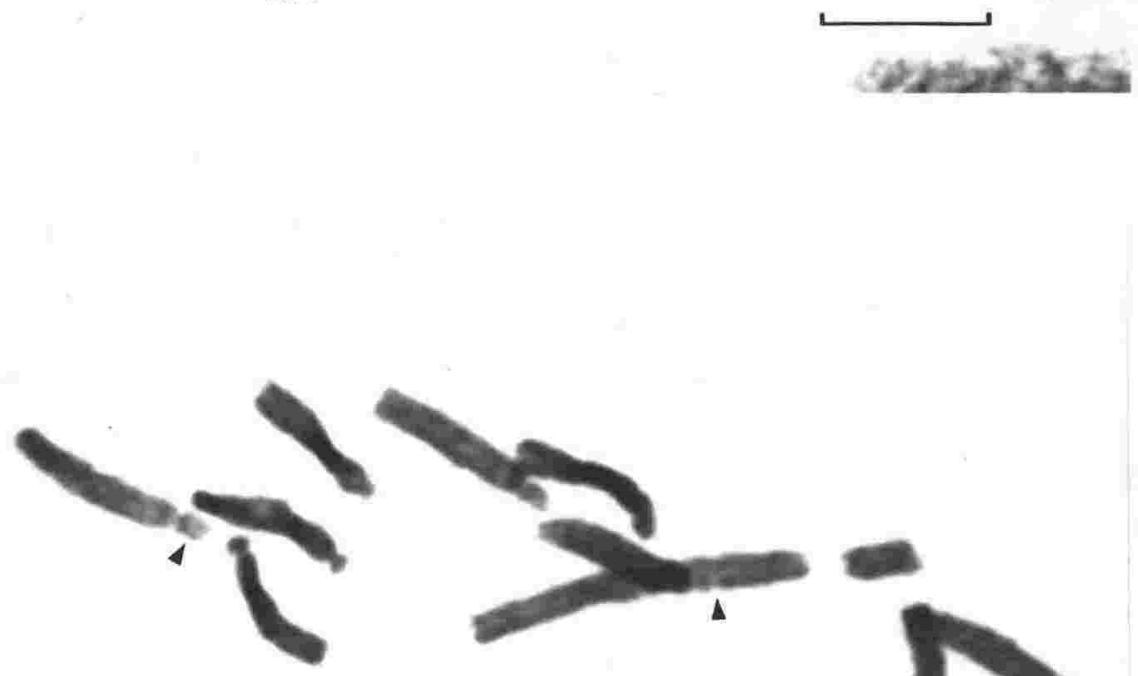

단

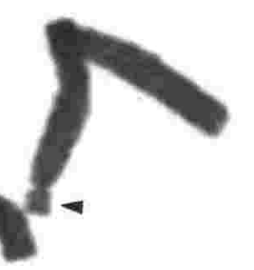

Fig 18

Fig 17

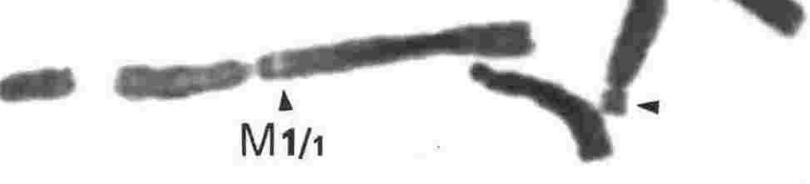


Figs. 19-21. Quinacrine Mustard Fluorescent Squashes.

Fig. 19. Three bands (MI/I, M2/I and M2/2) neighbour the centromere on each M chromosome. (Fluorescence microscopy).

Figs. 20 and 21 each show a third M2 band (M2/3) on the chromatids of one M chromosome. (Fluorescence micros copy).

One $\mathrm{S}$ chromosome is missing in each of Figs. 19 and 20. 


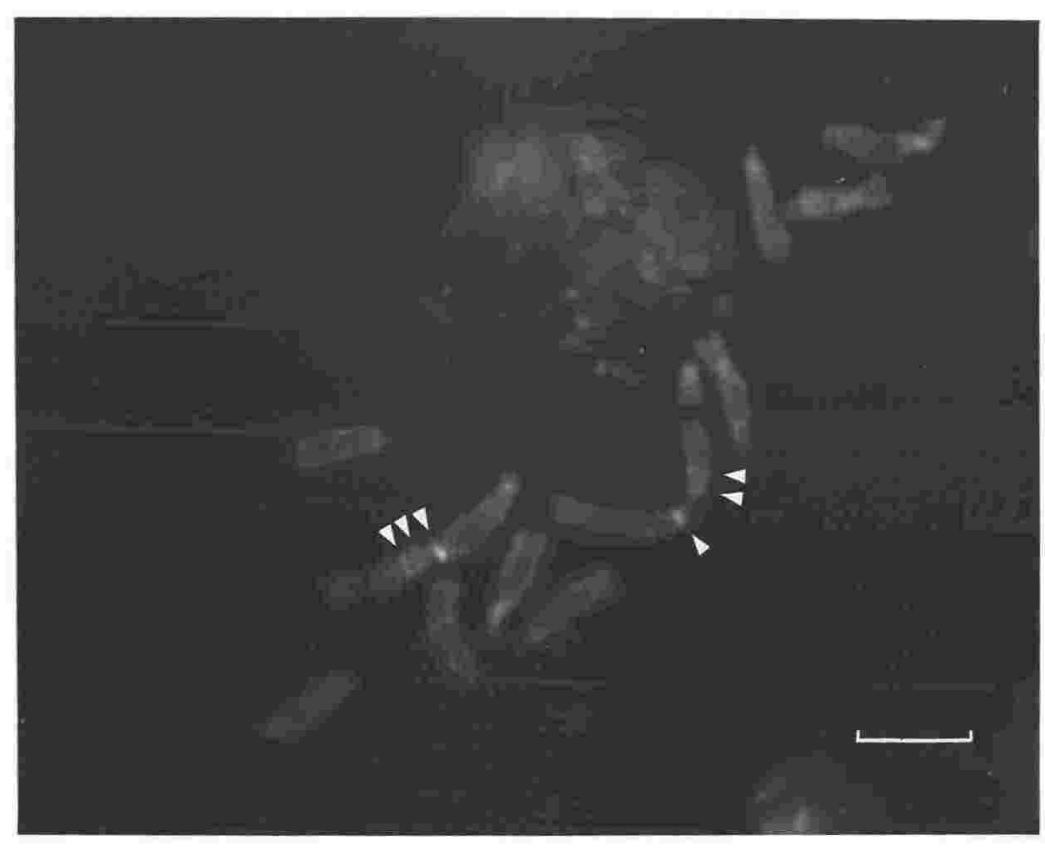

Fig 19

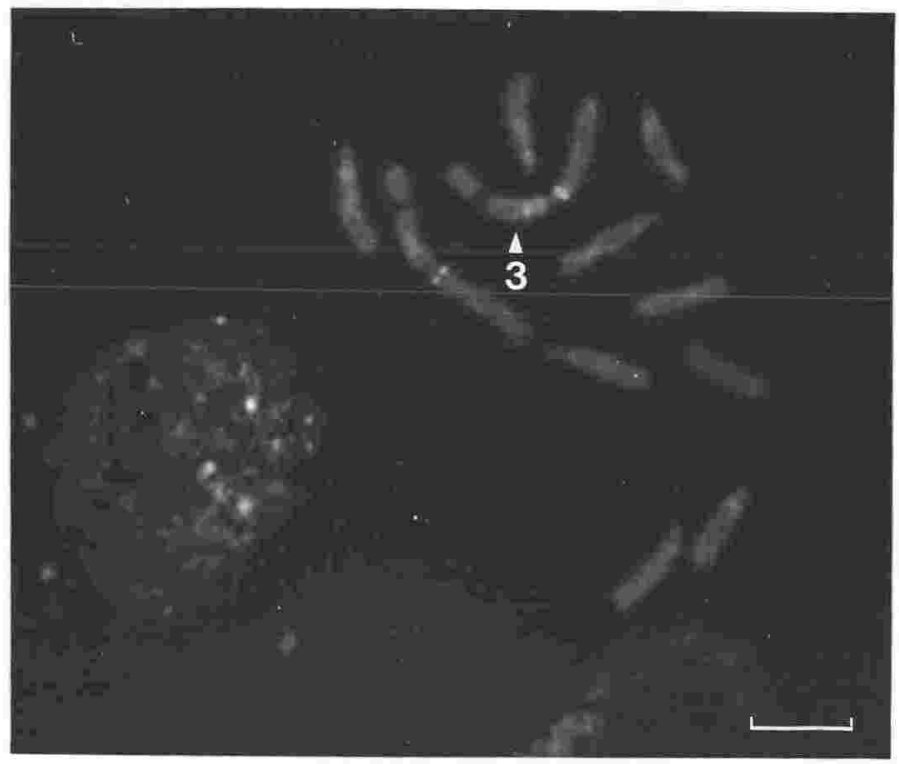

Fig 20

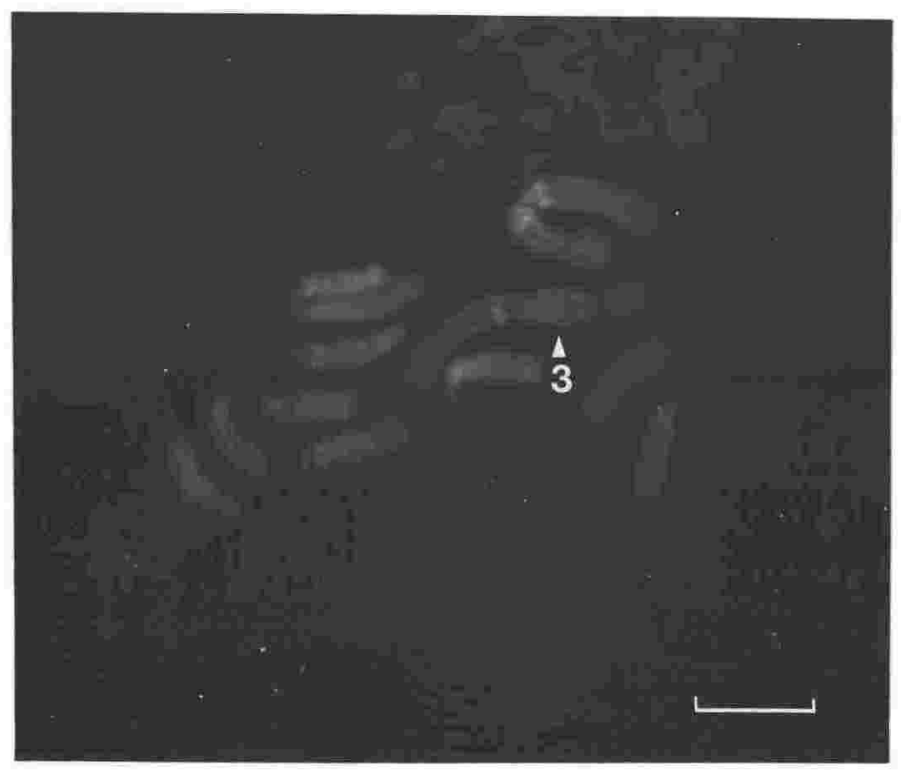

Fig 21 
Figs. 22-29. SSC-Giemsa Banded Squashes.

Fig. 22. Characteristic banding pattern of $V$. faba genome. $\quad \mathrm{sc}=$ secondary constriction.

Fig. 23. Karyogram and idiogram of Fig. 22.

Fig. 24. Giemsa-banded squash also showing differentially-stained M centromeres.

Fig. 25. Interphase nuclei.

Figs. 26a, 27a, 28a and 29a. Unstained ssc-treated squashes. C-dots on chromatids in $26 \mathrm{a}$ and $27 a$ but not obvious in $28 a$ and $29 a$. Phase-lucent cross-bands (arrows) in 28a and 29a. (Phase contrast microscopy).

Figs. 26b, 27b, 28b and 29b. Giemsa-stained complements of $26 a-29 a$. Giemsa bands arrowed in $28 \mathrm{~b}$ and $29 \mathrm{~b}$ coincide with arrowed phase-lucent bands. 


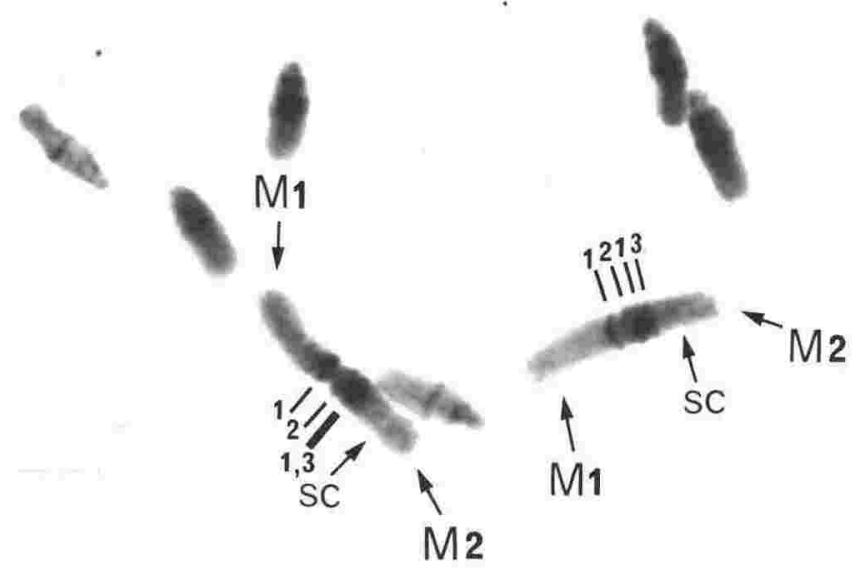

Fig 22

Fig 24

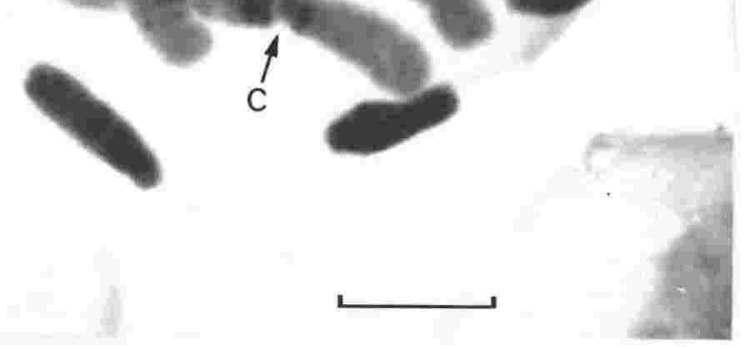

Fig 25

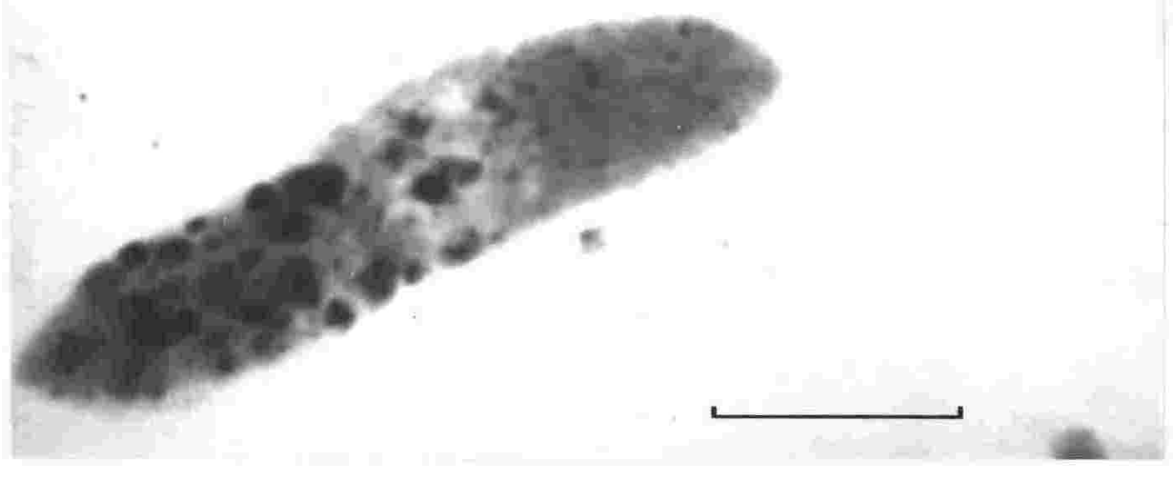


प्IIII

Qप्II

पाII

प्III

$\stackrel{M}{N}$

$\square \square$ - 운 


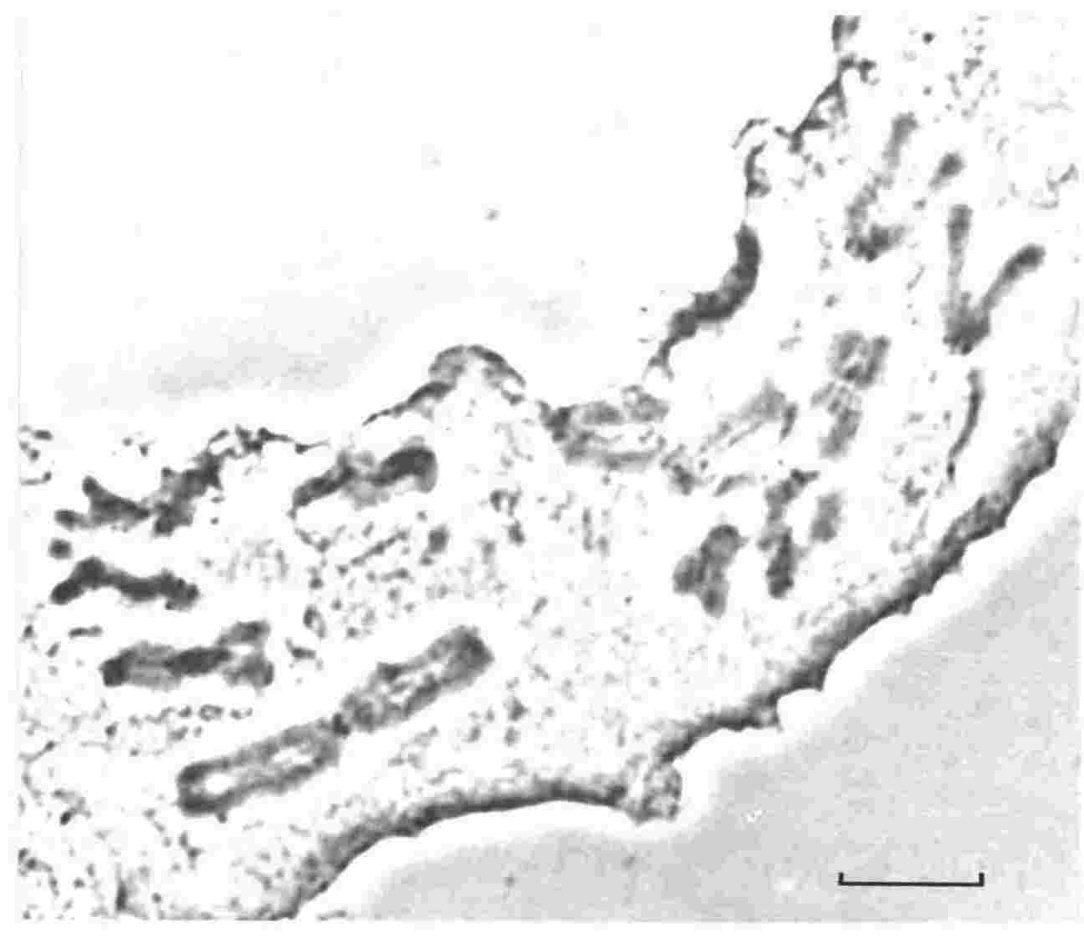

Fig $26 a$
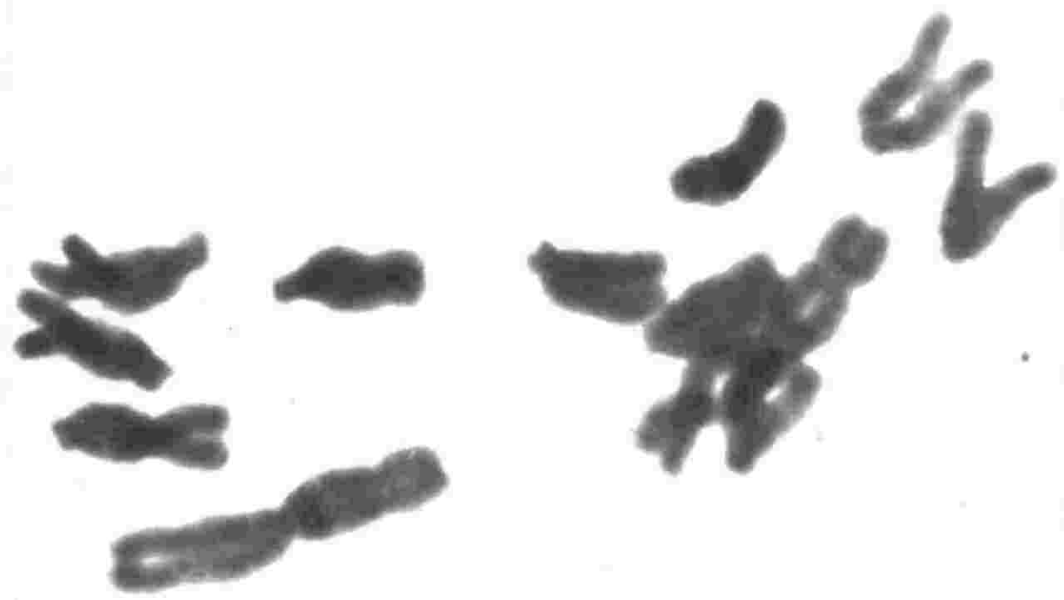

Fig $26 b$ 


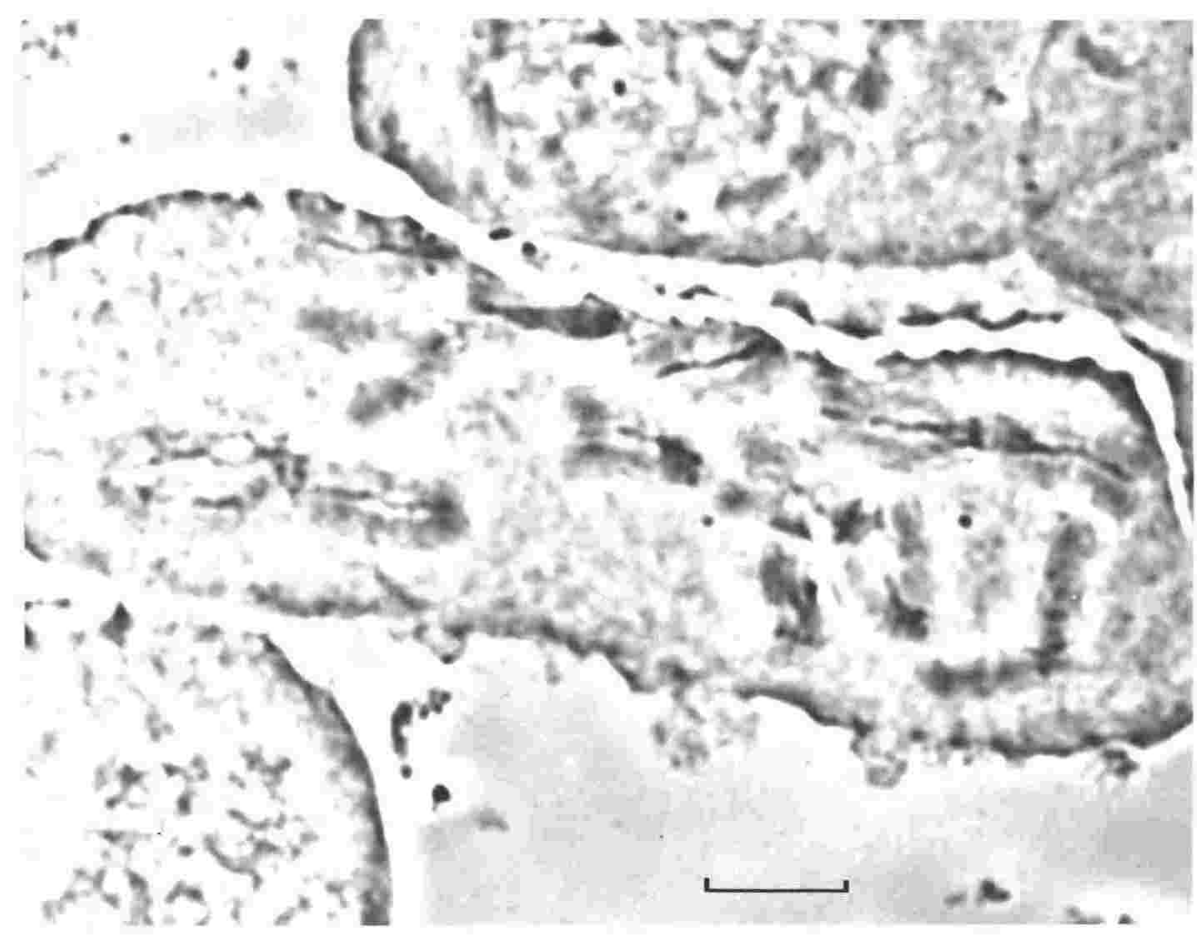

Fig $27 a$

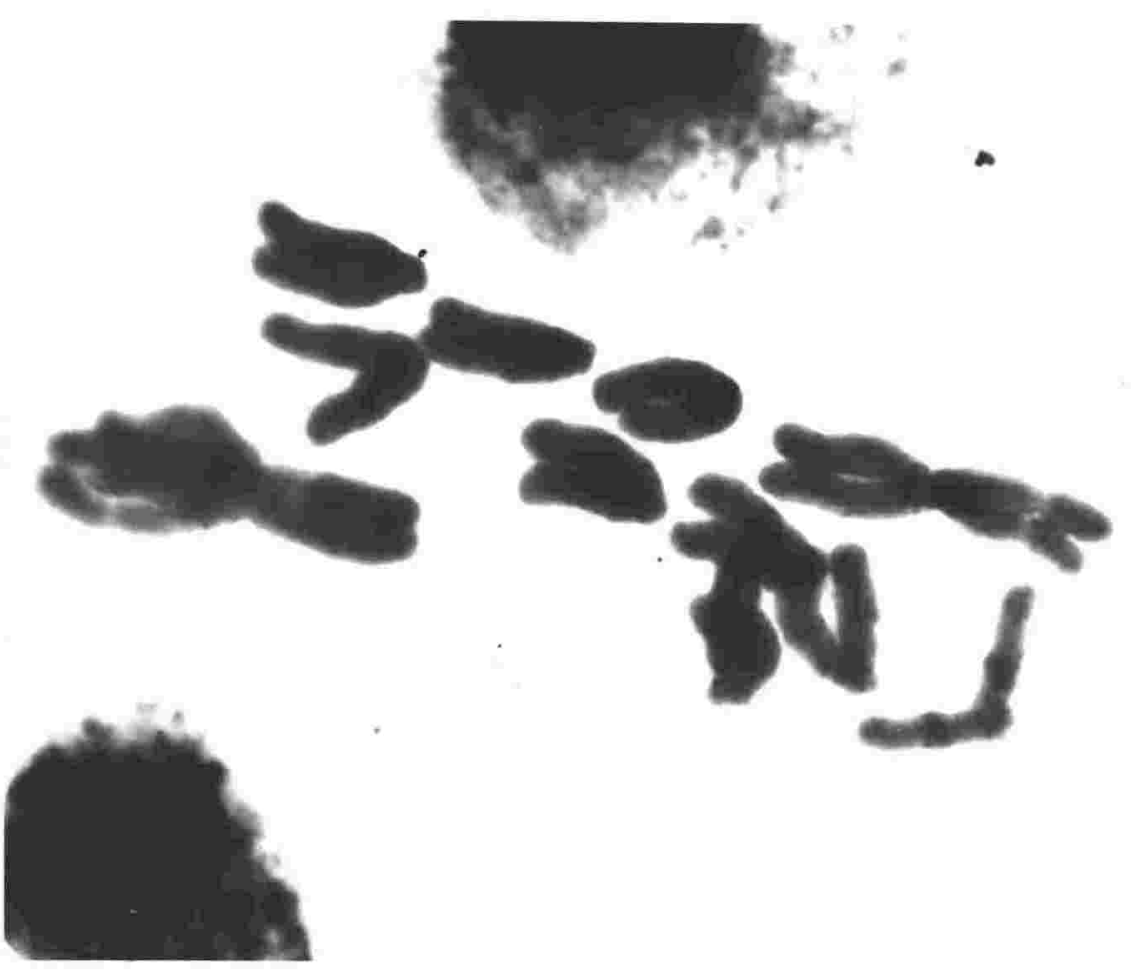

Fig $27 b$ 


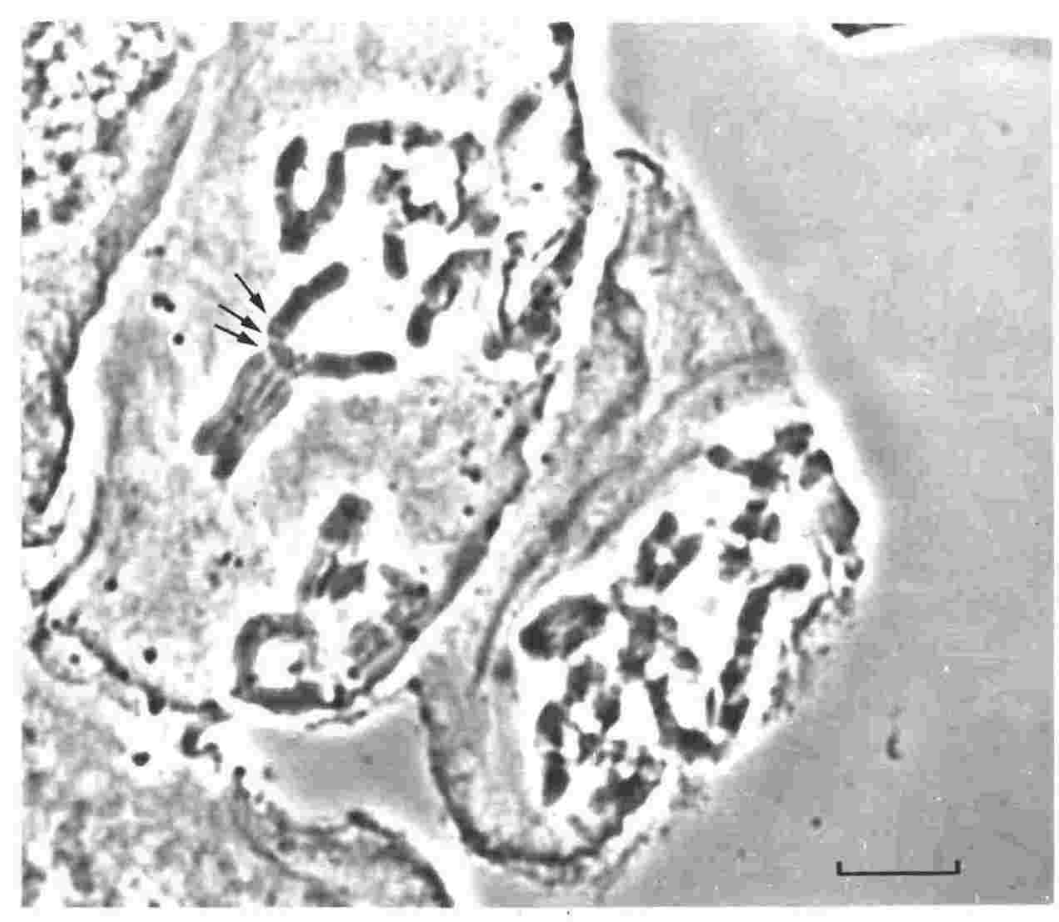

Fig 28a
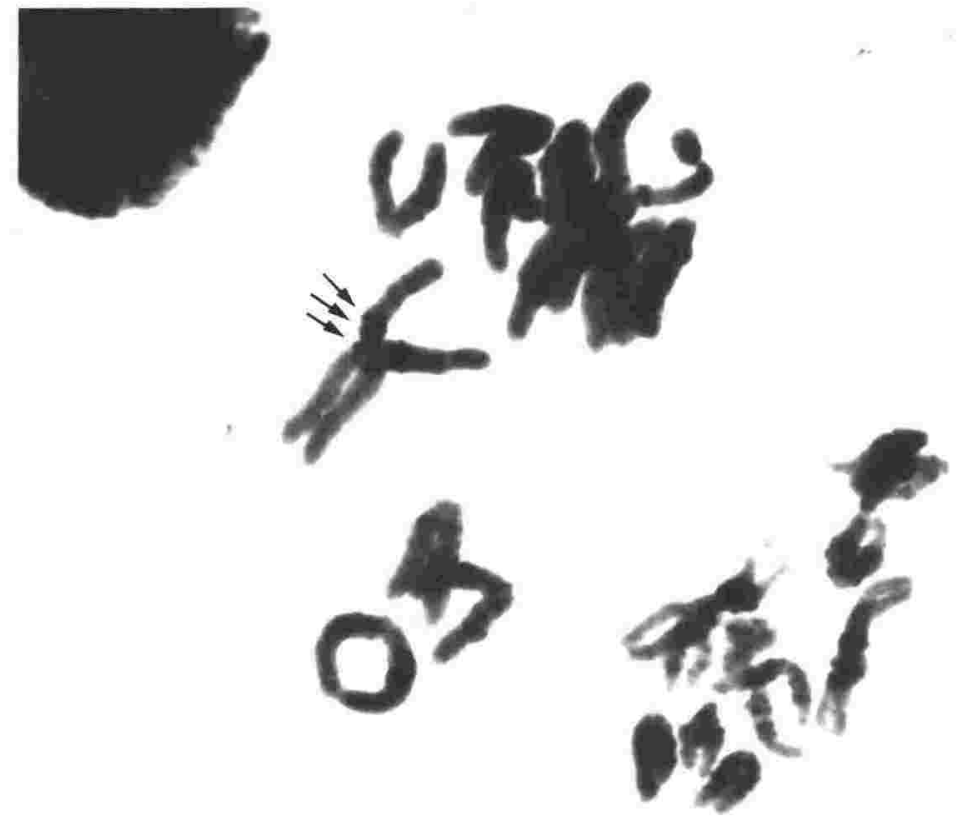

Fig $28 b$ 


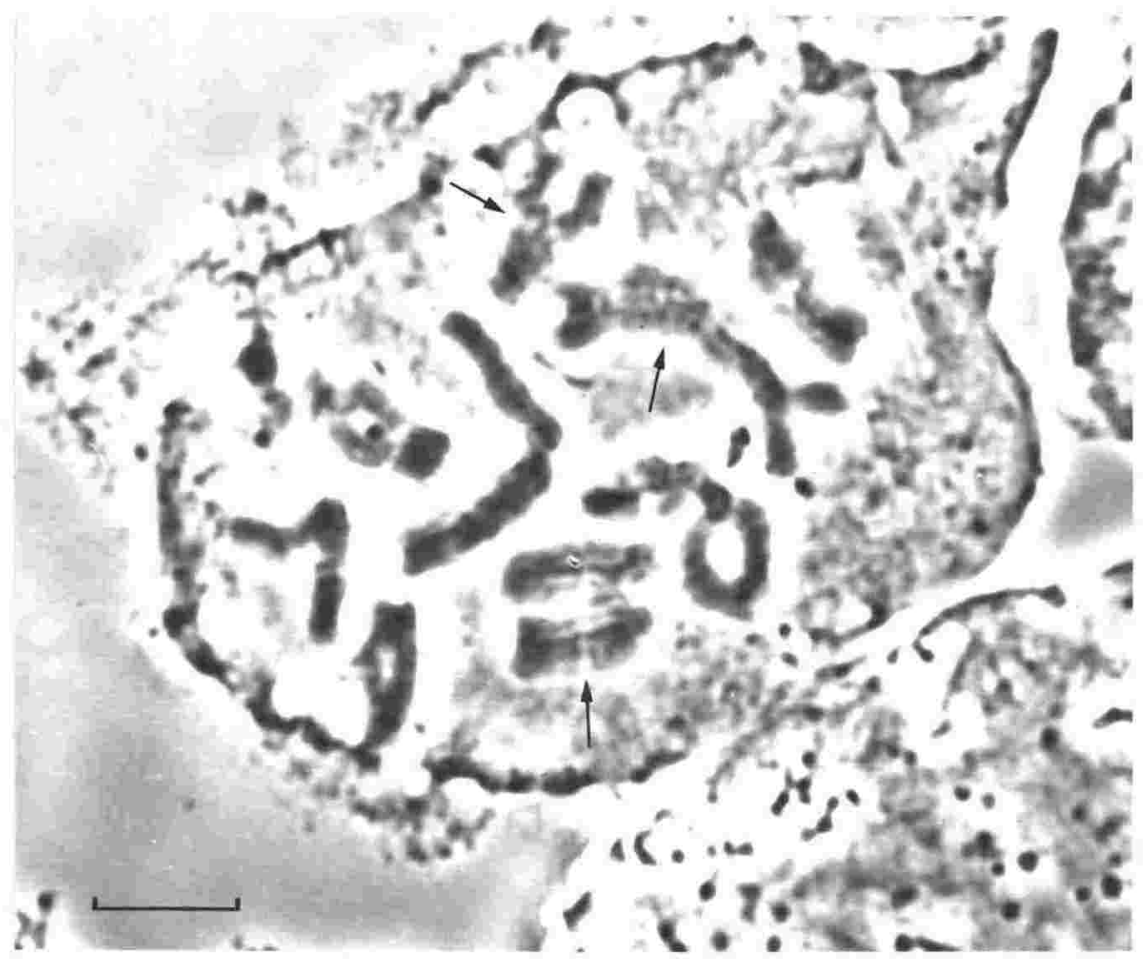

Fig 29a

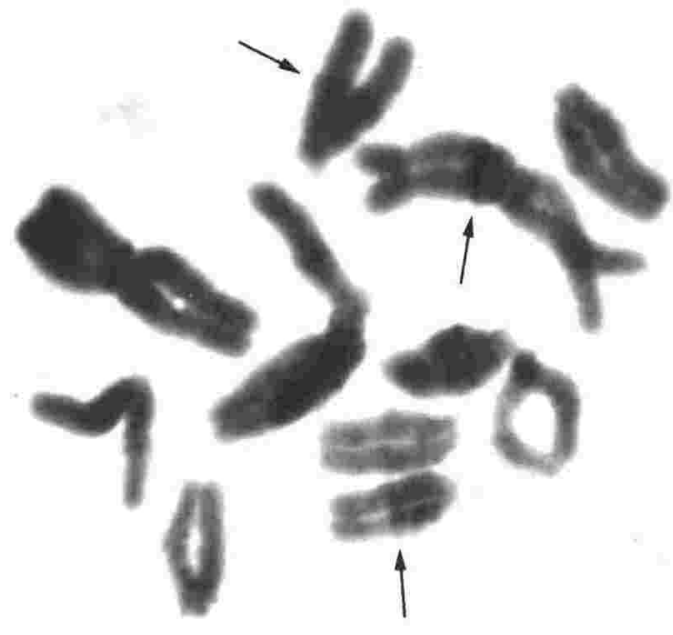

Fig $29 b$ 
Figs. 30-36. Trypsin-Giemsa Banded Squashes.

Fig. 30. Stained after $1-2 \mathrm{~min}$ trypsin digestion; partial appearance of bands (arrows).

Figs. 31-36. Stained after 4-7 min trypsin digestion.

Figs. 31 and 32. Prominent bands with peripheral chromosome ghosting.

Figs. 33 and 34 . Note ghosting around the chromosomes except for three darkly-stained s chromosomes in Fig. 34 .

Figs. 35 and 36. S chromosome at bottom of Fig. 35 and at $50^{\prime} \mathrm{clock}$ in Fig. 36 shows ghosting mostly absent in mid-band region. 

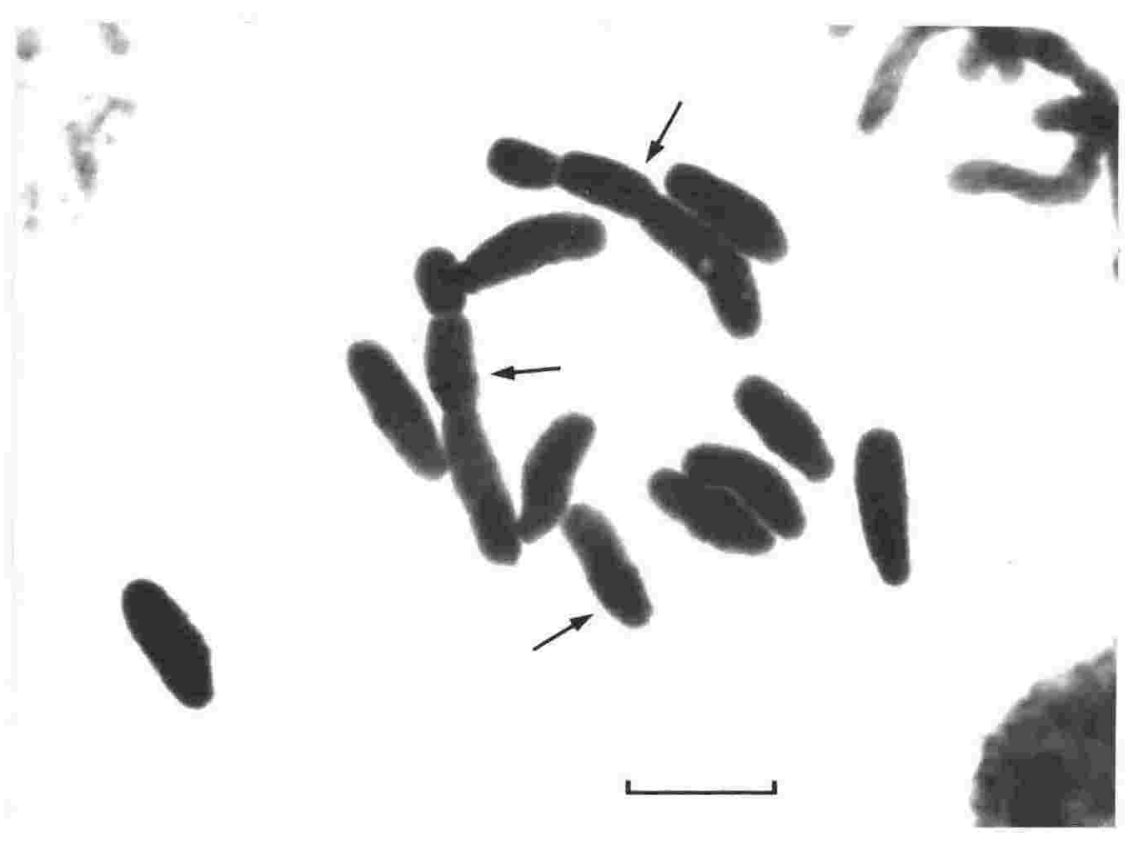

Fig 30

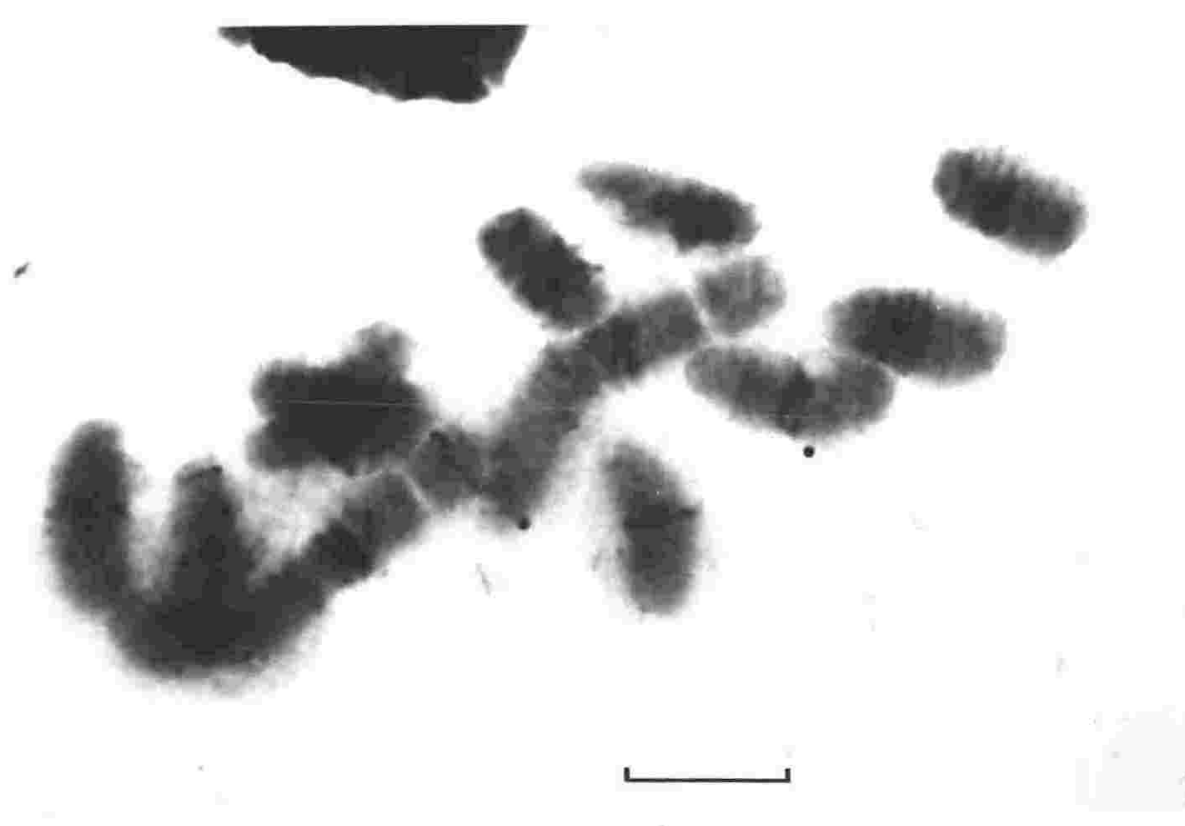

Fig 31

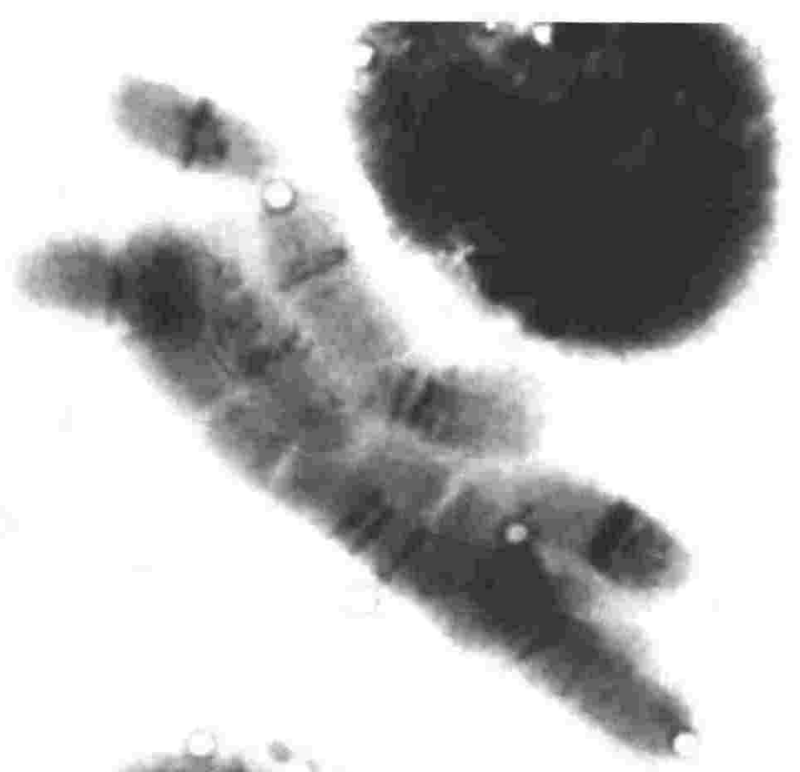

Fig 32 


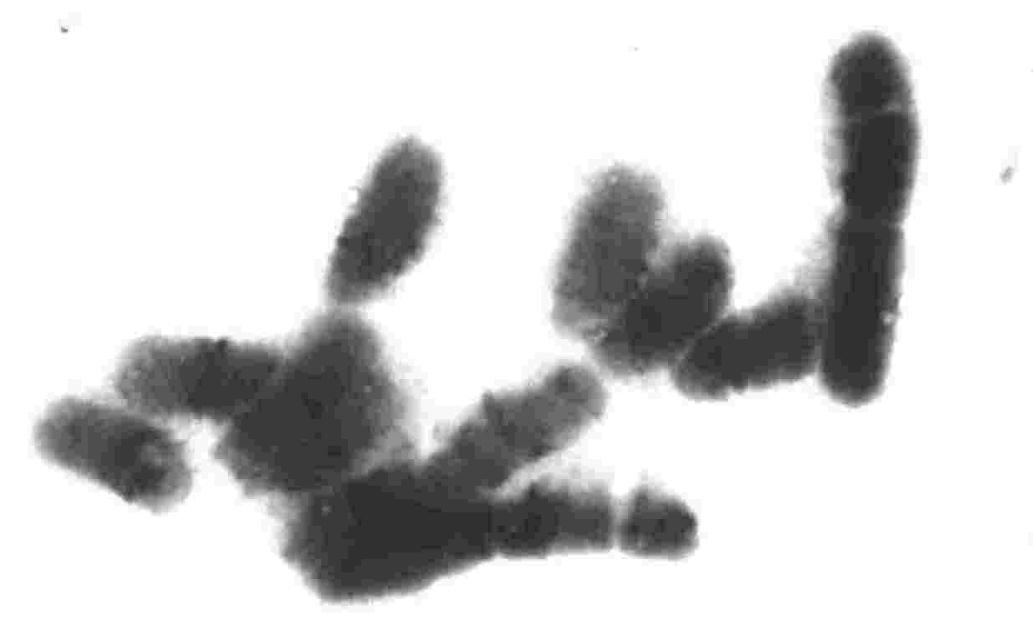

Fig 33

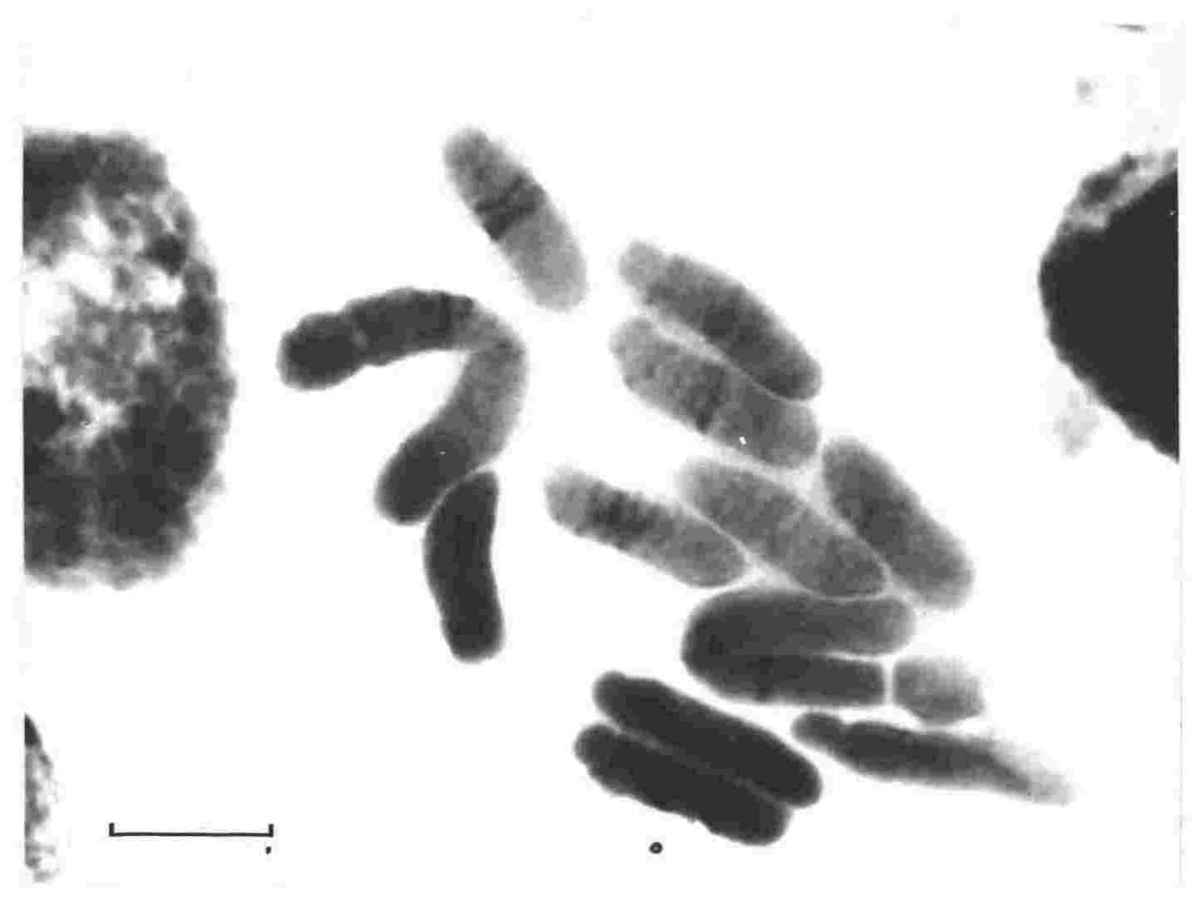

Fig 34 


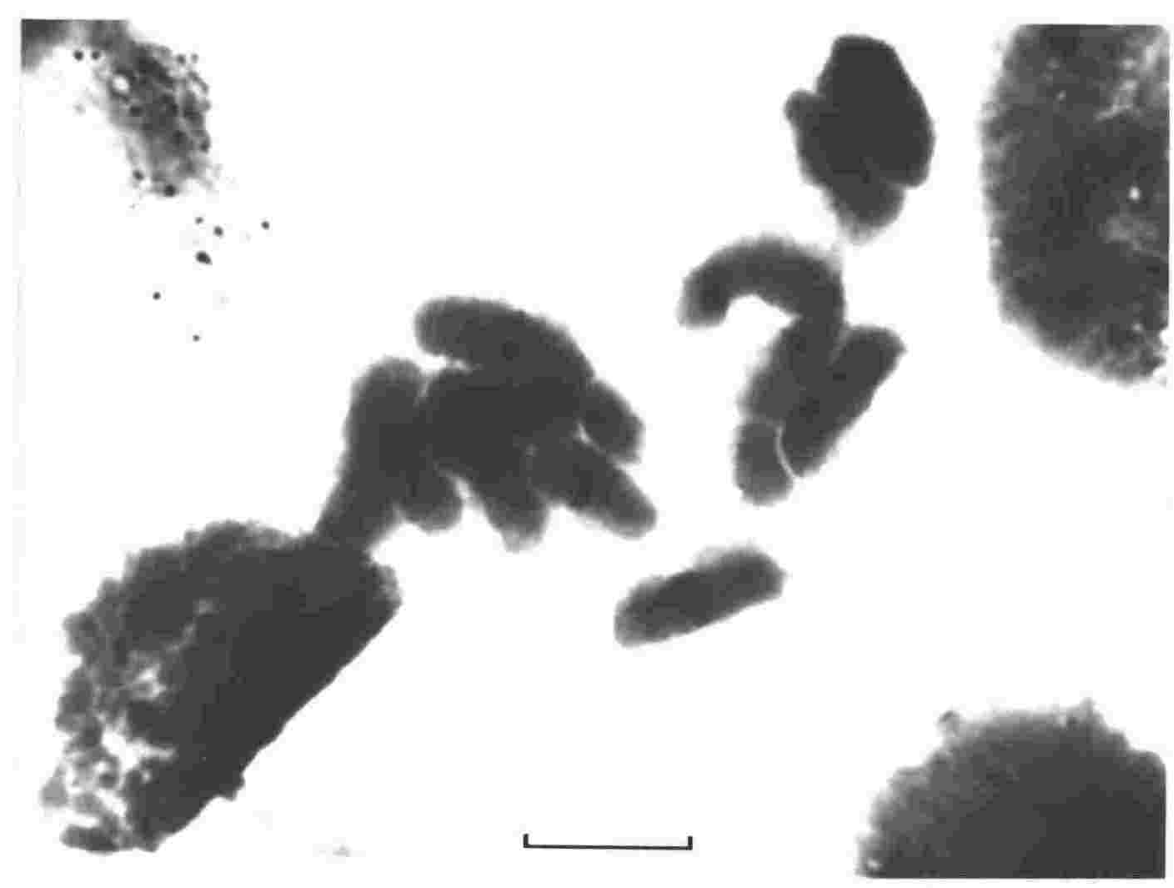

Fig 35

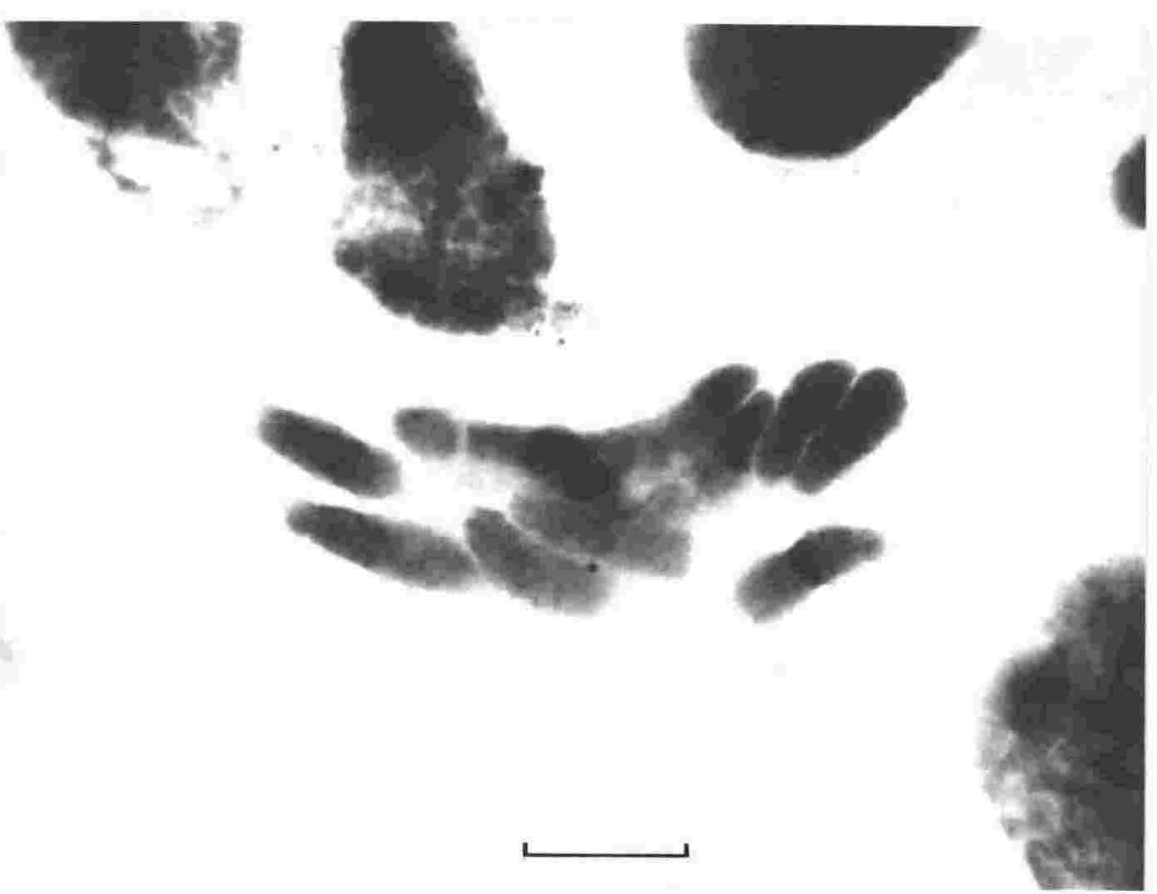

Fig 36 
Figs. 37-39. Urea-Giemsa Banded Squashes.

Fig. 37. Note particularly the two centromeric bands (M2/1 and $M 2 / 2)$ on the arrowed $M$ chromosome.

Figs. 38 and 39. Bands flank the $M$ centromere (M1/2 and M2/4, more distinct in Fig. 38) and the secondary constriction. 

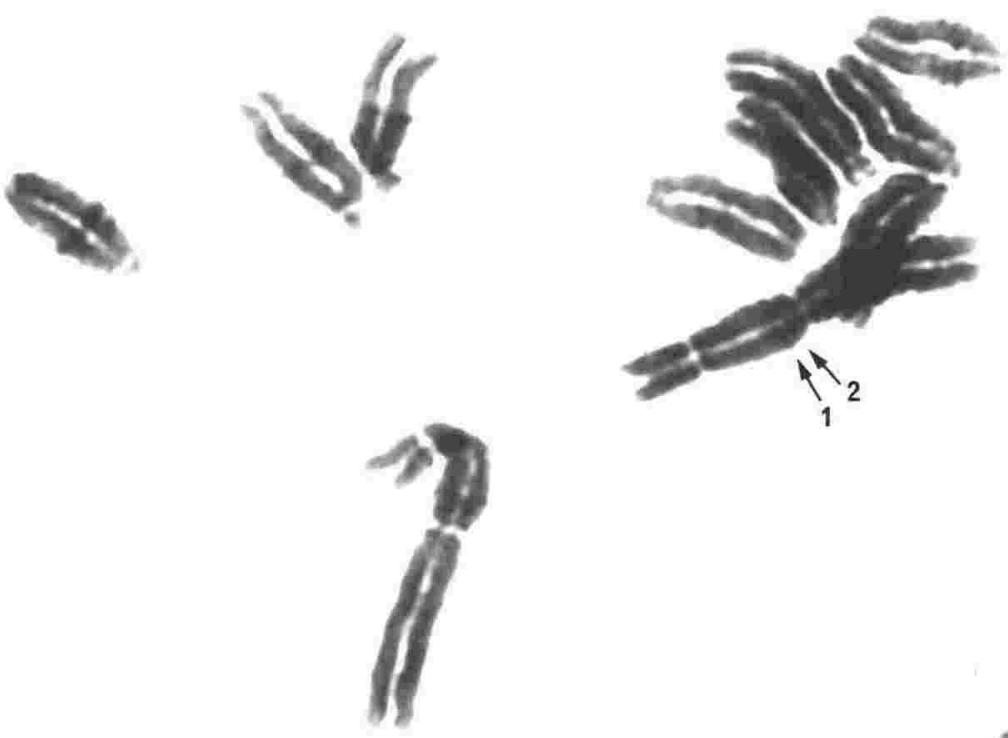

Fig 37
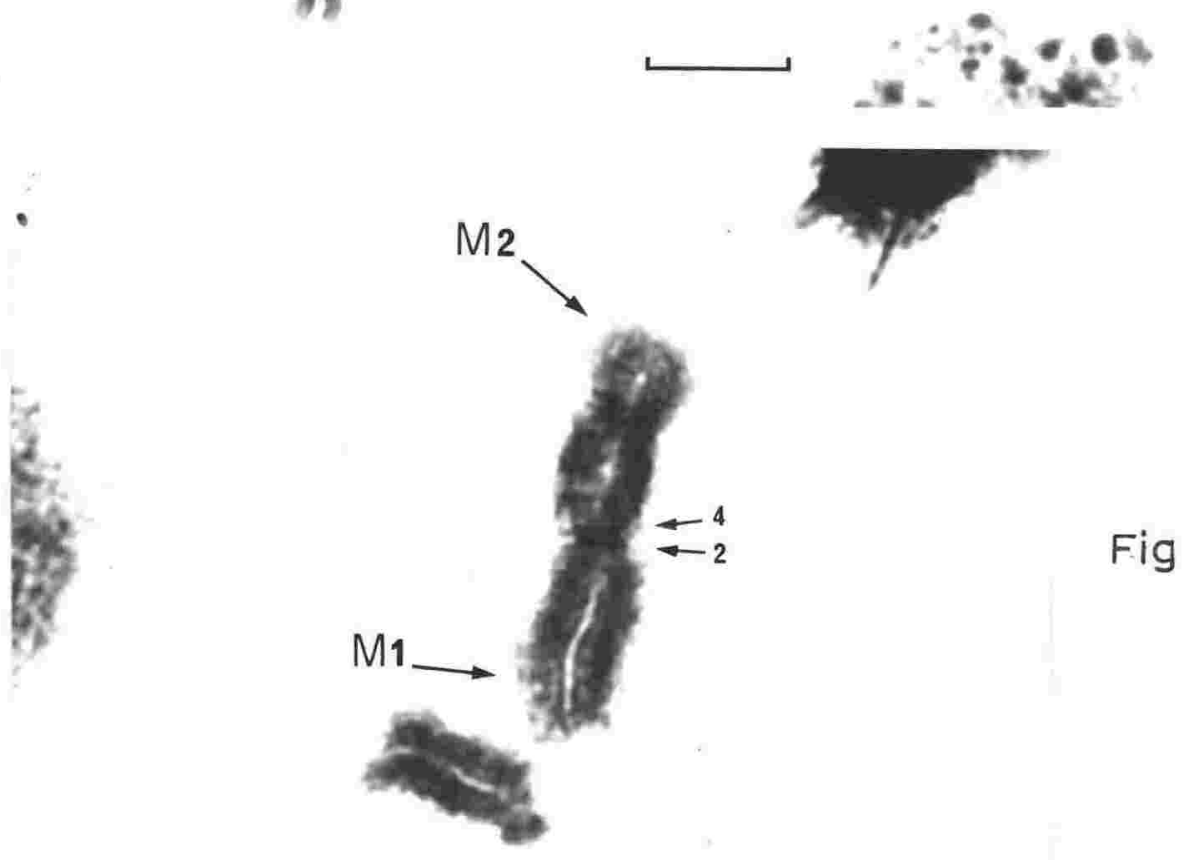

Fig 38

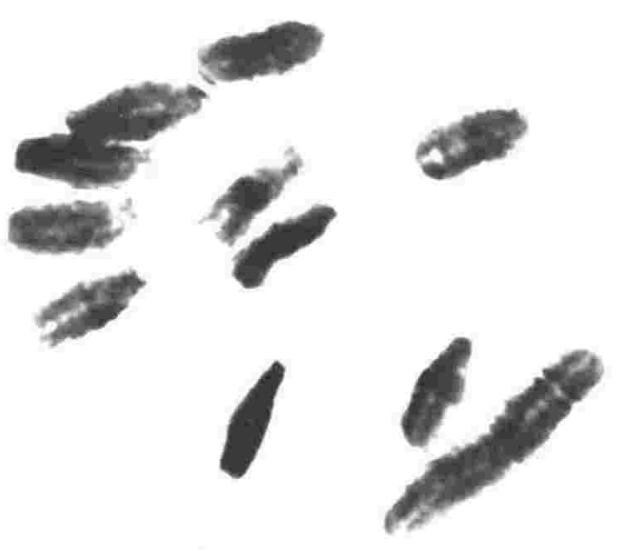

Fig 39

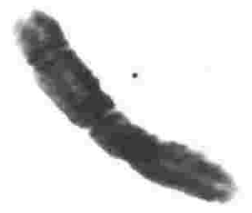


Fig. 40. Reverse banded squash showing achromatic cross-bands.

Fig. 4l. Gll banded squash. C-dots (arrows) are differentially stained and particularly distinct on the $\mathrm{S}$ chromosome at 10 o'clock. Note the prominent band (indicated with bar) close to the centromere of this chromosome and the suggestion of a band or dots at the M secondary constriction (arrowhead). 


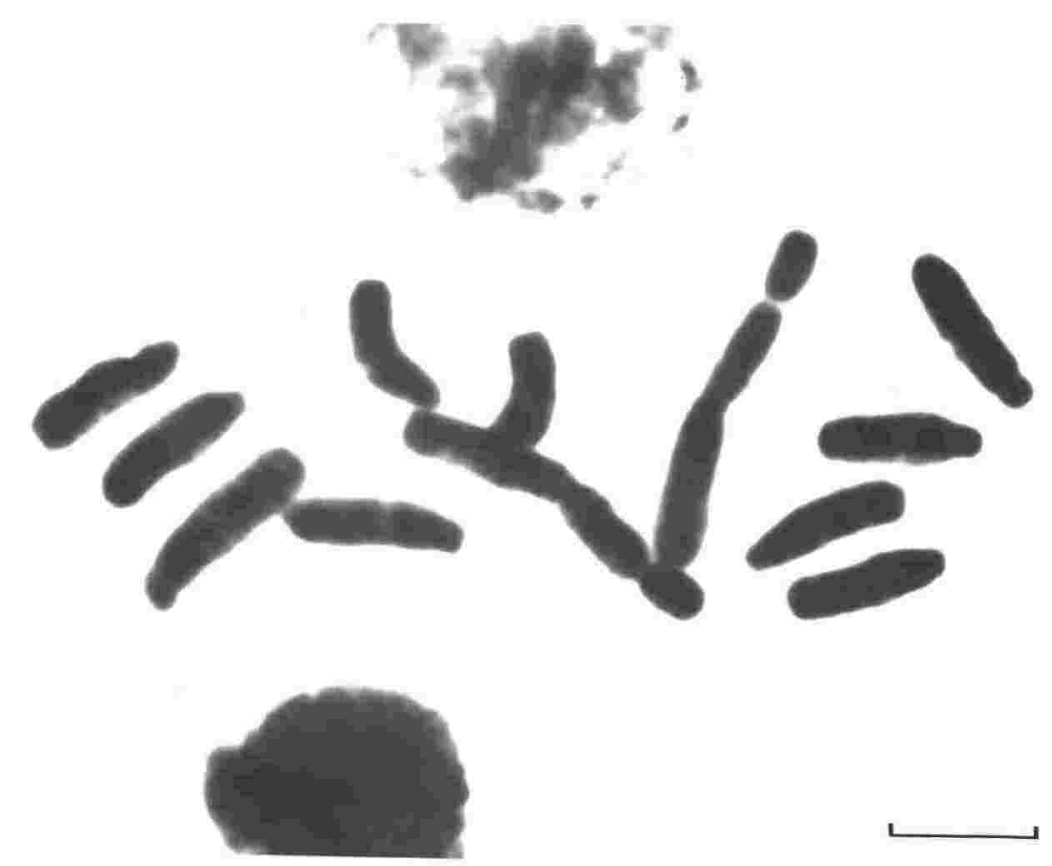

Fig 40

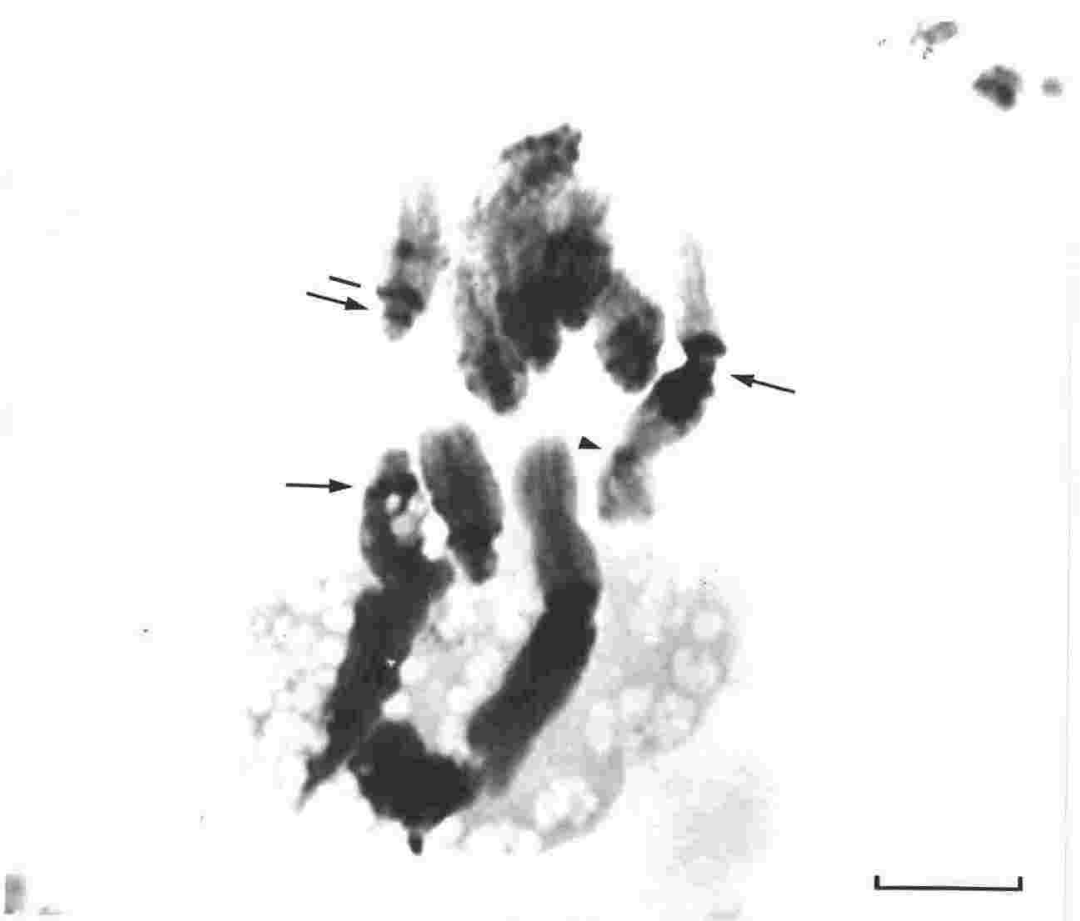

Fig 41 
Fig. 42. Reproductions of illustrations showing the distribution of Giemsa bands in $V$. faba chromosomes by
(a) Takehisa and Utsumi (1973)
(b) Schweizer (1973)
(c) Scheid and Traut (1973)
(d) Dobel, Rieger and Michaelis (1973)
(e) Burger and Scheuermann (1974)
(f) Klasterska and Natarajan (1975)
(g) Vosa and Marchi (1972) 



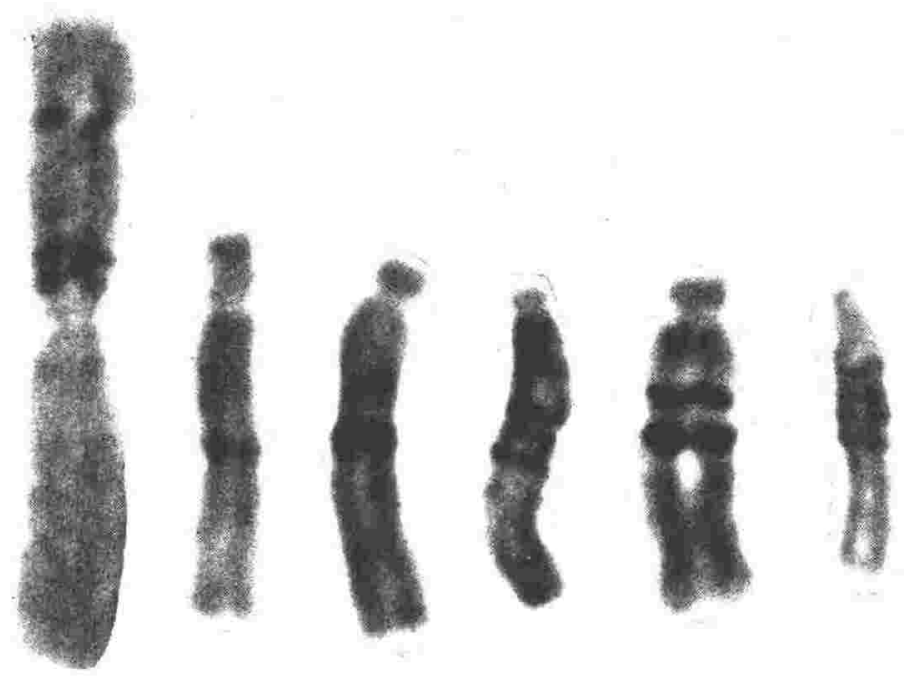

Fig $42 d$

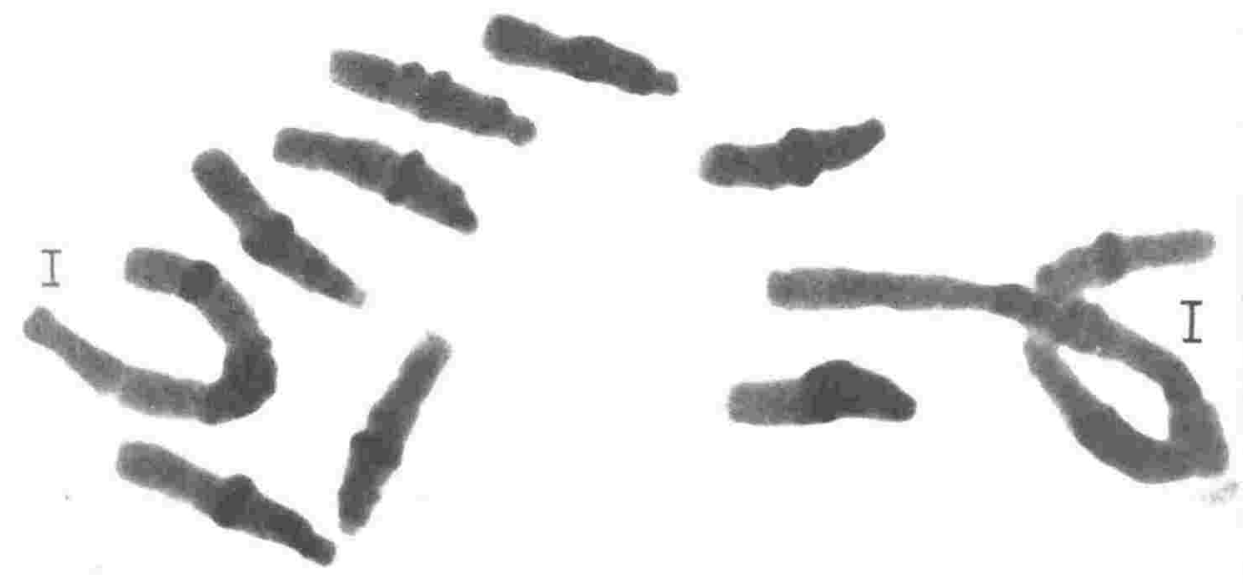

Fig $42 e$ 


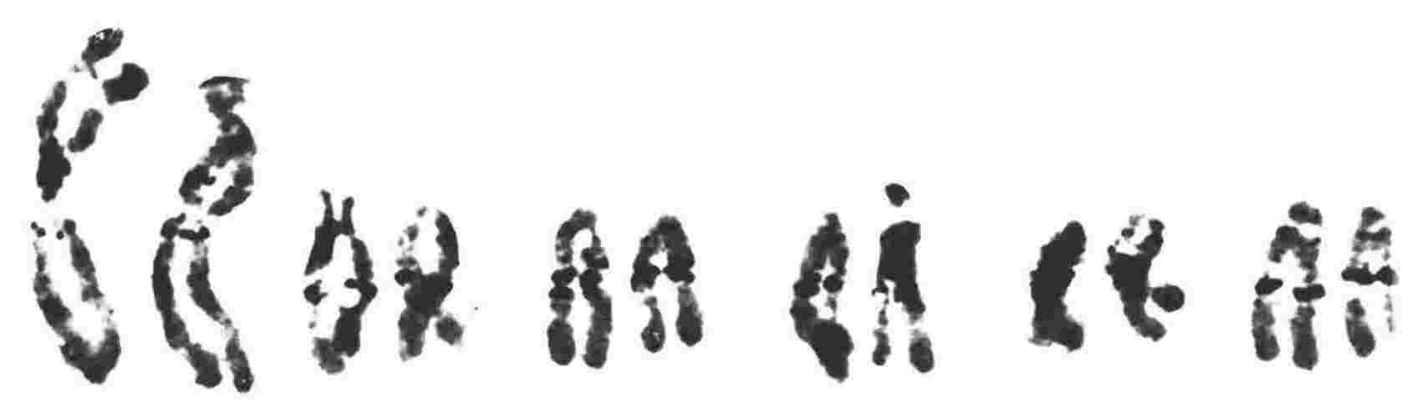

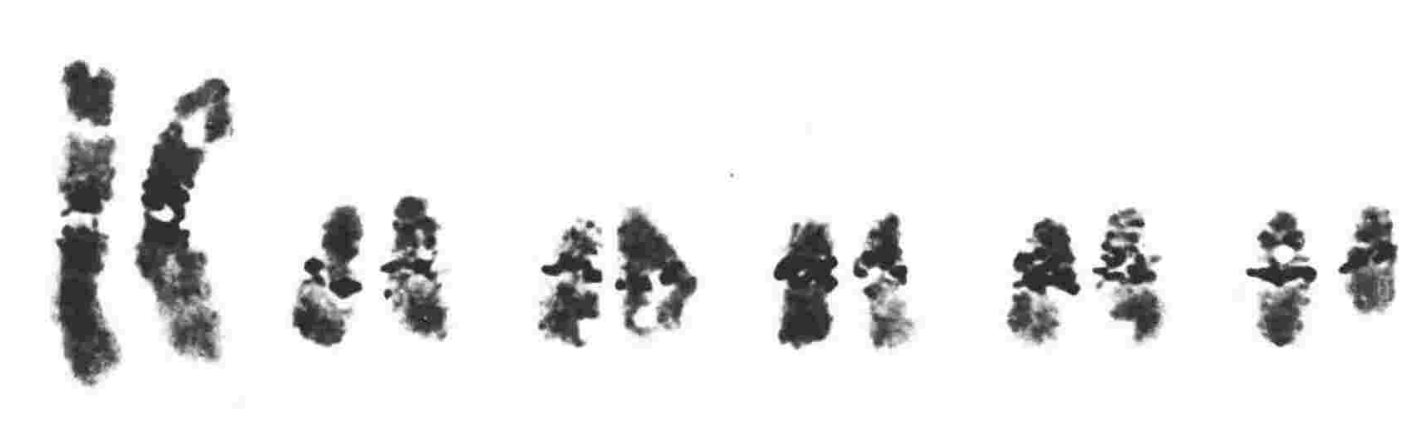


Figs. 43-49. Lacto-Aceto-Orcein Banded Squashes.

Fig. 43. Positive bands flank the secondary constriction of the upper M chromosome. Two negative bands ( $\mathrm{M} 1 / \mathrm{I}$ and $\mathrm{M} 2 / 1$ ) neighbour the centromere (c) with a break at the $\mathrm{M} 2 / 2$ region (arrow). The $\mathrm{M}$ chromosome at $8 \mathrm{o}^{\prime} \mathrm{clock}$ shows indistinct banding. Centromere position is judged from cold treatment and acid treatment studies.

Fig. 44. Two indistinct bands are positioned at the secondary constriction and two negative bands neighbour the centromere (c) with a break at the $M I / I$ region. 


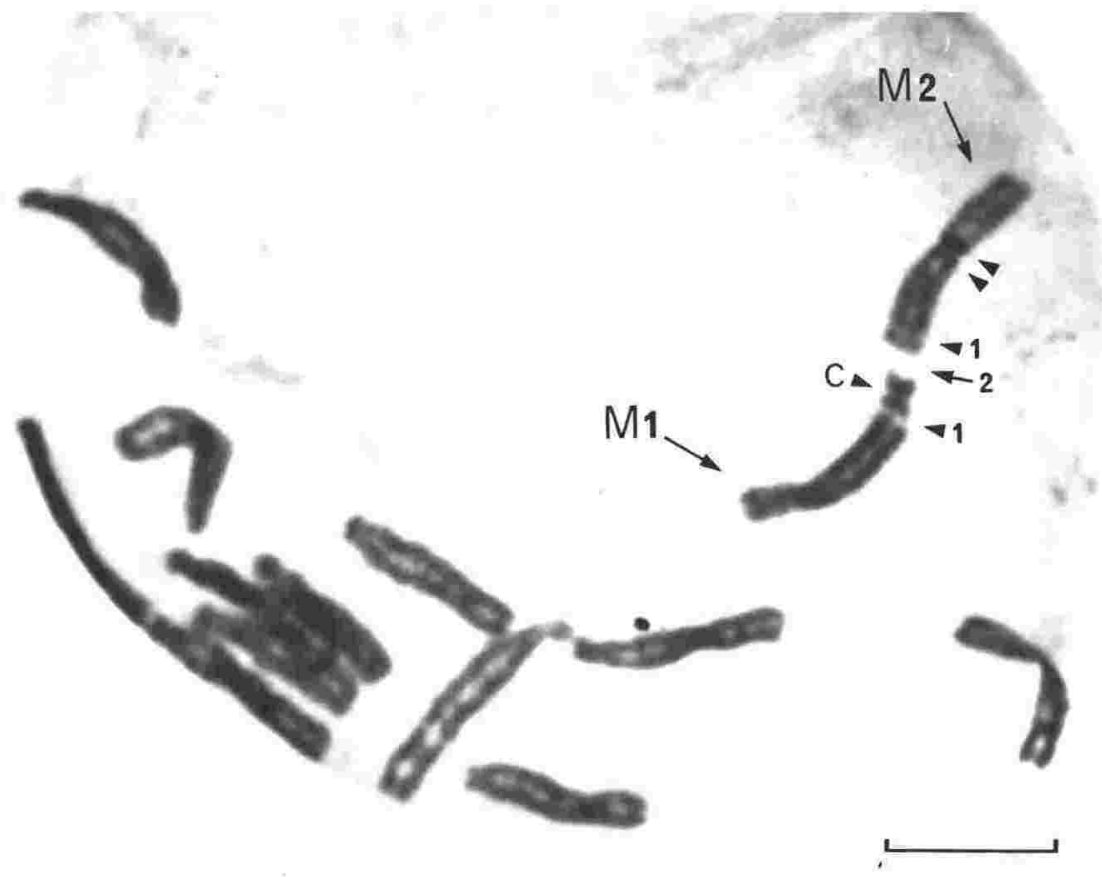

Fig 43

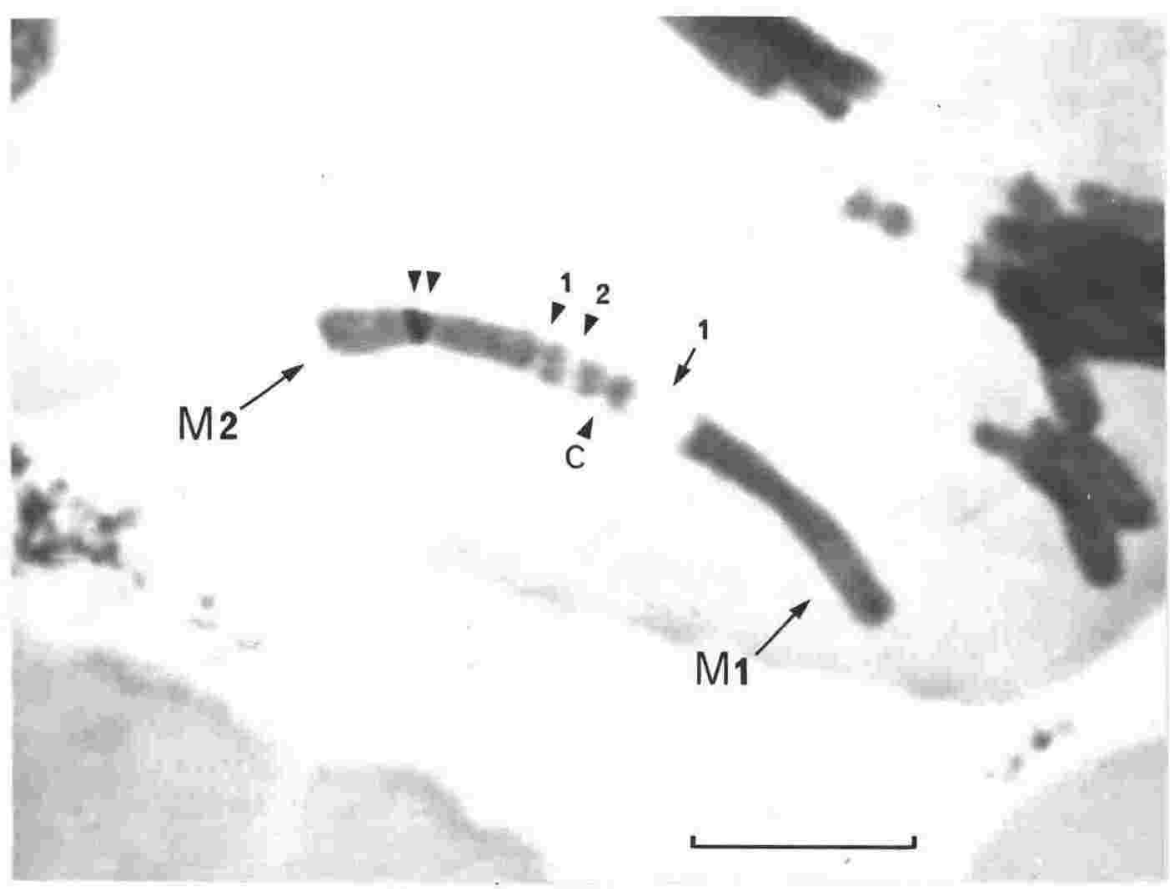

Fig 44 
Lacto-Aceto-Orcein Banded Squashes (cont.)

Fig. 45. Common observation of the flanking secondary constriction bands as one band, the NOR band (arrow). The centromeric bands are not defined in this $M$ chromosome. Note an adjacent chromosome fragment with the homologous NOR band (arrowhead).

Fig. 46. Unstained hydrolysed squash. NOR band is arrowed. (Phase contrast microscopy). 


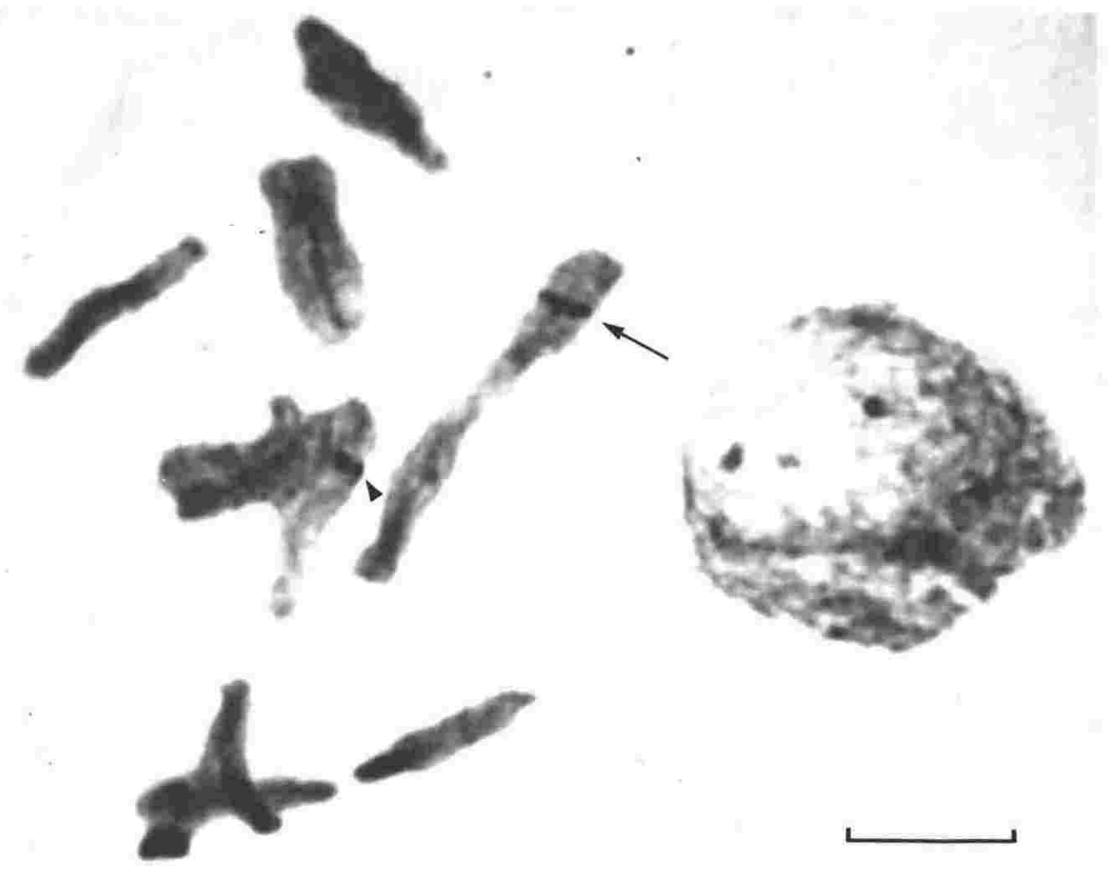

Fig 45

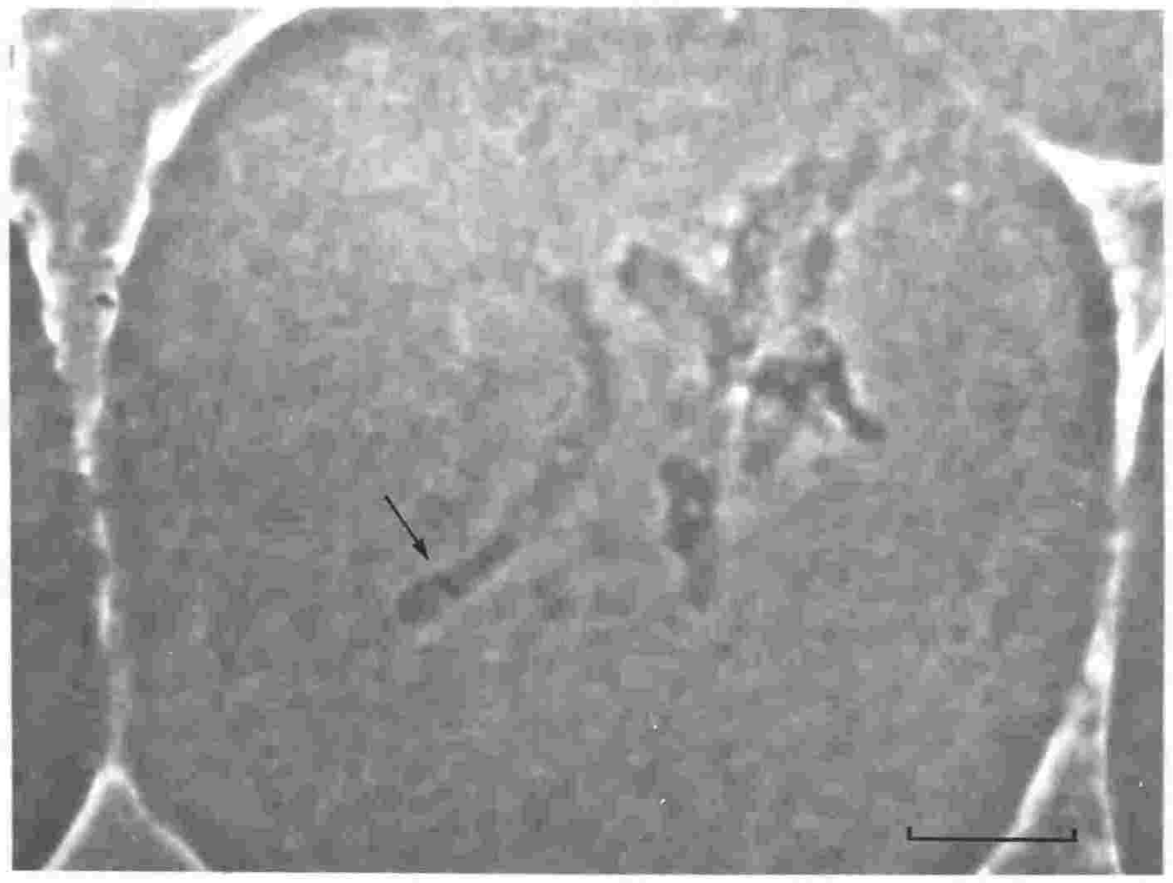

Fig 46 
152.

Lacto-Aceto-Orcein Banded Squashes (cont.).

Fig. 47a, b. Interphase nuclei, each showing two chromocenters associated with the nucleolus. 


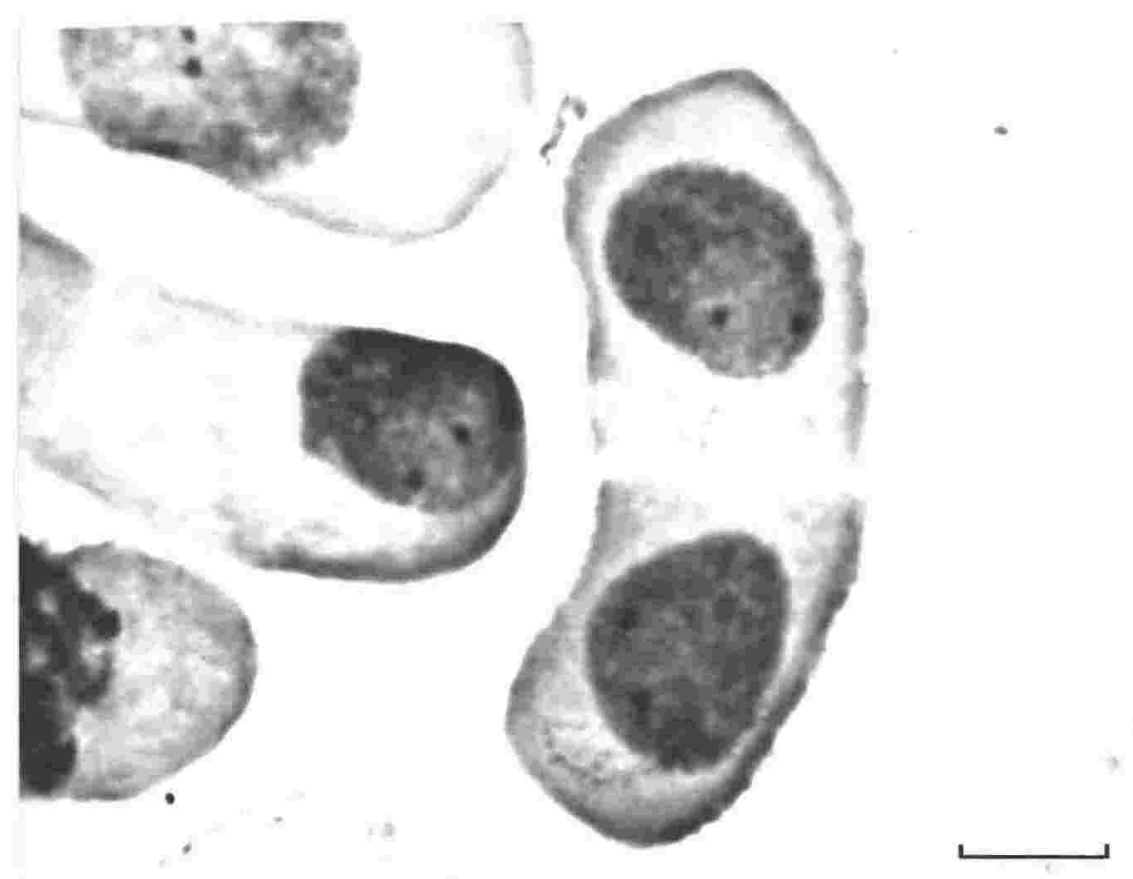

Fig $\quad 47 a$

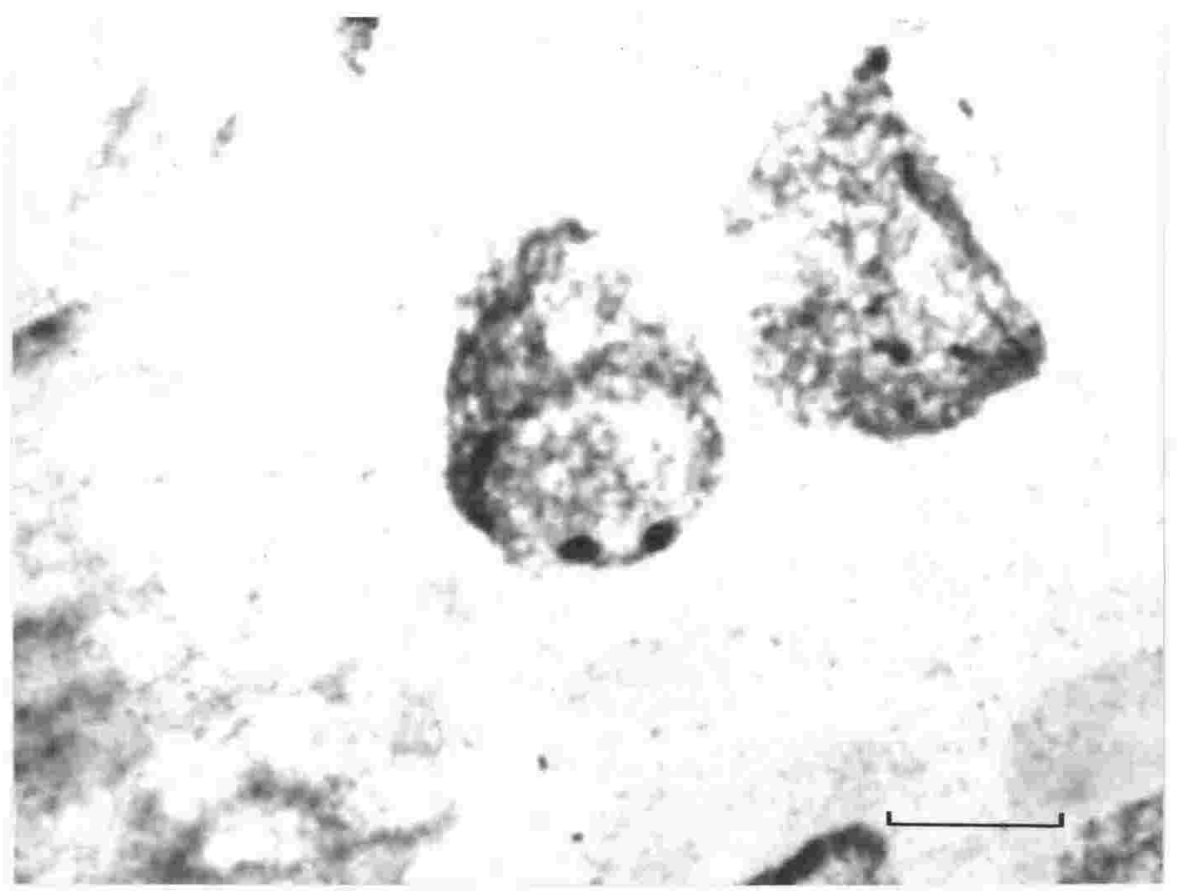

Fig $\quad 47 b$ 
Lacto-Aceto-Orcein Banded Squashes (cont.).

Fig. 48. Squash of standard fixed root-tips treated with LAO method. Achromatic bands are arrowed. Centromere (c) position is judged as in Fig. 43 above.

Fig. 49. Unstained, hydrolysed, standard fixed squash. NOR band not distinguishable. (Phase contrast microscopy). 


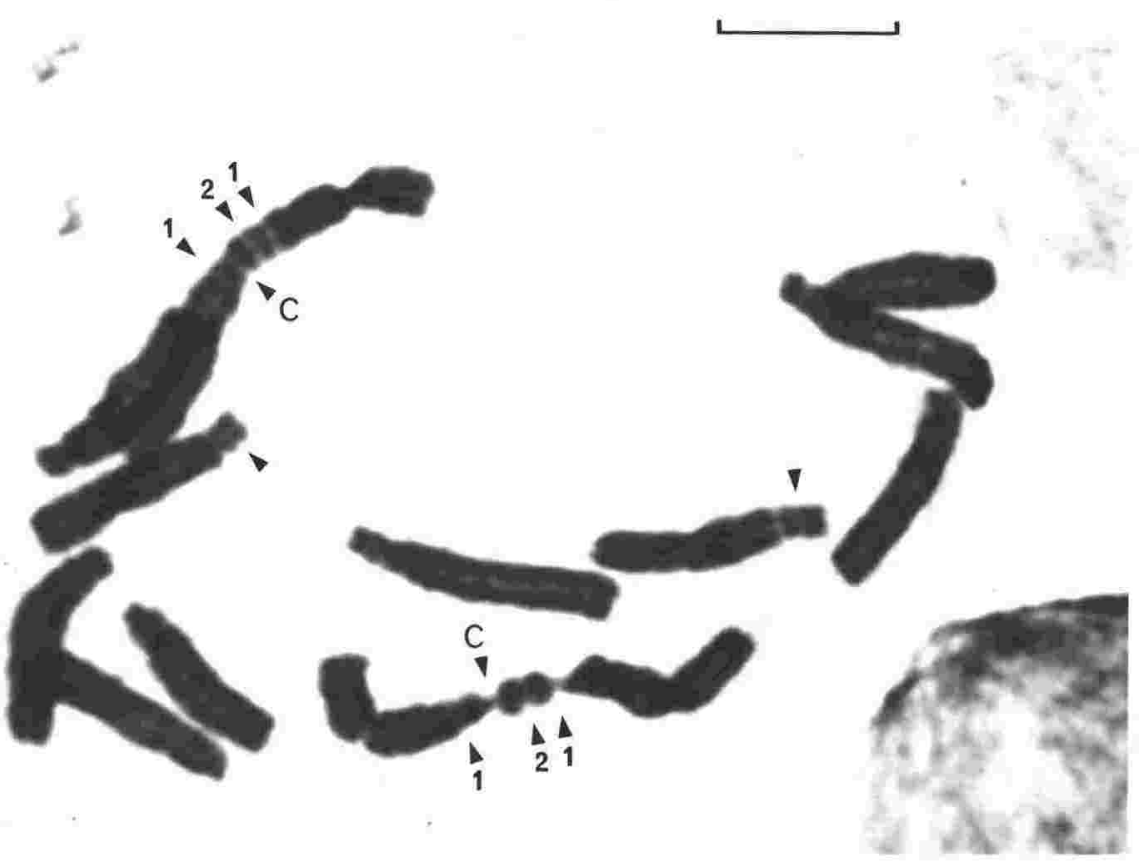

Fig 48

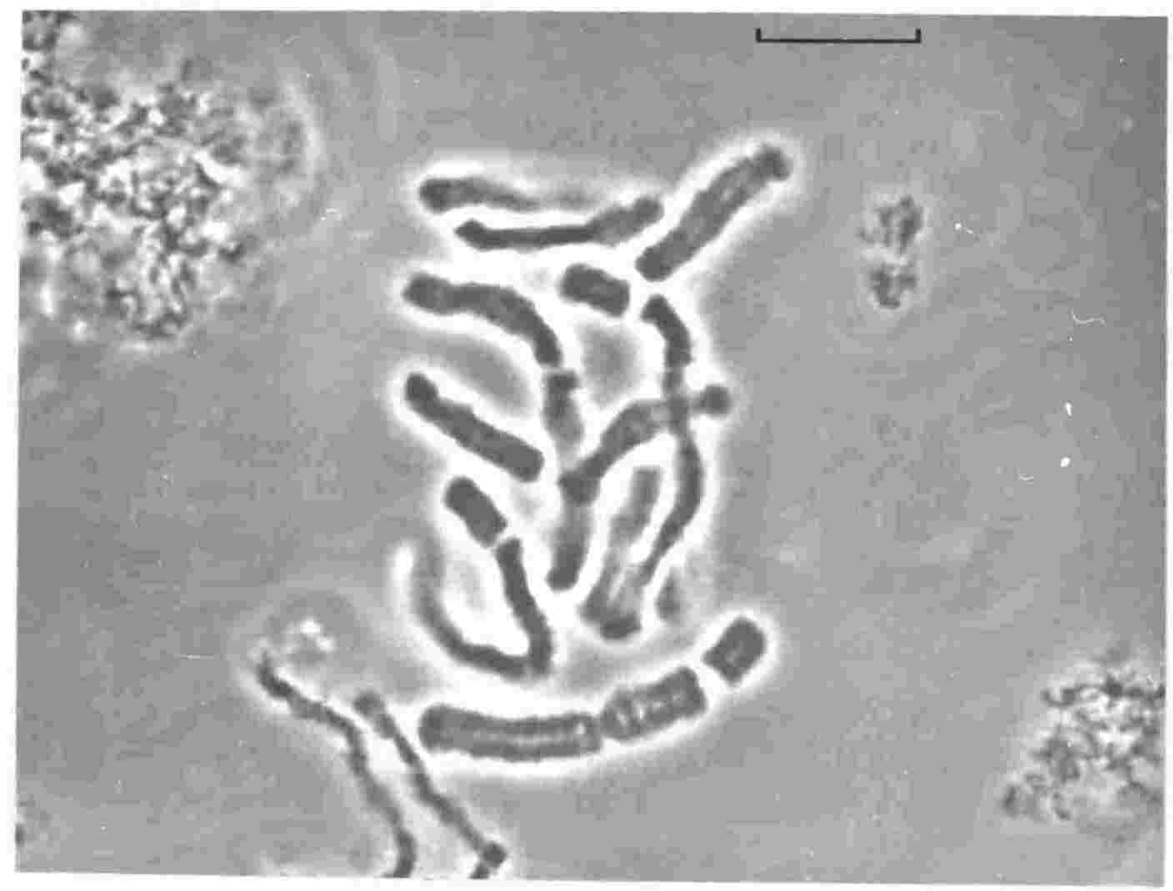

Fig $\quad 49$ 
Fig. 50. Reproduction of Funaki, Matsui and Sasaki's (1975) illustration of an N-band in the secondary constriction of the $V$. faba M chromosome. 


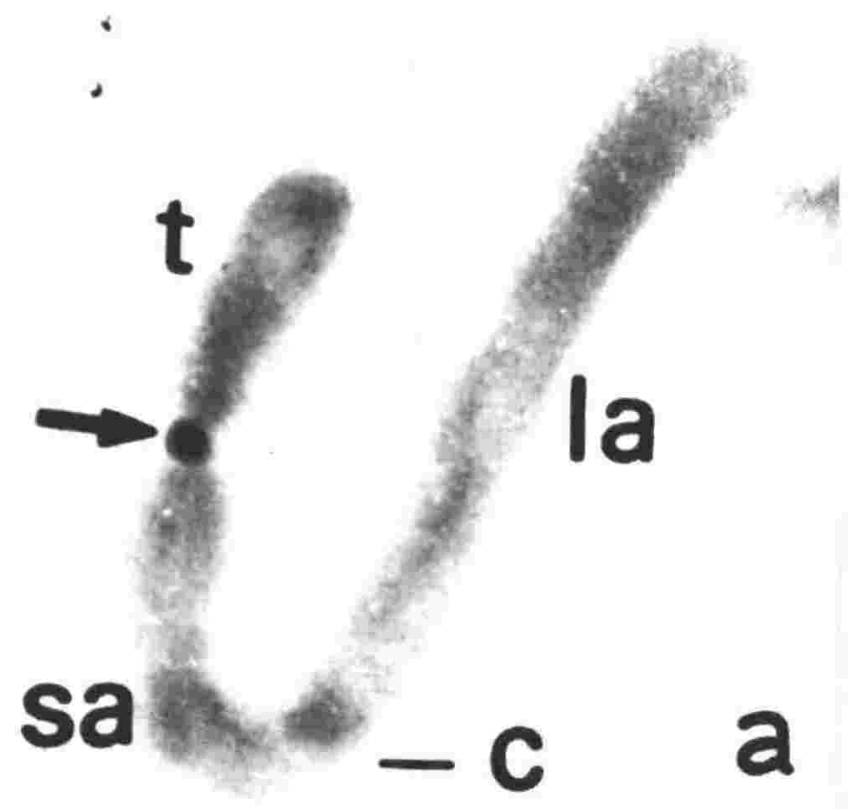

Fig 50 
Fig. 51. Representation of the band pattern revealed on the $M$ chromosome by different banding techniques used in this study.

(a) Cold treatment

(b) Acid treatment

(c) Quinacrine mustard fluorescence

(d) SSC-Giemsa

(e) Trypsin-Giemsa

(f) GIl technique

(g) Urea-Giemsa

(h) Lacto-aceto-orcein technique

(i) LAO technique with standard fixation

$$
\begin{aligned}
& \text { red = achromatic band } \\
& \text { blue = positive band } \\
& \text { green = fluorescent band }
\end{aligned}
$$



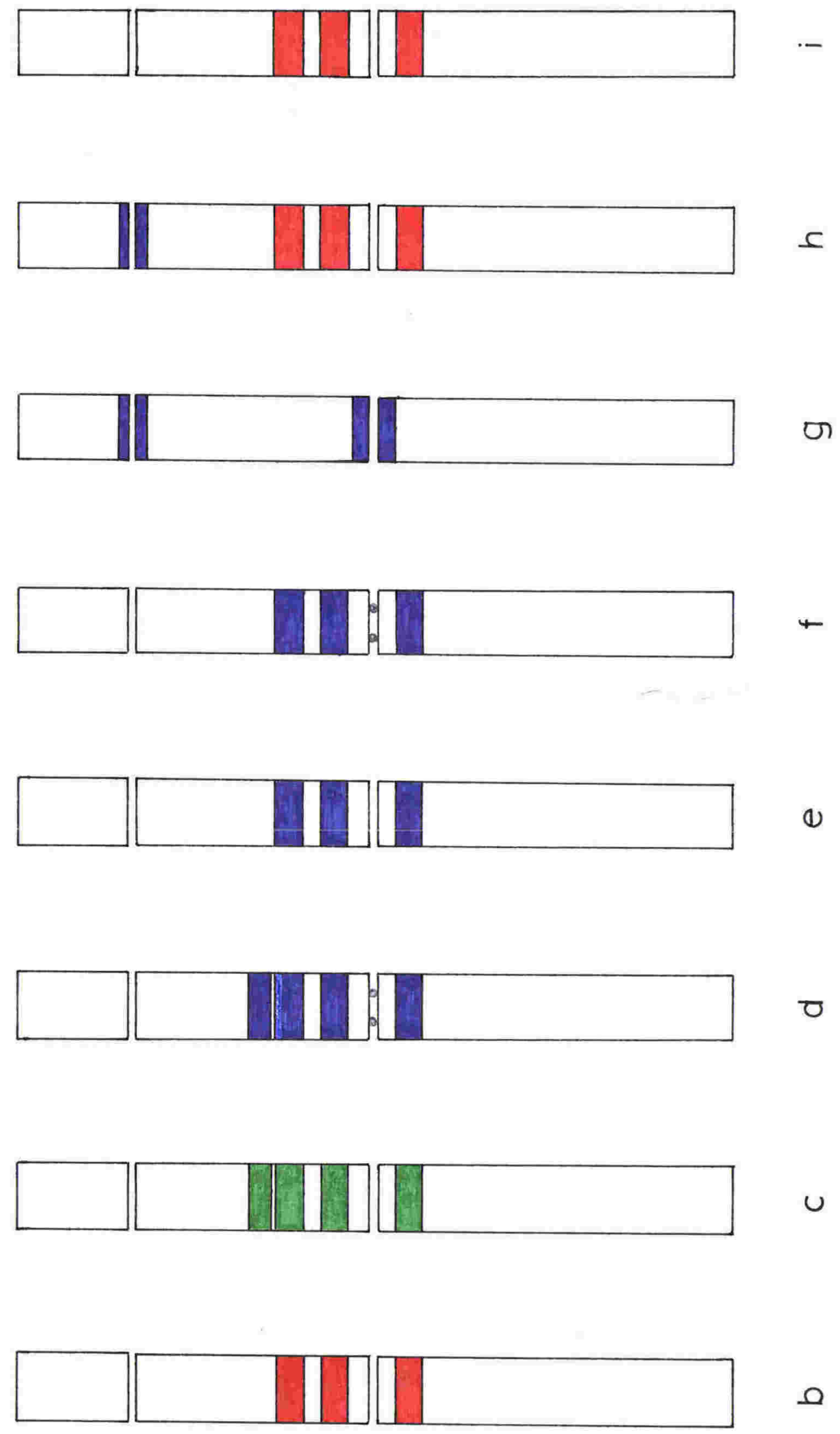

도

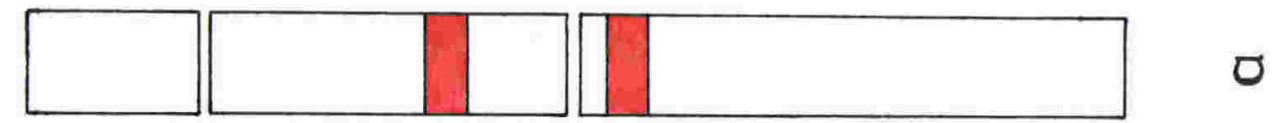


Figs. 52-55. Autoradiographs of Root-tip Cells Pulsed with ${ }^{3} \mathrm{H}$-thymidine for $30 \mathrm{~min}$.

Fig. 52. Chromosomes labelled in late $\mathrm{S}$ phase ( $4 \mathrm{~h}, 40 \mathrm{~min}$ chase; $\mathrm{sc}=$ secondary constriction).

Fig. 53. Interphase nucleus showing grains concentrated over chromocenters.

Fig. 54. Chromosomes labelled in early S phase $(10 \mathrm{~h}, 20 \mathrm{~min}$ chase; $\mathrm{sc}=$ secondary constriction).

Fig. 55. Nuclei from root-tip squash showing grains localized over nucleoli. (Selected from $4-6$ h chase). 


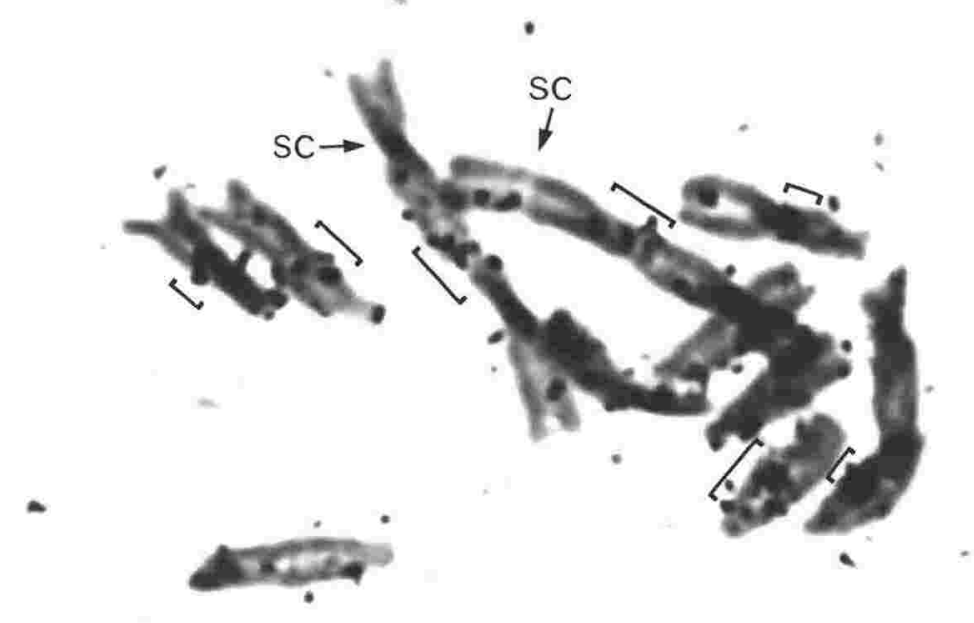

Fig 52
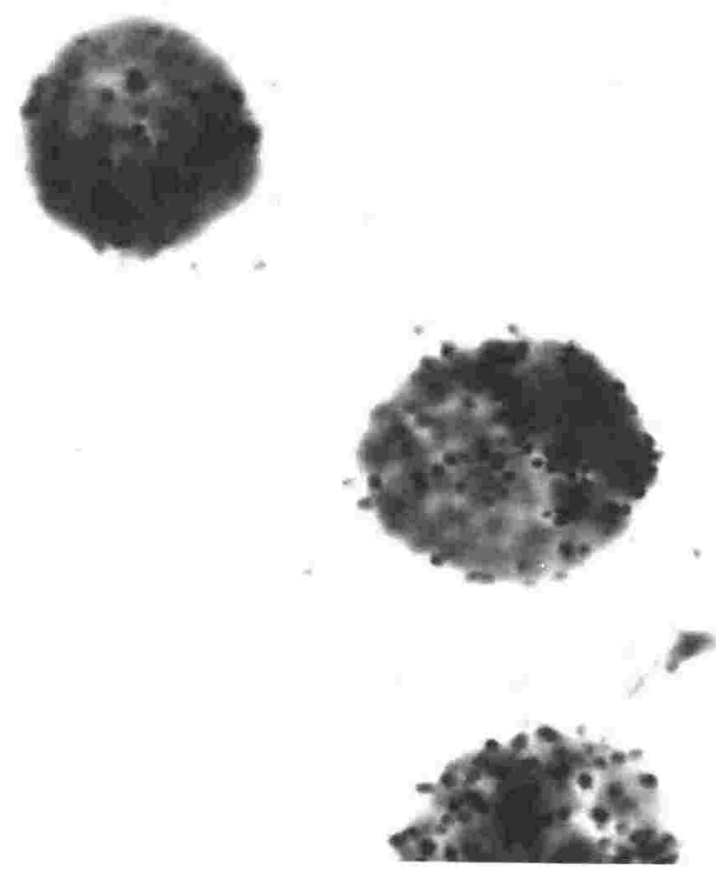

Fig 53 


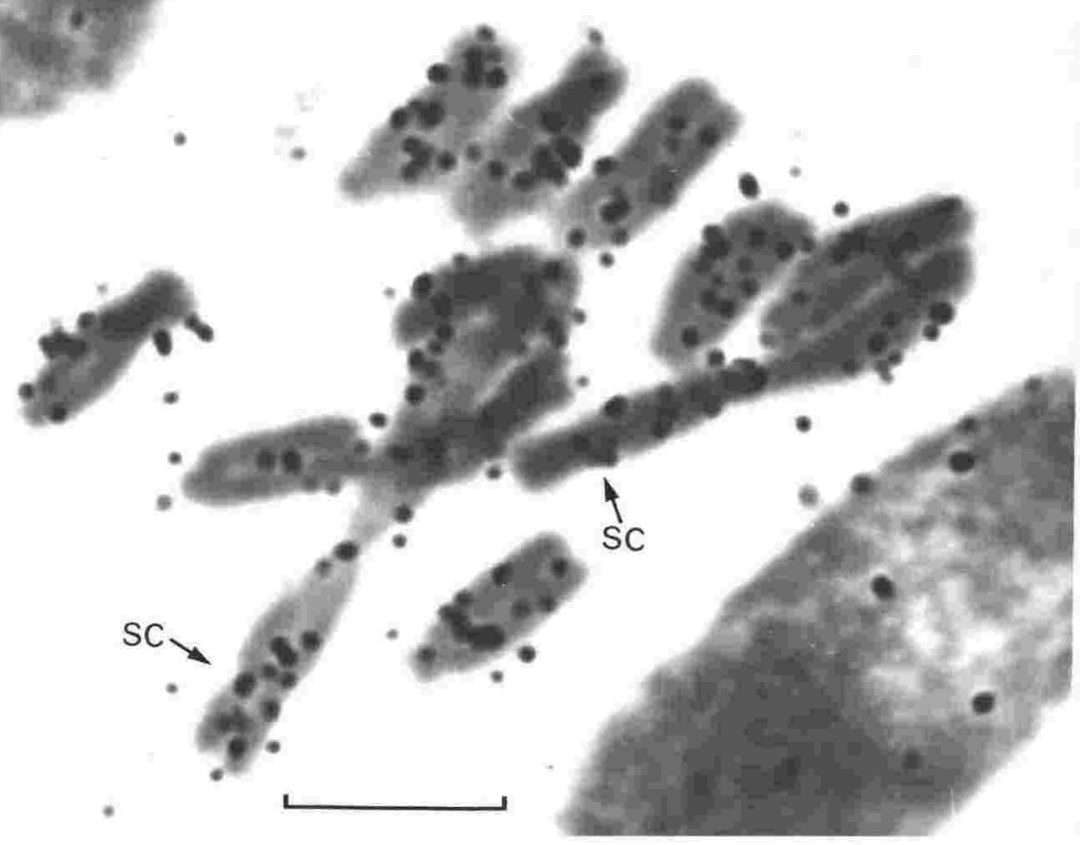

Fig 54

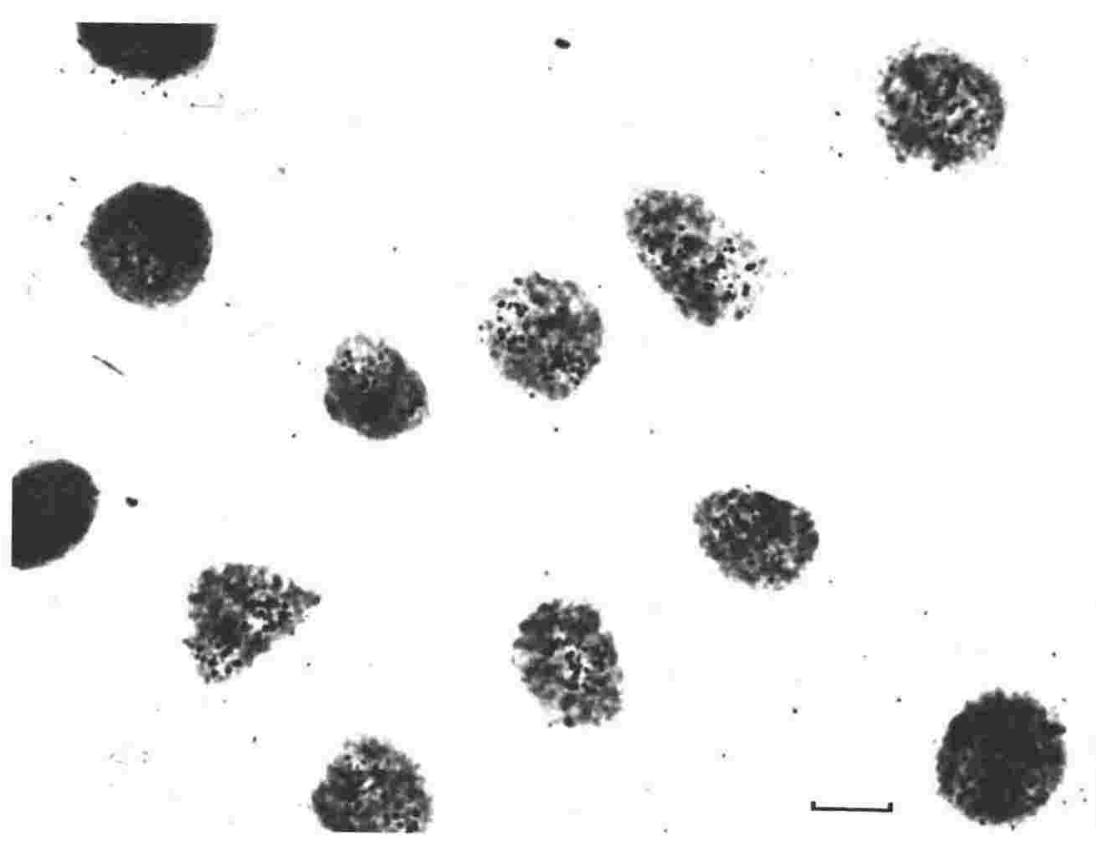

Fig 55 
163.

Figs. 56-58. Autoradiographs of chromosomes and nuclei hybridized in situ with total ${ }^{3} \mathrm{H}$-cRNA. Some chromosome regions tend to show grain localization (brackets). See text for $M$ chromosome grain distribution. $(\mathrm{c}=$ centromere $; \quad \mathrm{sc}=$ secondary constriction $)$. 


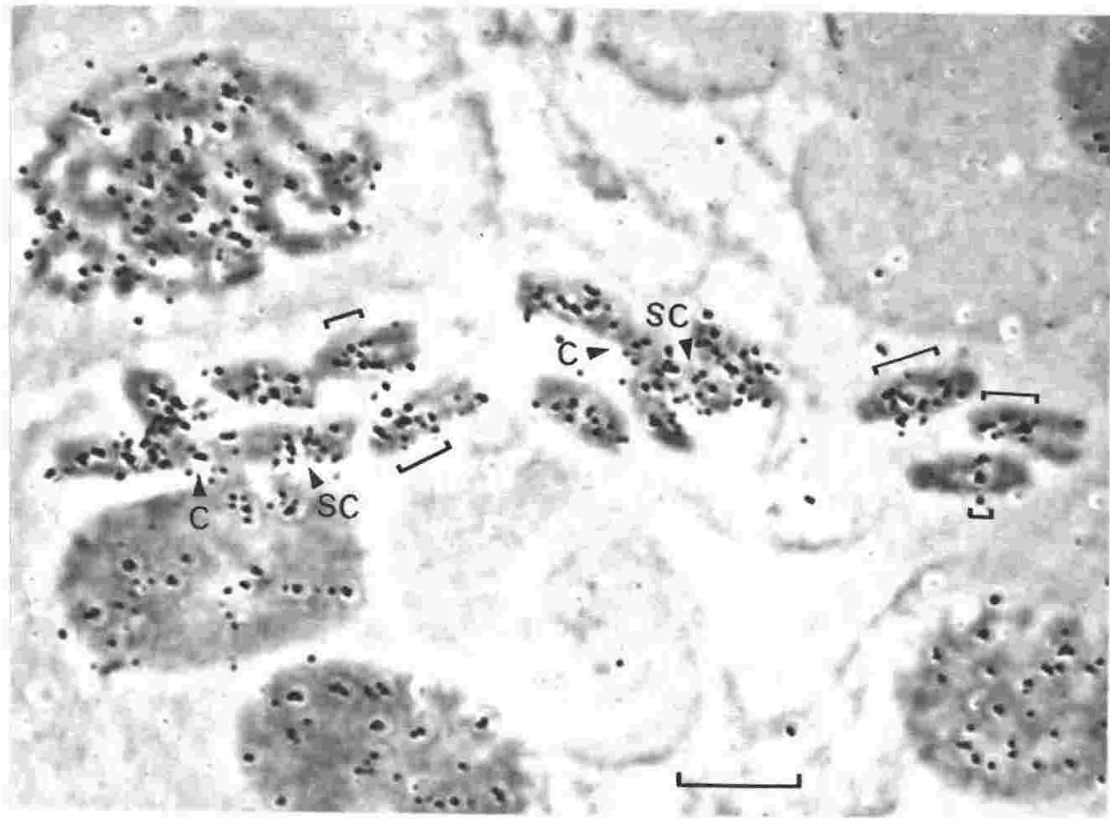

Fig 56

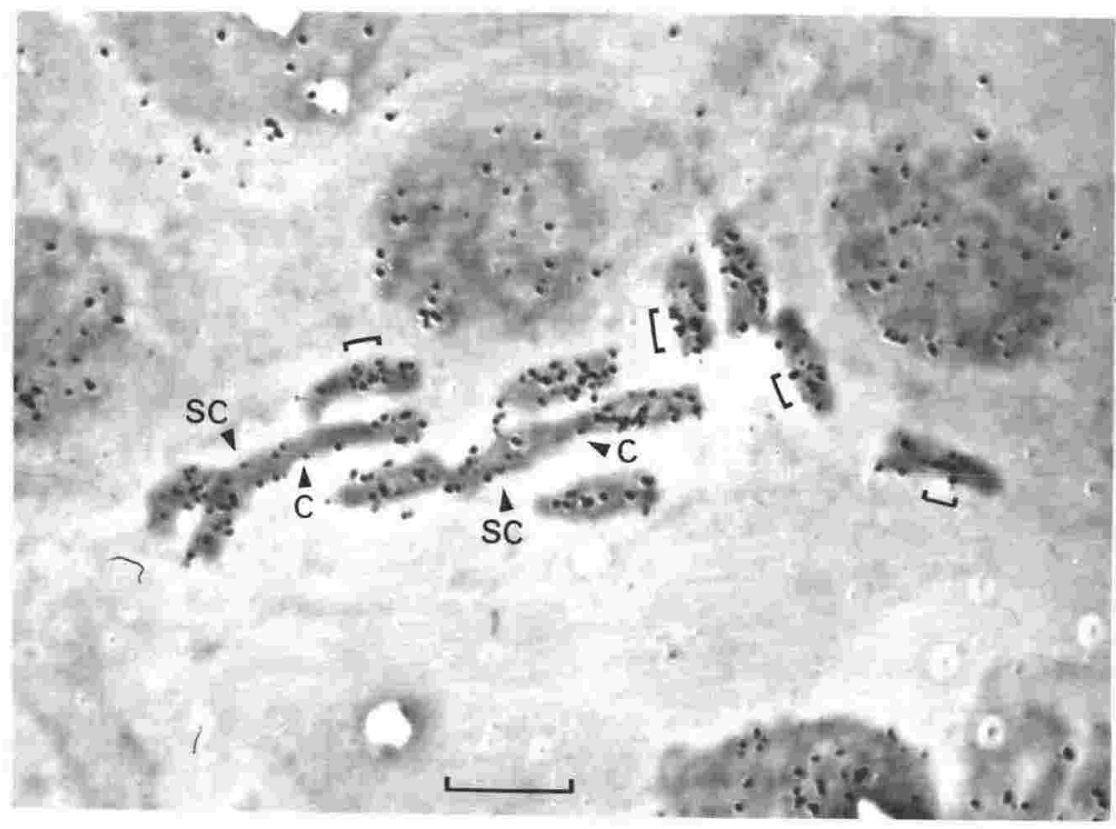

Fig 57

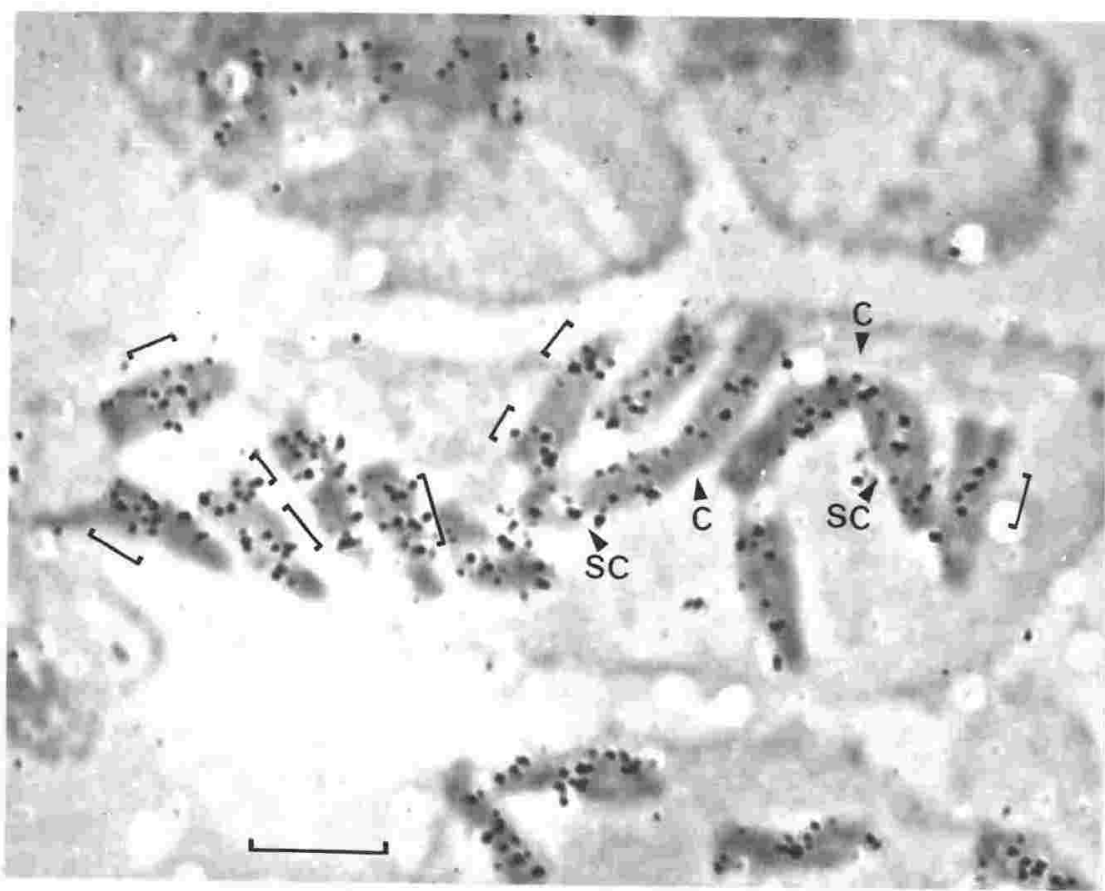

Fig 58 
Fig. 59. Histogram showing the total regional grain counts compiled from $40 \mathrm{M}$ chromosomes after in situ hybridization with total ${ }^{3} \mathrm{H}-\mathrm{CRNA}$.

Data from column totals, Table 2 (p. 40). 
Fig 59

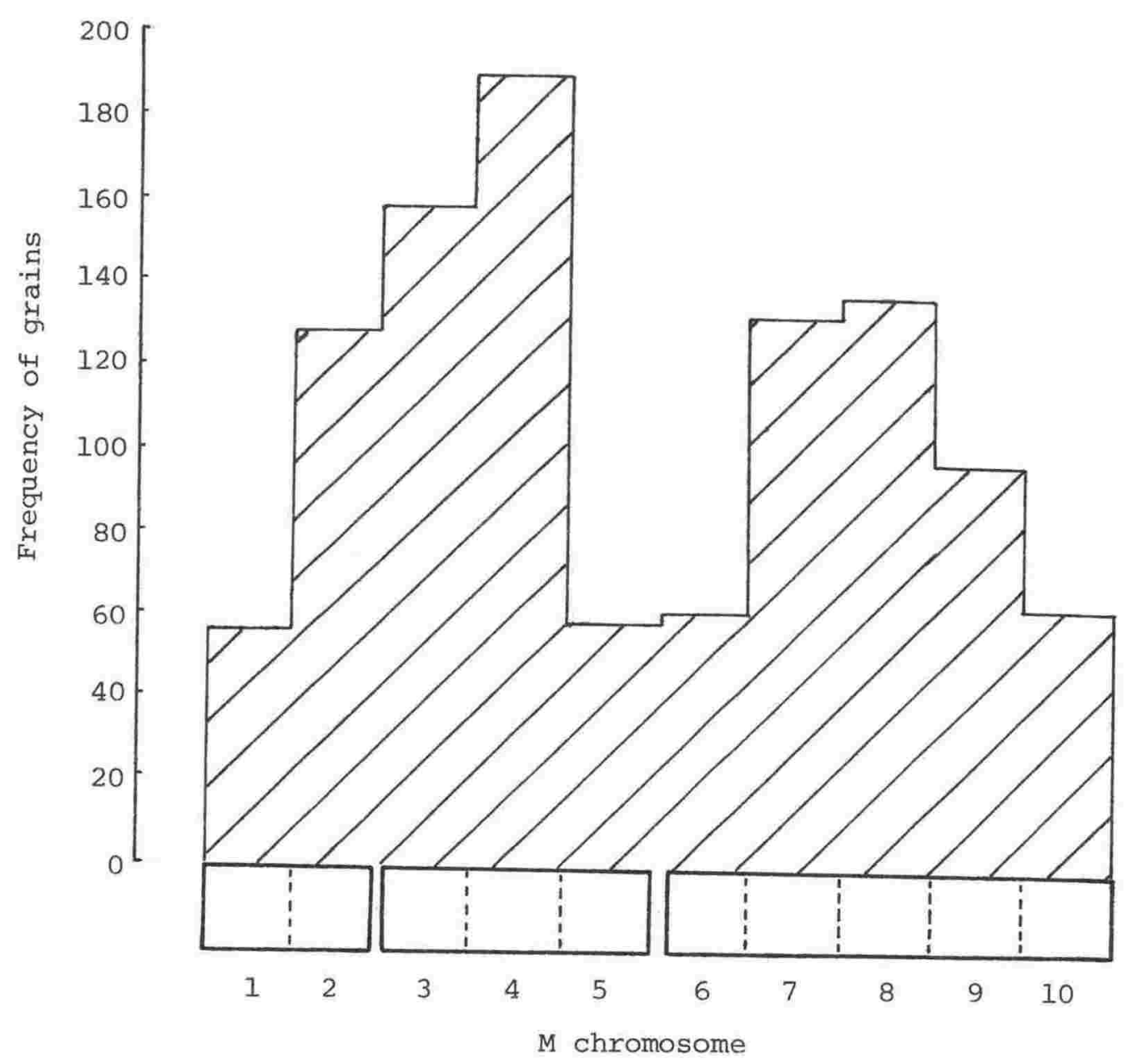


APPENDIX I

Transcription of RNA complementary to total $V$. faba DNA.

(a) Time course of in vitro DNA transcription.

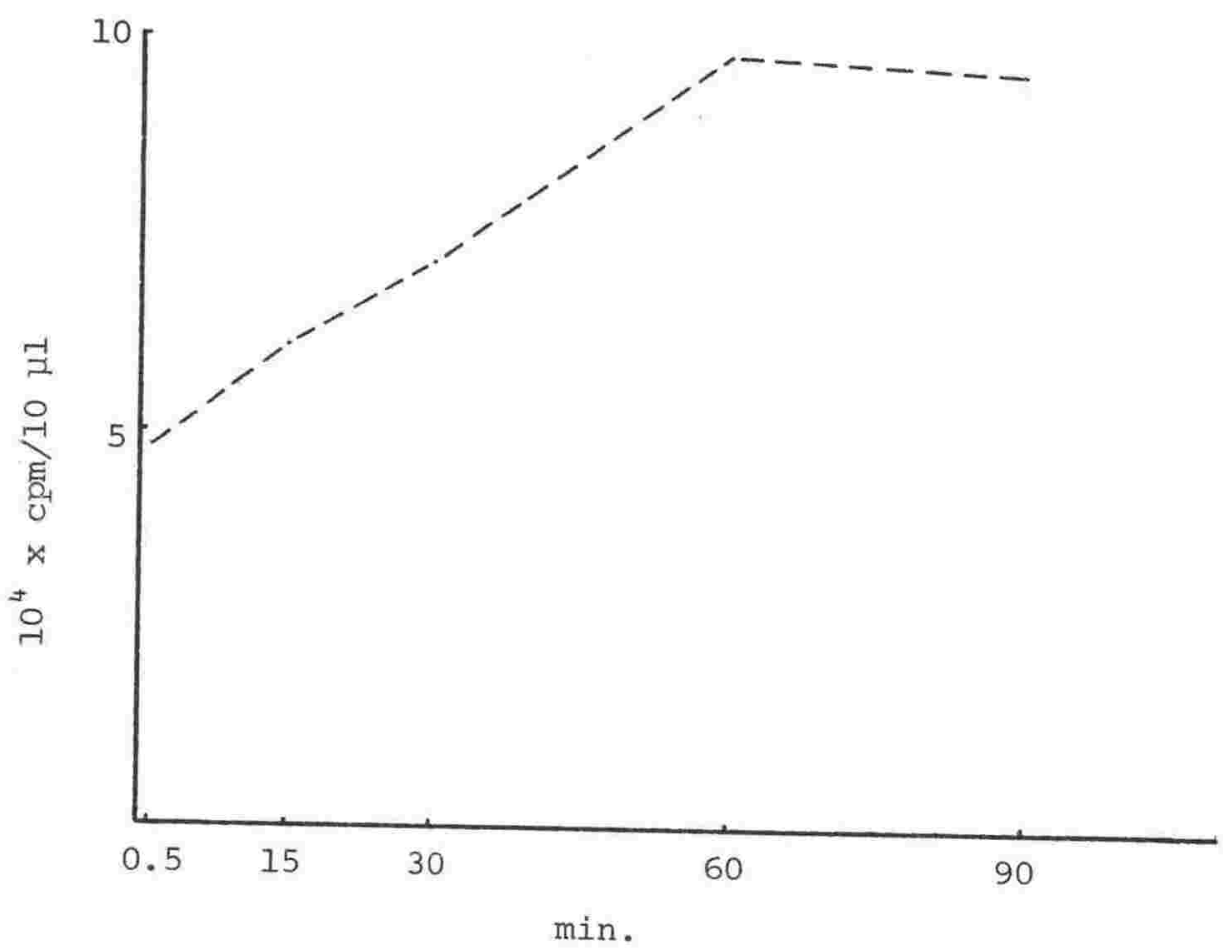

(b) Sephadex gel separation of transcription product see graph (b) p. 168.

(c) Stability of transcription product to RNase digestion One $10 \mu l$ sample was precipitated without RNase treatment. Two $10 \mu l$ samples were subjected to RNase $(80 \mu \mathrm{g} / \mathrm{ml})$ digestion for $1 \mathrm{~h}$ at $37^{\circ} \mathrm{C}$. One of these two samples was heated to $90^{\circ} \mathrm{C}$ for $3 \mathrm{~min}$ prior to digestion to remove any secondary structure.

Transcript precipitate RNase (melted sample) RNase (cold sample)

Counts/min 11,541 
168.

App. I (b) Sephadex gel separation of transcription product from free

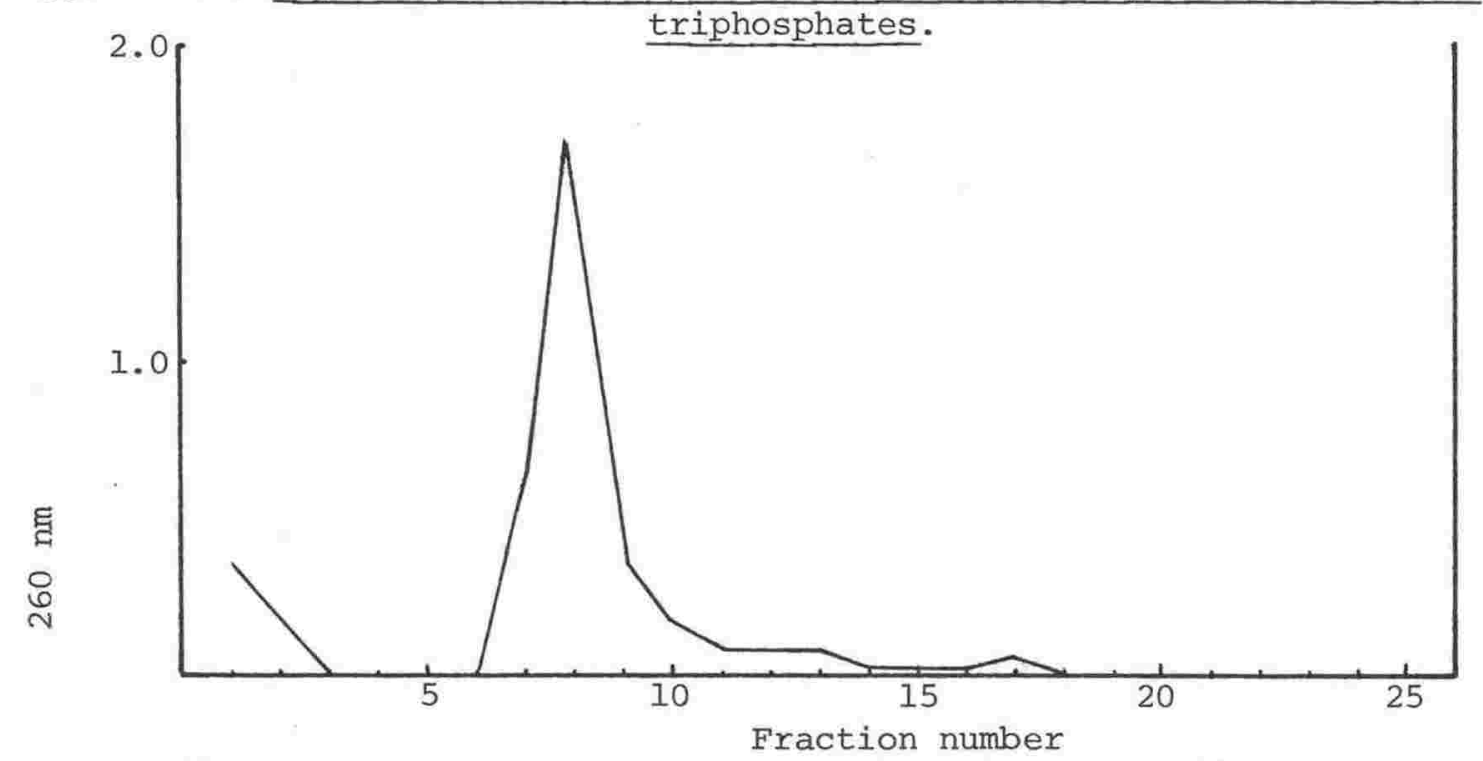

(i) Separate test run of highly polymerized E. coli rRNA.
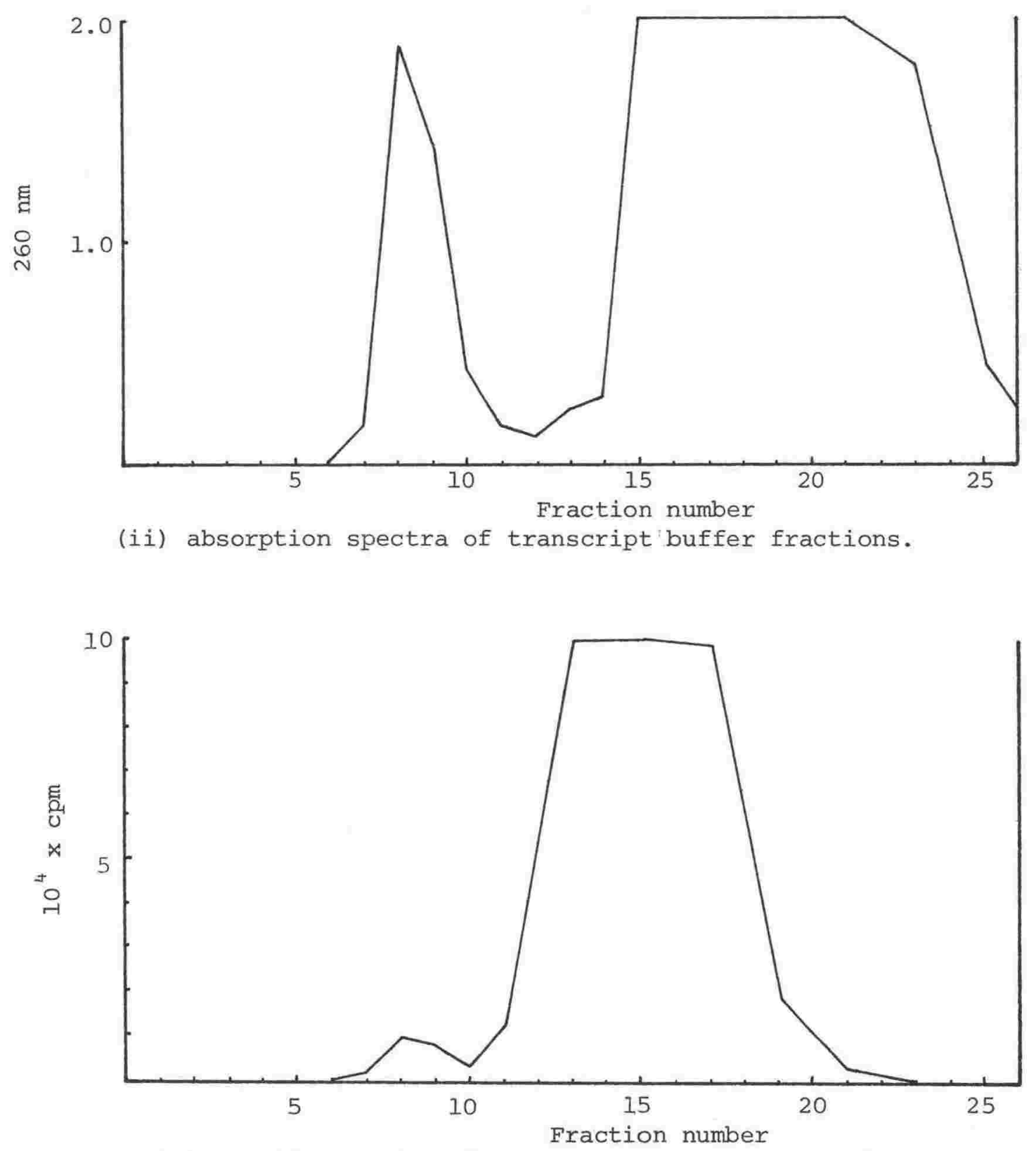

(iii) liquid scintillation counts of transcript buffer fractions. 


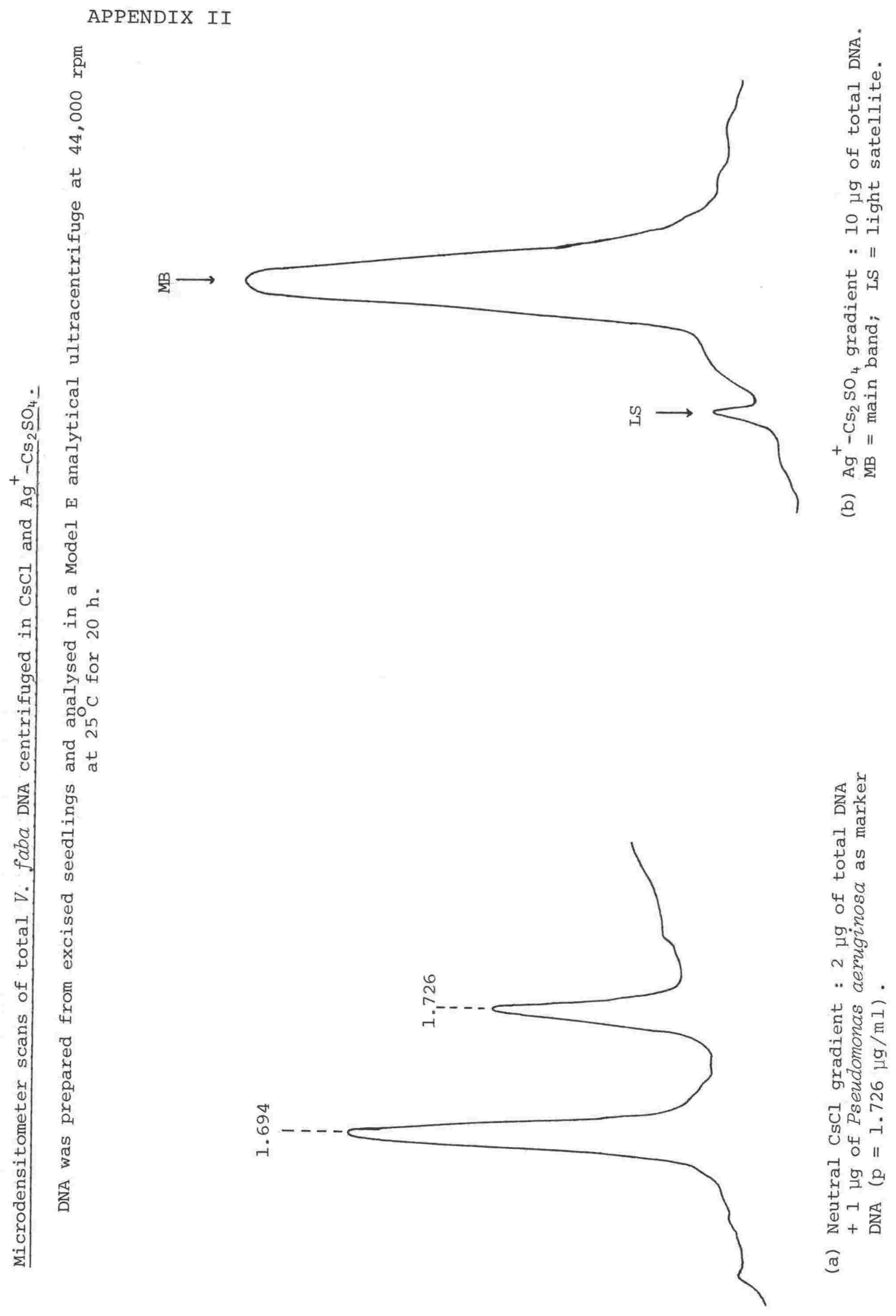


APPENDIX III

A reassociation curve of sonicated, denatured $V$. faba DNA.

present author; - - - - Straus (1972)

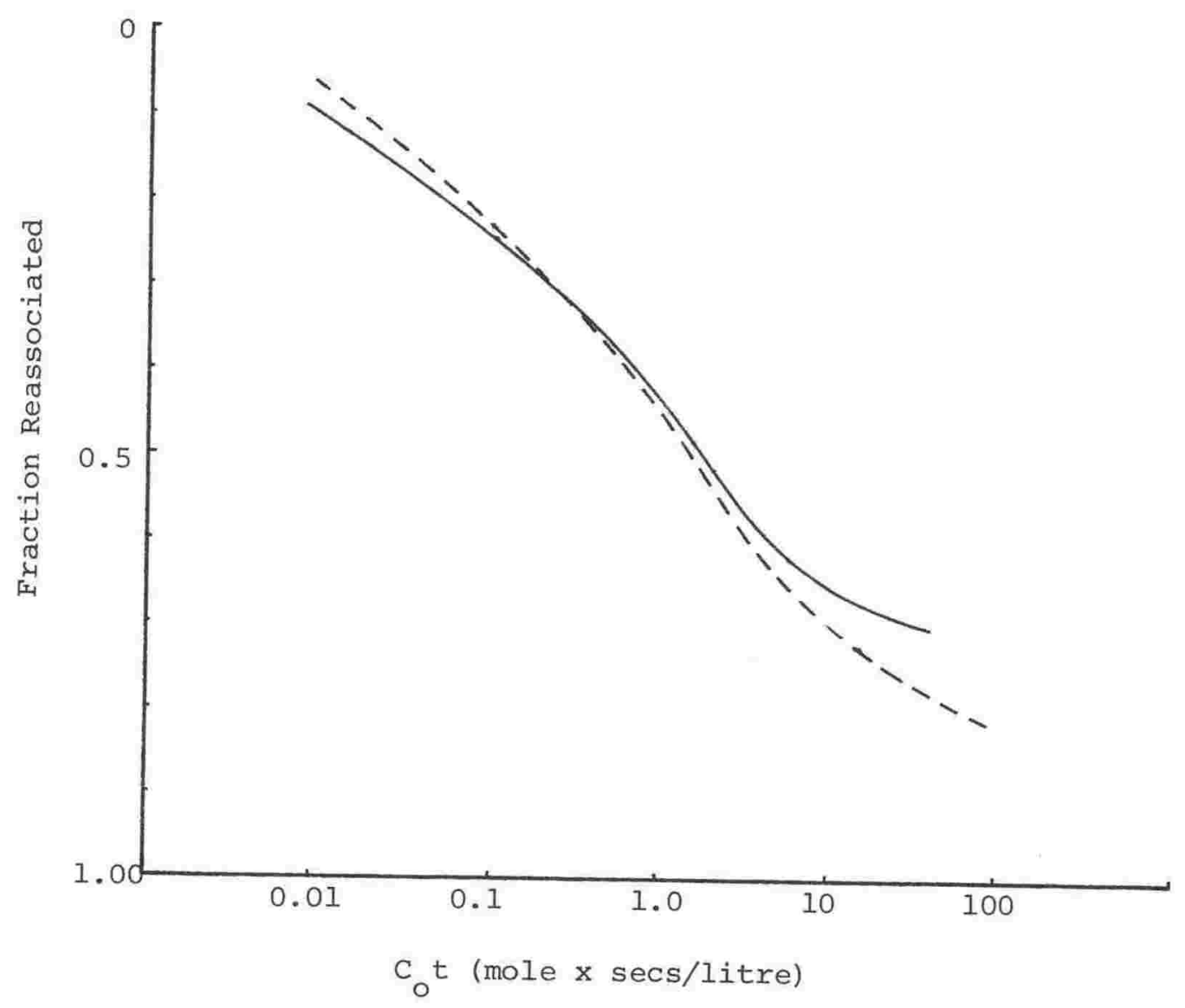

